\title{
A STUDY OF
}

\section{THE ROLE OF IMPURITIES AND. ADDITIVES}

ON CERAMIC DENSIFICATION

\section{By}

\author{
WILLIAM C. JOHNSON
}

\section{A DISSERTATION.}

Submitted in partial fulfillment of the requirements for the degree of DOCTOR OF PHILOSOPHY (Metallurgical Engineering)

MICHIGAN TECHNOLOGICAL UNIVERSITY 


\section{DISCLAIMER}

This report was prepared as an account of work sponsored by an agency of the United States Government. Neither the United States Government nor any agency Thereof, nor any of their employees, makes any warranty, express or implied, or assumes any legal liability or responsibility for the accuracy, completeness, or usefulness of any information, apparatus, product, or process disclosed, or represents that its use would not infringe privately owned rights. Reference herein to any specific commercial product, process, or service by trade name, trademark, manufacturer, or otherwise does not necessarily constitute or imply its endorsement, recommendation, or favoring by the United States Government or any agency thereof. The views and opinions of authors expressed herein do not necessarily state or reflect those of the United States Government or any agency thereof. 


\section{DISCLAIMER}

Portions of this document may be illegible in electronic image products. Images are produced from the best available original document. 


\section{Abstract}

Densification of ceramic materials has been thought to be controlled by interfacial effects, whether particle-particle, pore-particle, or grain boundary interfaces. Minor amounts of certain elements have been found empirically to ald in densification of sintered $\mathrm{Al}_{2} \mathrm{O}_{3}$ and hot pressed $\mathrm{MgO}$. This study applies Auger Electron Spectroscopy to densification of $\mathrm{Al}_{2} \mathrm{O}_{3}$ with $\mathrm{MgO} ; \mathrm{NiO}$, and $\mathrm{Y}_{2} \mathrm{O}_{3}$ additives and $\mathrm{MgO}$ with $\mathrm{LIF}$ and NaF additives to determine the interfacial chemistries involved and thereby understand the roles of the additives. Finally, the observed segregation is studied quantitatively in terms of Gibbsian segregation and models for densification enhancement proposed and supported with experimental evidence. 
This dissertation, "A Study of the Role of Impurities and Additives on Ceramic Densification", is hereby approved In partial fulfillment of the requirements for the degree of DOCTOR OF PHILOSOPHY in the field of Metallurgical Engineering:

DEPARTMENT Metallurgical Englneering

Thesis Advisor

Head of Department

Date 


\section{Acknowledgement}

The author wishes to express sincere thanks to his advisor, Dr. D. F. Stein, for his advice, encouragement and support throughout the work. The cooperation and advice of Mr. Roy Rice of Naval Research Laboratory, Dr. F. N. Bradley, Dr. H. I. Aaronson and Mr. Calvin White, as well as the technical assistance of S. Clough, J. Dufour, M. Hintz and M. Giannini is greatly appreciated.

Finaliy the author would like to thank his wife Cathy for understanding during the long hours spent. on this project. This study was sponsored by the A.E.C. under contract $\operatorname{AT}(11-1)-2166$. 
Table of Contents

Page

I. Introduction . . . . . . . . . . . . I

A. Objective: . . ............ I

B. Problem Definition ............. . I

C. Use of Additives in Sintered $\mathrm{Al}_{2} \mathrm{O}_{3}$. . . . . 4

D. Use of Additives in Hot Pressed $\mathrm{MgO}^{3} . . .5$

II. Experimental and Equipment ......: . : : 7

A. Auger Electron Spectroscopy . . • $\cdot \bullet \cdot \cdot \cdots \cdot 7$

B. Inert Ion Sputtering . . . . . . $\therefore 15$

C. Scanning Electron Microscopy . . . . . . . 18

D. Ceramic Fabrication. .......... 18

III. Densification in Doped $\mathrm{Al}_{2} \mathrm{O}_{3} \cdots \cdots \cdots \cdot \ldots \cdot 23$

A. Use of Mgo to Densify $\mathrm{Al}_{2} \mathrm{O}_{3}$. . . . . . . . 23

B. Previous Evidence for segregation. . . . 32

C. Detectability of $\mathrm{Mg}$ on $\mathrm{Al}_{2} \mathrm{O}_{3}$....... . 35

D. Use of $\mathrm{NiO}$ to Densify $\mathrm{Al}_{2} \mathrm{O}_{3}$....... . 38

E. Grain Boundary Chemistry in Non-Dense Alumiras 40

F. Use of $\mathrm{Y}_{2} \mathrm{O}_{3}$ to Achieve Dense:Alumina . . .. 42

G. Equilibrium Segregation of Impurities. . . . 50

H. Experimental Verification of Segregation

I. Proposed Model for Densification of $\mathrm{Al}_{2} \mathrm{O}_{3}+$

J. Modification of Solvent Defect Structure. . 58

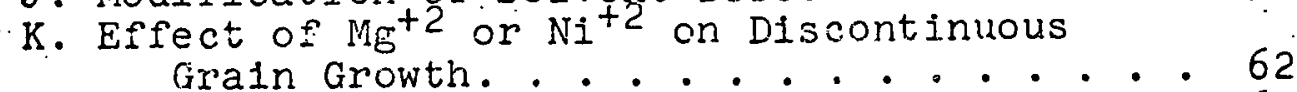

L. Conclusions of Doped $\mathrm{Al}_{2} \mathrm{O}_{3}$ Study . . . . 65

IV. Role of Additives in Hot Pressing MgO. . . . . 67

A. Hot Pressed MgO With No Additives. . . . 67

B. MgO Hot Pressed With LiF . . . . . . . 70

C. Hot Pressed MgO With NaF . . . . . . 76

D. Hot Pressing of $\mathrm{Al}_{2} \mathrm{O}_{3}$ and $\mathrm{MgPl}_{2} \mathrm{O}_{4}$ With LiF. . 78

E. Analysis of Results in Terms of Densification 83

F. Conclusions of Hot Pressed MgO Study . . . 83

V. Appendices . . . . . . . . . . 85

A. A Calculation of Sputter Removal Rates . . 86

B. Use of $\mathrm{CCl}_{4}$ Displacement to Measure Porosity 87

C. Calculation of Image Stress From a Segregant 88

D. Calculation of Grain Boundary Concentration

of a Segregant. . . . . . . . . . . 91

E. Calculation of Interaction Energies and Upper Limits for Segregants in $\mathrm{Al}_{2} \mathrm{O}_{3} \cdot \cdot 95$ 
F. Cajoulation of Residual Fluorine Levels in

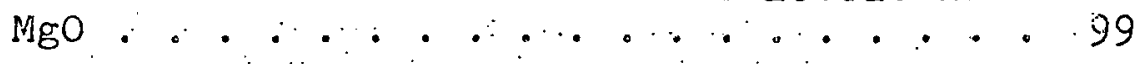

G. Further Stidy of Equilibrium Segregation . . 101 VI. References................ . . 103 


\section{List of Figures}

1: Selected Electron Energy Levels in an Isolated Ag Atom

2. Schematic of a Cylindrical Analyzer for AES

3. Saturation Coverage Curve

4. Schematic of an Inert Ion Sputtering Device

5. Isostatic Press

6. Gas Torch Furnace

7. R F Induction Furnace

8. Top View of UHV System

9. SEM Fractograph of AFC $\mathrm{AI}_{2} \mathrm{O}_{3}$

10. SEM Fractograph of Westinghouse $\mathrm{Al}_{2} \mathrm{O}_{3}$

11. SEM Fractograph of General Electric $\mathrm{Al}_{2} \mathrm{O}_{3}$

12. AES Spectrum of $\mathrm{AFC} \mathrm{Al}_{2} \mathrm{O}_{3}$

13. AES Spectrum of Westinghouse $\mathrm{Al}_{2} \mathrm{O}_{3}$

14. AES Spectrum of General Electric $\mathrm{Al}_{2} \mathrm{O}_{3}$

15. Sputter Profile of $\mathrm{Ca}$ in Genera! Electric $\mathrm{Al}_{2} \mathrm{O}_{3}$

16. Microhardness Frofile in $\mathrm{Al}_{2} \mathrm{O}_{3}+.1^{\mathrm{W}} / 0 \mathrm{MgO}$

17. Grain Growtin Data for $\mathrm{Al}_{2} \mathrm{O}_{3}$

18. AES Spectrum of Vacuum Evaporated MgO

19. High Energy Region of AES Spectrum of General Electric $\mathrm{Al}_{2} \mathrm{O}_{3}$

$20 \because$ AES Spectrum of $\mathrm{AI}_{2} \mathrm{O}_{3}+.1^{\mathrm{W}} / \mathrm{O} \mathrm{N} \mathrm{N}$

21. SEM Fractograph of Pure $\mathrm{Al}_{2} \mathrm{O}_{3}$

22. AES Spectrum of Pure $\mathrm{AI}_{2} \mathrm{O}_{3}$

- 23. AES Spectrum of $\mathrm{Al}_{2} \mathrm{O}_{3}+. I^{\mathrm{w}} / \mathrm{O} \mathrm{CaO}$

24. SEM Fractograph of Sylvania $\mathrm{Al}_{2} \mathrm{O}_{3}$

25. SEM Fractograph of Coors $\mathrm{Al}_{2} \mathrm{O}_{3}$

26. AES Spectrum of Sylvania $\mathrm{Al}_{2} \mathrm{O}_{3}$

27. AES Spectrum of Coors $\mathrm{Al}_{2} \mathrm{O}_{3}$

28. AES Spectrum of Quenched $\mathrm{Al}_{2} \mathrm{O}_{3}$ 
29. $\mathrm{C}_{\mathrm{gb}}$ of $\mathrm{Ca}$ in $\mathrm{Al}_{2} \mathrm{O}_{3}$

30. Density of $\mathrm{Al}_{2} \mathrm{O}_{3}$ Versus Time at Temperature

31. Discontinuous Grain Growth

32. SEM Fractographs of MgO Hot Pressed Without Additives

33. AES Spectrum of MgO Hot Pressed Without Additives

34. SEM Fractographs of Lot I MgO Hot Pressed with $2 \%$ LIF

35. AES Spectra of Lot I MgO Hot Pressed with $2^{\mathrm{W}} / 0$ LiF.

36. SEM Fractographs of Lot II MgO Hot Pressed with $2^{\text {w }} / 0$ LiF

37. AES Spectra of Lot II MgO Hot Pressed with $2 \%$. LiF

38. AES Spectrum of. Mgo Doped with LiF Annealed for 60 Hours

39. SEM Fractographs of MgO Hot Pressed With 2 W $/ 0 \mathrm{NaF}$

40. AES Spectra of MgO Hot Pressed with 2\% $/ 0$ NaF

41. AES Spectra of $\mathrm{Al}_{2} \mathrm{O}_{3}$ Hot Pressed with 2 W $/ \mathrm{LiF}$

42. AES Spectrum of $\mathrm{MgAI}_{2} \mathrm{O}_{4}$ (spineI) Hot Pressed with $3.5 \% \mathrm{~W} \% \mathrm{LIF}$

43. Image Stress for A Dislocation 


\section{Introduction}

\section{A. objective}

The purpose of this investigation was tc study the roles of additives and impurities on the densification of sintered $\mathrm{Al}_{2} \mathrm{O}_{3}$ and hot pressed $\mathrm{MgO}$. The study was undertaken because of the possibility of obtaining for the first time, definitive data on grain boundary chemistry through the use of Auger electron spectroscopy.

\section{B. Problem Definition}

In general, ceramic materials are not easy to fauricate. The raw materials are in powder form and compaction techniques must be used to shape the desired body. The compact must then be sintered or hot pressed to obtain a dense material. Relatively high temperatures are necessary for both of these processes and the finished products often contain residual porosity. Incomplete densification is often the result of a phenomenon known as discontinuous grain growth, a topic which w1ll be examined later. Due to the rapid growth of discontinuous grains, porosity is trapped well within them. If the distance from these trapped pores to the paths of fast material transport or vacancy sinks (grain boundarles) is long, over finite times the rate of material transport necessary to close off the pores will be kinetically limited. The material will exhibit residual porosity and a duplexed microstructure with the associated poor mechanical properties. Methods have been developed to promote the densification of ceramic materials through the use of additives. These additives, when added to the ceramic in powder form were found 
to aid fabrication by either allowing densification to occur at lower temperatures in shorter times or by inhibiting discontinuous grain growth and allowing pore elimination to proceed to completIon.

Use of these additives was for the most part empirical and experimental verification of their role impossible, due to the limited region over which they acted (usually assumed to be the grain boundaries or inter-particle interfaces). At least. four theories were advanced to explain the effect of these additives. I) Liquid phase assistance - In th:s mechanism. an additive with a lower melting point is used to aid densification: By meluting and coating the ceramic particles, the rapld dissolution and transfer of the base material to fill the interparticle spaces leads to enhanced densification. The additive has to be fairly soluble in the base ceramic and several weight percent of the additive is necessary to provide sufficient liquid phase to coat all of the powder particles. 2) solld solution effect - This mechanism predicts enhanced bulk material transport due to the introduction of vacancies into the ceramic when a solute with a different valence is added. These vacancies render the diffusion coeficient extrinsic by making the thermal vacancy concentration insignificant up to a certain temperature and if added in sufficient quantity, can significantly alter the rate of - material transport through the solid phase. The additive must be solubie in the base material and must induce vacancies which alter the rate controlling diffusivity. 3) Grain boundary pinning by a second phase - This mechanism involves the formation of second phase particles at grain boundaries in a material susceptible to discontinuous grain growth. These second phase particles act 
to pin the grain boundarles, preventing discontinuous grain growth from occurring. Inclusions can increase the energy necessary for grain growth and inhibit motion of grain boundaries by lowerIng their energy. The energy of the moving boundary is decreased when it encounters an inclusion, since an area of boundary roughly the size of the second phase cross section has been eliminated. For the boundary to continue moving, this boundary area must be created again, a process requiring energy. Hence a boundary pinned by inclusions represents" a cusp situation energetically and unless the driving force for continued growth exceeds this barrier. growth will stop. It has been found that when the grain diameter $D$ is greater than the ratio of the average inelusion diameter, $d$. divided by the volume fraction of inclusions, $f$, growth can proceed.1.

$$
D=\frac{d}{f}
$$

4) Solute segregation to grain boundaries inhibiting discontinuous grain growth - Similar to the second phase pinning hypothesis, this involves the drag on grain boundary motion due to the presence at the boundaries of an adsorbed solute. Theoretical ireatmert.s of this problem have indicated that the controling effect for. movement of a boundary containing adsorbed solute is the ability of the solute to diffuse through the base material.2-4. Since the solute has segregated to the boundarles from the bulk to lower the free energy of the system, this energy wili increase if the boundary moves on and leaves the solute behind. Hence the solute w1Il maintain a minimum energy condition by occupying sites in the region of high energy/disorder ( 1 .e grain boundary) $: 3,4$ Conditions of high boundary veloclty (high driving force for motion) and low binding energy of the solute to the boundary can 
lead to "breakaway". and normal growth after the solute has been left behind. Conversely; low velocity and/or high binding energy will Iead to "solute drag" as the segregant must be dragged with the moving interface. Highly dependent on the amount of solute. as well as the previously mentioned factors, this latter condition wiIl lead to a slower rate of growth since the segregant must be carried. with the boundary by a diffusive mechanism, which will be slower than the atomic rearrangement responsible for normal.grain growth.

All of these mechanisms are presumed to operate in certain systems. The particular one or combination operative in a given material depends on the properties and relationships between the base material and additive.

c. Use of Additives in Sintered $\mathrm{AL}_{2} \mathrm{O}_{3}$

The use of small amount (about $0.05^{\mathrm{WJ}} / 0$ ) MgO to aid sintering of $\mathrm{Al}_{2} \mathrm{O}_{3}$ was described first by coble in the late $1950^{\prime s} .^{-7}$ The resulting material, marketed commerically by the General Electric Company under the trade name Lucalox, is theoretically dense with uniform equiaxed grains. ${ }^{7}$ The amount of MgO necessary to obtain theoretical density is not sufficient to form a continuous liquid film between particles (as was mentioned earlier; in general several weight percent additive is necessary). Further, Jorgensen and Westbrook found that the amount of $\mathrm{MgO}$ necessary is within the solubility limit for $\mathrm{MgO}$ in $\mathrm{Al}_{2} \mathrm{O}_{3}$, thereby eleminating the second phase mechanism. ${ }^{8}$

other mechanisms have received notice in recent years. 
Coble ${ }^{5}$ and Bruch ${ }^{9}$ have both supported a soldd solution theory involving enharicement of the siritering rate. This was presumed due to increased diffusivities because of oxygen vacancies. created by $\mathrm{Mg}^{+2}$ ions substituted for $\mathrm{Al}^{+3}$ Ions. Jorgensen on the other hand, favored a solute segregation theory supported in part by micro-hardness data.ô, 10

This study was begun to test the solute segregation theory by directly measuring lmpurity and solute levels at grain boundaries and correlating this chemistry with densification. Sincelit was felt that the solid solution theory could be operative as weII, previous studies of grain growth rate, densification versus time, and diffusivities in $\mathrm{Al}_{2} \mathrm{O}_{3}$ and $\mathrm{Al}_{2} \mathrm{O}_{3}$ doped with Mgo were examined to determine the feasibility of this mechanism.

\section{Use of Additives in Hot Pressed MgO}

The use of LiF additions to obtain transparent hot pressed Mgo was first described by Rice in 1962.11 The addition of $2 \%$ LiF to the Migo powcier allowed a theoietically dinse MgO to be obtained at relatively low $\left(700^{\circ} \mathrm{C}-1000^{\circ} \mathrm{C}\right)$ temperatures a The mechanical and optical properties of the as-hot pressed. material could be improved markedly by subsequent annealing at temperatures higher than the hot pressing temperature; unti $i$ material almost as transparent as single crystal Mgo resulted.12-15

- Use of $\mathrm{NaF}$ can also lead to a derse material, but higher hot-: pressing temperatures are required. The mechanism for densification was felt to be a pressure enhanced liquid phase sintering phenomenon, 16,17 although enhanced diffusion though vacancy alteration was also suggested.12 The improved properties after annealing were presumed due to alteration of the grain boundary 
chemistry, although it was difficult to determine what had actually changed due to the previously mentioned problems in obtaining grain boundary chemistry. The current study was begun to directly determine grain boundary chemistry, use this information to investigate mechanisms of densification, and correlate changes in mechanical and optical properties wịth changes in this chemistry. Spinel $\left(\mathrm{MgAI}_{2} \mathrm{O}_{4}\right)$ material and $\mathrm{AI}_{2} \mathrm{O}_{3}$, both hot pressed to theoretical density with LiF were also examined to provide additional data concerning hot pressing with LIF additives. 


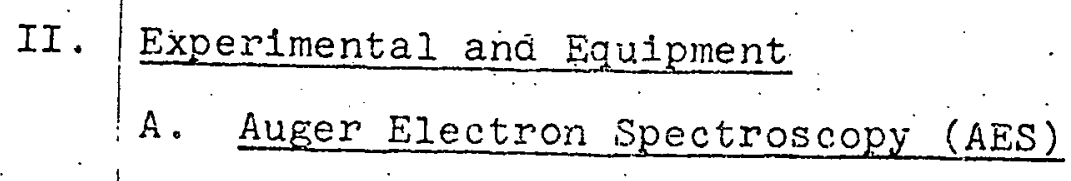

Auger electron spectroscopy, a technique used extensively throughout this study to obtain grain boundary chemistries, has been developed in recent years to fill a gap in the tools avaliable for materials research:18-20

Basically AES differs from other analysis techniques such as electron microprobe in that it is sensitive to the first few surface layers (4-20\%). In AES, an electron beam of moderate energy (1000-3000 ev) strikes the specimen and causes the ionization of an inner electron level. When an electron from an outer level fills the vacancy, a photon or an Auger electron is emitted, depending on the relaxation time for photon emission. This relaxation time is found to increase rapidly as the energy of the transition decreases. The relaxation time for Auger electron emission, however, is approximately independent of the transition energies and therefore for light elements (1.e., for transitions below about $2000 \mathrm{eV}$ ) Auger emission is the major relaxation mechanism. 20 For an individual atom with well-defined energy levels, the characteristic energy of a particular transition can be calculated from energy conservation. For example, the electron energy levels. In a silver atom should give rise to an Auger emission with energy, $E_{M I V}-E_{N V}-E_{N V}=366 \mathrm{eV}$ (Figure I). $E_{M I V}$ is the energy of the originally ionized level and $E_{N V}$ is the energy of the doubly ionized level from which the Auger emission originates. 21

An Auger emission is detected at $356 \mathrm{eV}$ which differs from the $366 \mathrm{eV}$ calculated due to the work function of the analyzer and the non-validity of the simple single atom model used for the 


\section{AUGER ELECTRON}

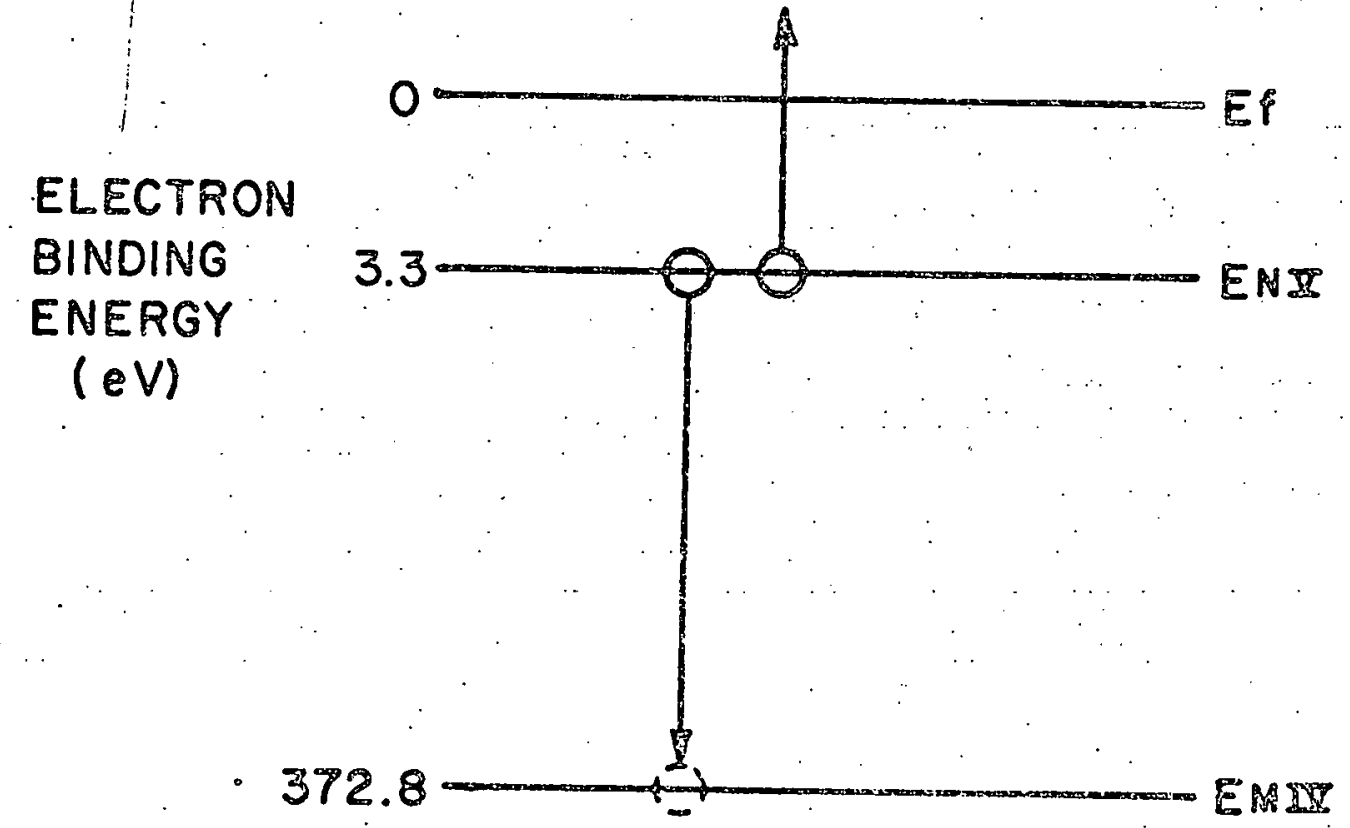

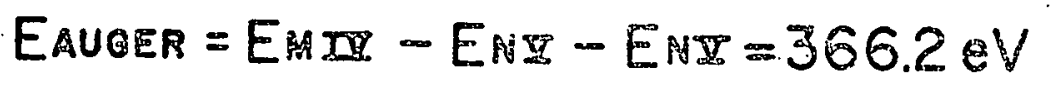

Figure I Selected Electron Energy Levels in an Isolated Ag A.tom 
calculation. However, it can be seen that the energy from a given transition is characteristic of the leveis and therefore the element involved in that emission.

Lander. first demonstrated the possibility of using the Auger emission for qualitative investigation by interpreting the small. fixed energy peaks in the energy distribution of secondary electrons as resulting from Auger transitions. 22 The technique lacked sensitivity because of the high background of other secondary electrons. Later, Harris found that sensitivity could be improved by méasuring the derivative of the energy distribution.23

Then in 196\%, Weber and Peria demonstrated the use of standard hemispherical low energy electron diffraction (IEED) optics to detect Auger electrons using a retarding potential techinique. 24

The second generation of Auger electron detection equipment utilfzing a cylindrical electrostatic energy analyzer, was described by Palmberg, Bohn, and Tracy in 2959.25 In chis technique elther a coaxial (normal igcidence) or grazing incidence electron gun is used and the electrors from the specimen are collected by a velocity selector (Figure 2). The outer cylinder is biased negative and is swept over the voltage range of Interest. Electrons of the correct energy are focused through the exit silt and collected by an electron multiplier. Since in this case the collected signal is proportional to the energy distribution, $N(E)$, it is necessary to take only one derivative. This is obtained by applying a modulated voltage to the outer cylinder and measuring the component of collected current with that frequency. The energy of the electrons collected is proportional to the potential applied to the outej cylinder, with the propor- 


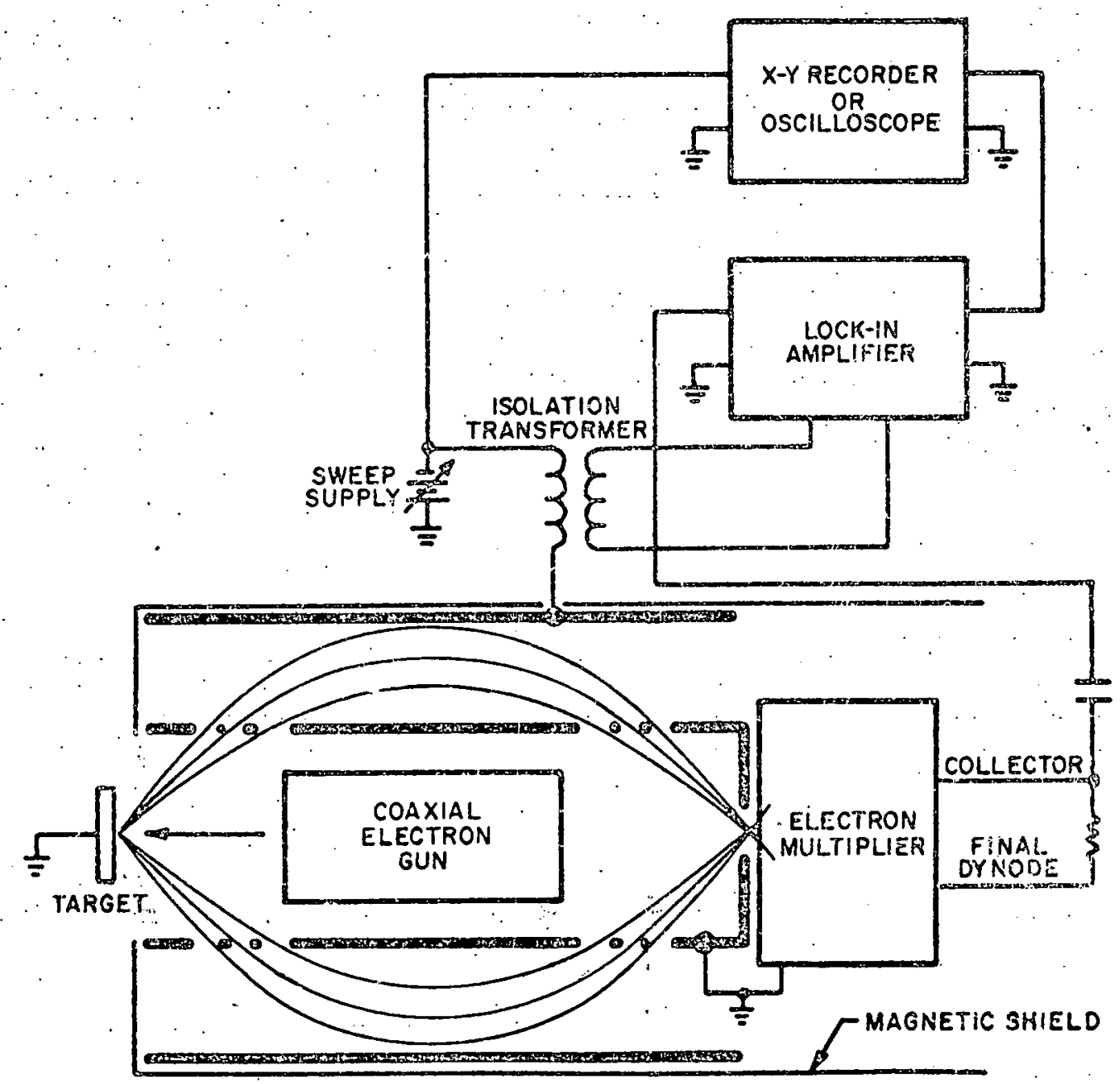

COAXIAL CYLINORICAL ANALYZER

Figure 2 Schematic of a Cylindrical Analyzer for AES 
tionality factor dependent on the cylinder geometry.

The cylindrical analyzer is superior to the LEED optics for AES for several reasons.

(I) The signal-to-noise ratio (S/N) is higher. Since the analyzer is a band pass device as contrasted to the high pass charácteristics of retarding barrier techniques; the background current is as little as $10^{-4}$ that of a LEED device and shot noise is reduced by a factor of 100 .

(2) Only the first derivative of the signal is needed; this gives an increase of four in the signal.

(3). Due to the high $S / N$ ratio, low beam currents can be used; this is useful for experimerts where high cument densities can be damaging.

(4) Due to the fast response of the analyzer $(10,000 \mathrm{eV}$ $\sec ^{-1}$ ) the spectrum can be displayed on an osc11].oscope.

Special problems arise in the use of AES on Insulators or poorly conducting materials such as ceramics. The emission of electrons depends strongly on the ability of a material to carry away excess charge. The secoriary yield of a surface (defined as the number of secondary electrons created per fncident primary) is. very dependent on primary energy. The primary energy. dependence is not important for good conductors since the charge $\because$ due to excess primaries or secondaries is easily neutralized. On insuiators, however, it is important to work with primary energies which produce a secondary yield greater than i: then, the only effect of surface charging is to shift the entire spectrum by a few eV.20

Intuitively, it might be suspected that the relationship between the number of atoms contributing to Auger emissions and 
the observed signal strength would be linear, but the problem is complicated by electron escape and energy loss mechanisms. What is important for quantitative work is the volume of the solid contributing Auger emissions with the characteristic energy, not the total number of emissions. To first approximation, this volume is defined by the beam dianieter, surface of the solid, and effective depth from which electron escape at Auger energies (viz., 50-2000 ev) is relatively unimpeded by the atom layers above. It is found, not surprisingly, that the major portion of the signal originates in the first few surface layers and the signal drops off rapidly with increasingly depth.26 Therefore. a signal calibration curve of coverage should be linear up to one monolayer coverage beyond which the curve should approach an assymptote corresponding to a "saturation" coverage of the calibrated element (Figure 3). At this coverage, the volume contributing to the Auger signal lies entirely in the overlayer and the signal observed should correspond to that observed from a bulk sample of the element. Calibration curves have been obtained for two element systems which correspond to this model. For example, Weber and Johnson have shown AES to be quantitative for the system $K$ on clean $G e$ (III) and linear for less than one monolayer coverage.27. Yet meticulousiy clean surfaces are difficult to obtain for surface characterization and calibration work, and impossible to obtain in conventional surface or grain boundary investigations.

In an effort to examine the effects of multiple elements on calibration of AES, a study was done by Johnson on the effect of additional elements on the calibration curve for low Ag coverages on $\mathrm{Au} .{ }^{28}$ The results indicate that the same general curve 


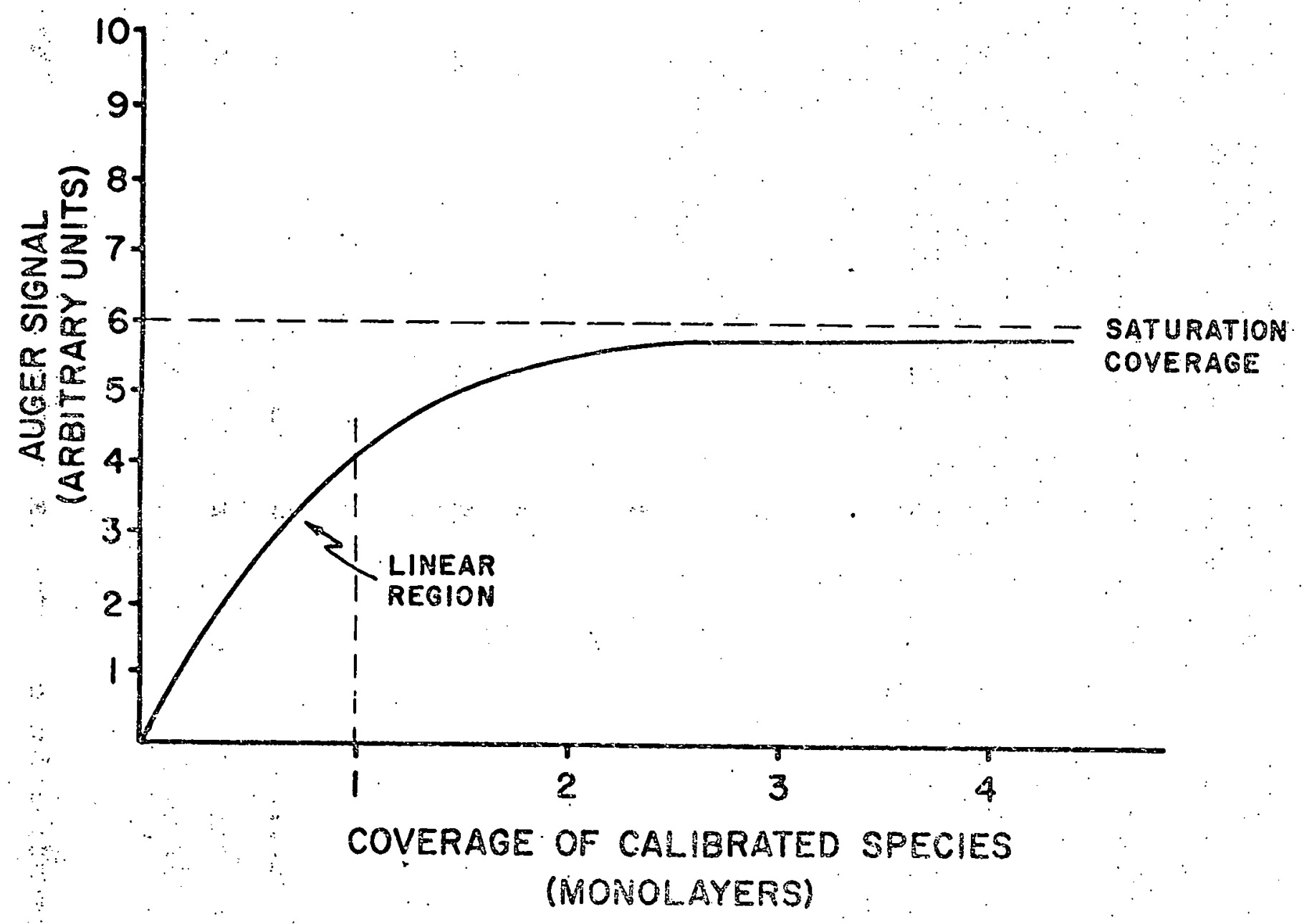

Figure 3 Saturation Coverage Curve 
is obtained, but all of the signals are attenuated by the Impurities present. The same volume of material contains less of the overlayer species since the element of interest is "diluted" by Impurites. Size and electron escape differences lead to different amounts of attenuation depending upon the contaminant element concentration. Results are consistent within a given system of contaminant species at fixed concentrations, but altering the ratio of contaminants or introducing a new species invalidates the previous calibration. Although detailed quantitative statements about real samples are difficult to make, semi-quantitative results can be obtained by comparing a spectrum of a pure specimen of a given species to the signal- irom a contaminated surface.

To aid in calculations of coverages in this fashion, a book contalnjing spectra of all elements obtainable in pure or combined form, ali taken at tile same sersitivities, is avallable from a commercial source.29 In practice the spectrum of the unknown sample is taken and a spectrum from a clean plece of Ag taken at the same sensitivities. The unknown spectrum is then calibrated by comparing the helght of the Auger peaks present with the peak to peak helght in the standard book, using $\mathrm{Ag}$ as a reference. The results must be interpreted carefuliy due to the obvious errors possible from the above mentioned interference effects.

An additional difficulty when ionic materials are examined Is the definition of percent coverage on the surface. In a completely rigorous definition, : $\mathrm{x}$ : would refer to the percentage of avallable sites for $X$ to occupy and this can vary depending on whether $X$ is an anion or a cation $\left(\mathrm{e} \cdot \mathrm{g} \cdot \mathrm{Al}_{2} \mathrm{O}_{3}\right.$ has 2 cation sites 
for every 3 anion sites). However, since in general regions of disorder (grain boundaries or surfaces) are examined rather than stolchiometric cleavage planes, and further since the presence of other ions of different valance $\left(\mathrm{Ca}^{+2}\right.$ lons of $\mathrm{Al}_{2} \mathrm{O}_{3}$ or $\mathrm{F}^{-1}$ ions in $\mathrm{MgO}$ ) can lead to ambiguities in the above definition, the following definition will be adhered to throughout this study. The $a / 0 x$ refers to the percentage of total ionic sites on the given surface occupied by element $X$. For purposes of calculating Inert ion sputter removal rates, this density of sites will be. defined as $10^{15}$ sites $/ \mathrm{cm}^{2}$. From a calcuiation of the actual numbers of sites for different planes in $\mathrm{MgO}$ and $\mathrm{Al}_{2} \mathrm{O}_{3}$ it is observed that $10^{15}$ sites $/ \mathrm{cm}^{2}$ is a very reasonable figure:

\section{B. Inert Ion Sputtering}

A tool lised to great advantage in conjunction with AES in this study, was ineit-ion sputtering. In this technique an Inext gas ion beam is used to etch a surface (analogous to a microscopic sand blasting), which allows controlled removal of angstrom thick layers of substrate. Alternate use of sputtering and AES yields a profile of chemical composition perpendicular to the original surface. Unlike chemical etchants or microtome methods, there is essentially no contamination and sub-monolayer quantities can be removed.

A schematic of an apparatus used for inert-1on sputtering is presented in Fig. 4. A tungsten filament is heated to produce electrons, which are accelerated toward an anode placed in front of the filarient and biased postitive with respect to the filament. By backfliling the vacuum system to a low pressure of an inert gas, a cloud of ionized gas is formed near the anode from coilistons between electrons and gas atoms. The target is placed 


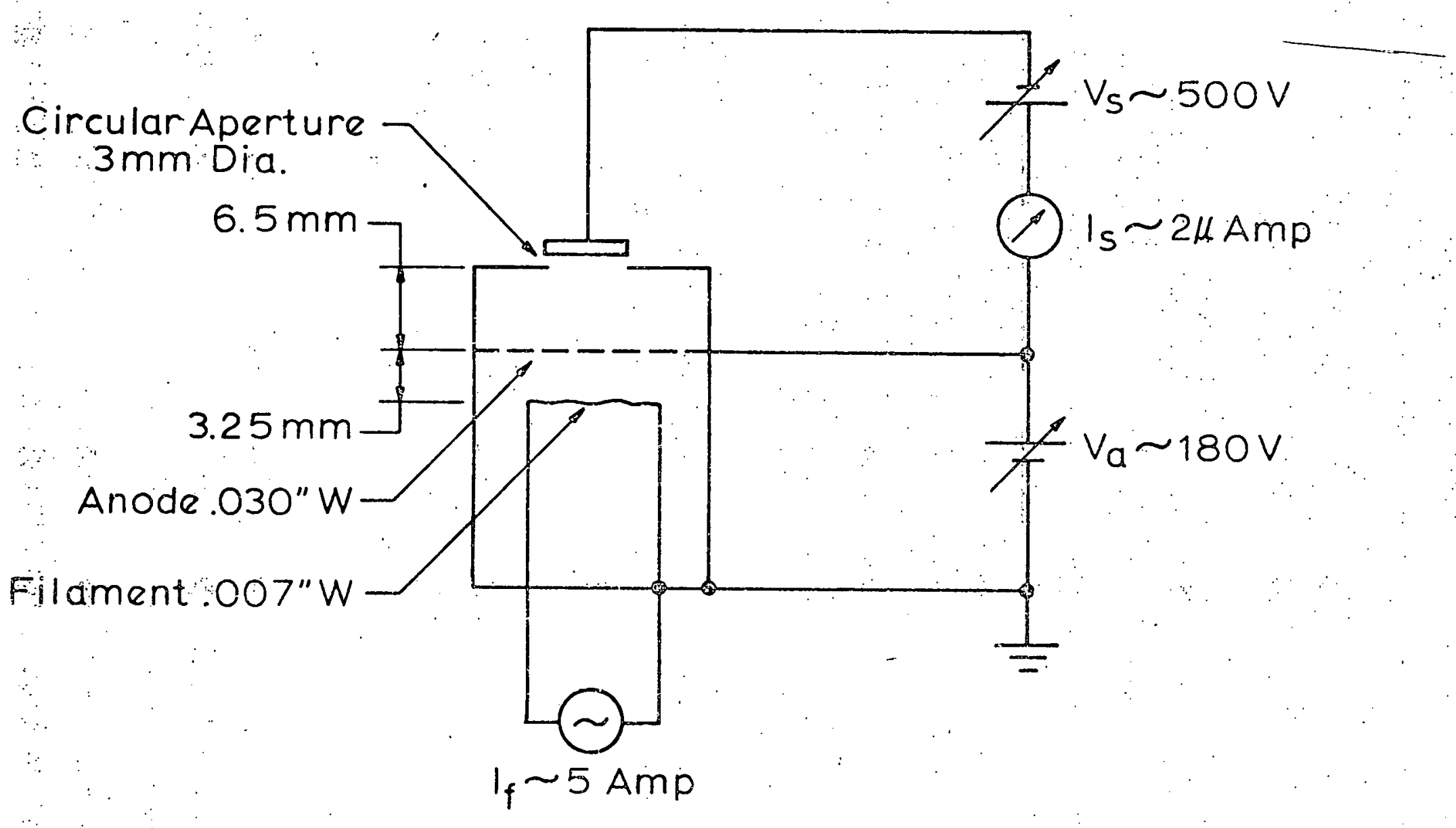

Figure 4 Schemat1c of an Inert Icn Sputtering Device 
in front of the anode and blased negative with respect to the anode. By surrounding the filament and anode with a tantalum container maintained at anode potential and placing a hole in the container between the target and anode, a beam of Ions is produced. By placing an auxiliary fllament near the target, the suriace is bathed in electrons, which allows proper charge neutralization on non-conducting targets. Typically, the voltage difference between the anode and the target j:s $200-900 \mathrm{~V}$ and the 200-900er ions striking the substrate material sputter etch the surface. The process is quantified by measuring anode-to-target current (i.e., total charge arriving at the surface, nence total. number of Ion collisions per second) and assuming a given number of substrate atoms removed per incident ion coliision fdependent on colifsion cross sections and hence ion energy). Measurement of current is complicated due to the release of $\gamma$ electrons from the surface undergoing ion bombardment. This is particularly. serious for low atomic weight sputtering gases. Observed currents can be off by as much as $30 \%$ for He, 25\% for Ne, $10 \%$ for Ar, $7 \%$ for $\mathrm{Kr}$, and $2 \%$ for $\mathrm{Xe} .30,31$ Hence $\mathrm{Xe}$ is a good choice for sputtering work.

The energy dependent removal rate is controlled by a variable known as sputter yield which is defined as the number ol substrate atoms removed per incident Ion collision. Extensive yield dáta has been tabulated by Wehner for several gases on most metals: as a function of sputtering energy, but yleid data for ceramics are generally not available. ${ }^{30-33}$ The sange of sputter ylelds is from near zero to over 3 for most metals in the energy range 200 to $900 \mathrm{eV} .{ }^{-}$Although yield data for ceramics has not been published, data for $\mathrm{Al}_{2} \mathrm{O}_{3}$ and MgO for a particular sputtering energy were. 
available from contemporary studies of sputtering phenomena. 34 Using this yield data, removal rates were calculated for the $\mathrm{Al}_{2} \mathrm{O}_{3}$ and $\mathrm{MgO}$ studied (Appendix A). The rate of removal was about I atomic layer per minute for the conditions used and was sufficiently low to allow the experimental error to be independent of time and depend on the admittedly uncertain yield data. The final results were assumed to be accurate to within a factor of two in terms of distance sputtered into the material. This was felt to be sufficient to indicate long versus short range effects and the shape of the profile is also independent of the removal rate. When the problem of preferential sputtering (preferential removal from a. surface of an easily removed species) is recognized and it is realized that the process is an averaging technique, inert ion sputtering can be of great value when used in conjunction with AFS to obtain segregant profiles avay from interfaces:

C. Scanning Electron Microscouy

Use of the scanning, election microscope for characterizing fracture surfaces is a standard technique. However, when used on insulating materials, charging of the surface can present problems. Use of a vacuum evaporated metal film over the fracture suirface can eliminate this charging. In this particular study, 50-100\& of a Au-Pd alloy was vacuum evaporated on the fresh fracture surfaces. 35 The scanning electron microscope could then be used to characterize fracture and residual porosity.

\section{Ceramic Fabrication}

Some of the ceramic materials used were prepared inhouse, some were obtained commercially, and the remainder were 
fabricated on a service basis by an outside agency. The in-house materials were isostatically pressed in a press manufactured at Mich. Tech. and similar to a press described by McCreight (Figure 5).36

Materials sintered in $\mathrm{O}_{2}$ were fabricated in an in-house built gas torch furnace utilizing a propane-oxygen burner (Figure 6). Vacuum sintered materials were fabricated in an R-F induction furnace, which utilized a Mo susceptor tube and two Mo heat shields (Figure 7). The quenching experiments were carried out in the $R-F$ furnace using dry He gas as the quenching medium.

The hot pressing and heat treating of the $\mathrm{MgO}$ and hot pressed $\mathrm{MgAI}_{2} \mathrm{O}_{4}$ and $\mathrm{AI}_{2} \mathrm{O}_{3}$ was carried out at Naval Research Laboratories, Washington, D.C.

In addition, optical microscopy, x-ray diffraction, and standard $\mathrm{CCl}_{4}$ displacement techniques to measure porosity (Append1X B), were utilized when necessary. 


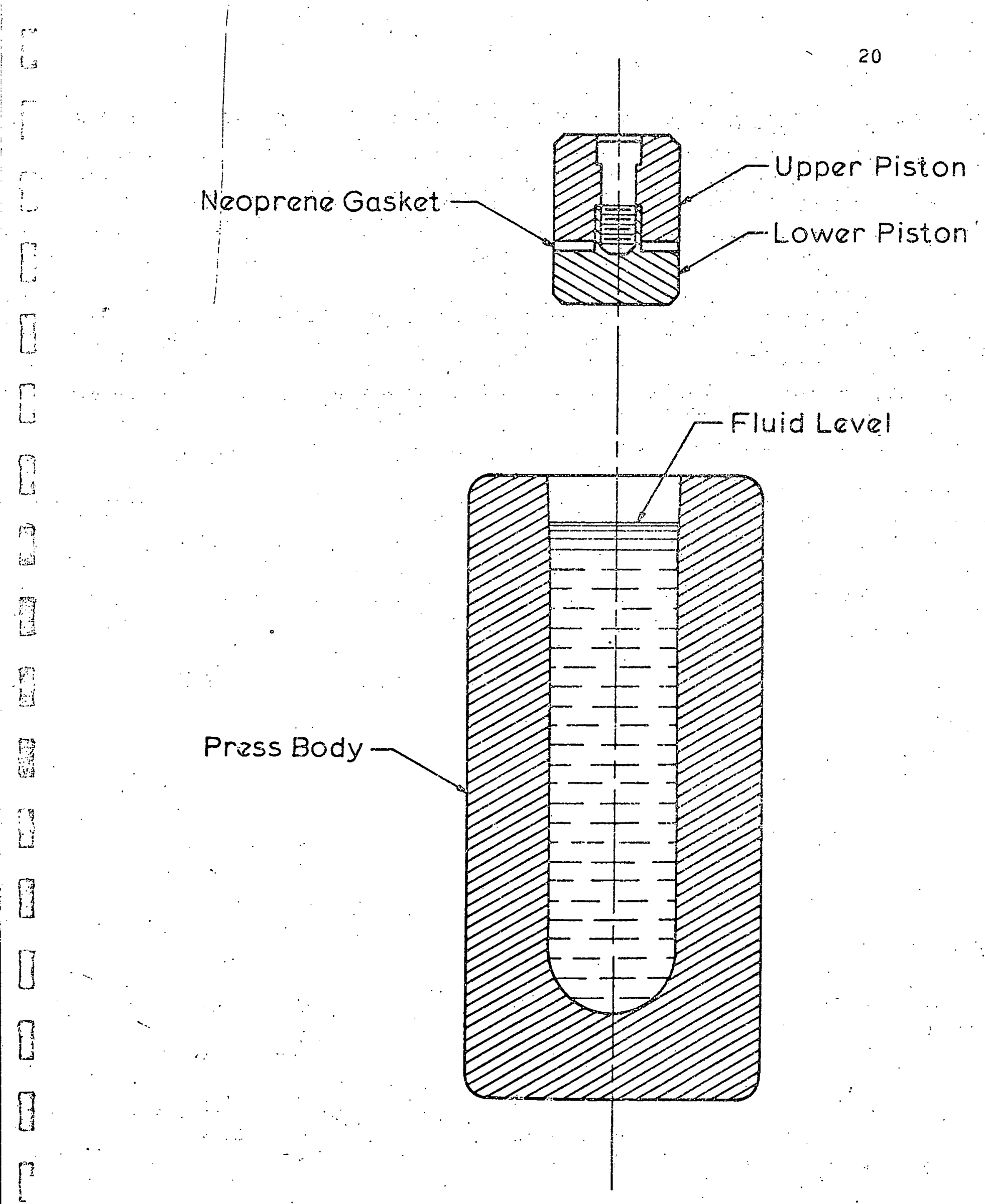

Figure 5 Isostatic Press. 


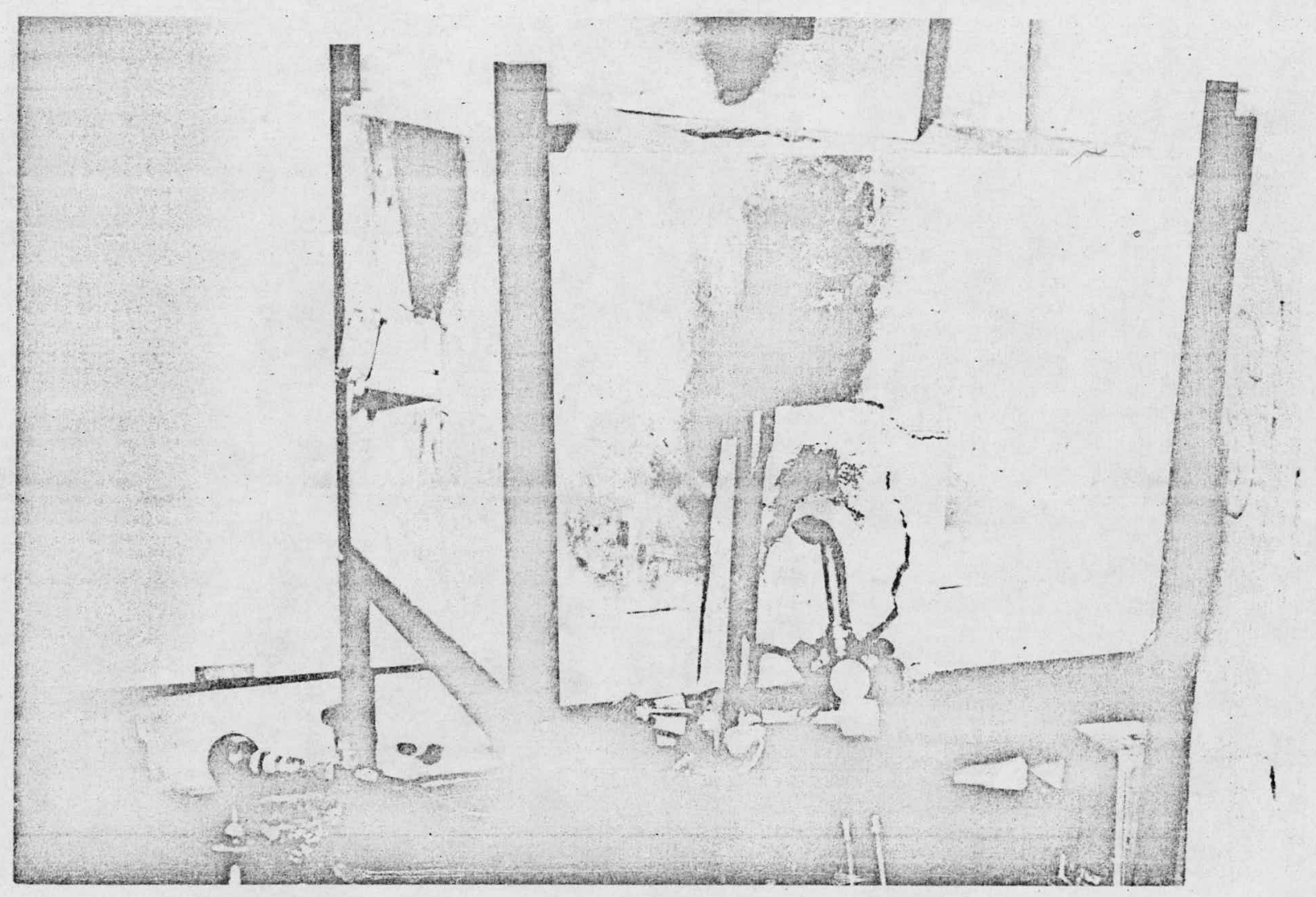

Figure 6 Gas Torch Furnace 

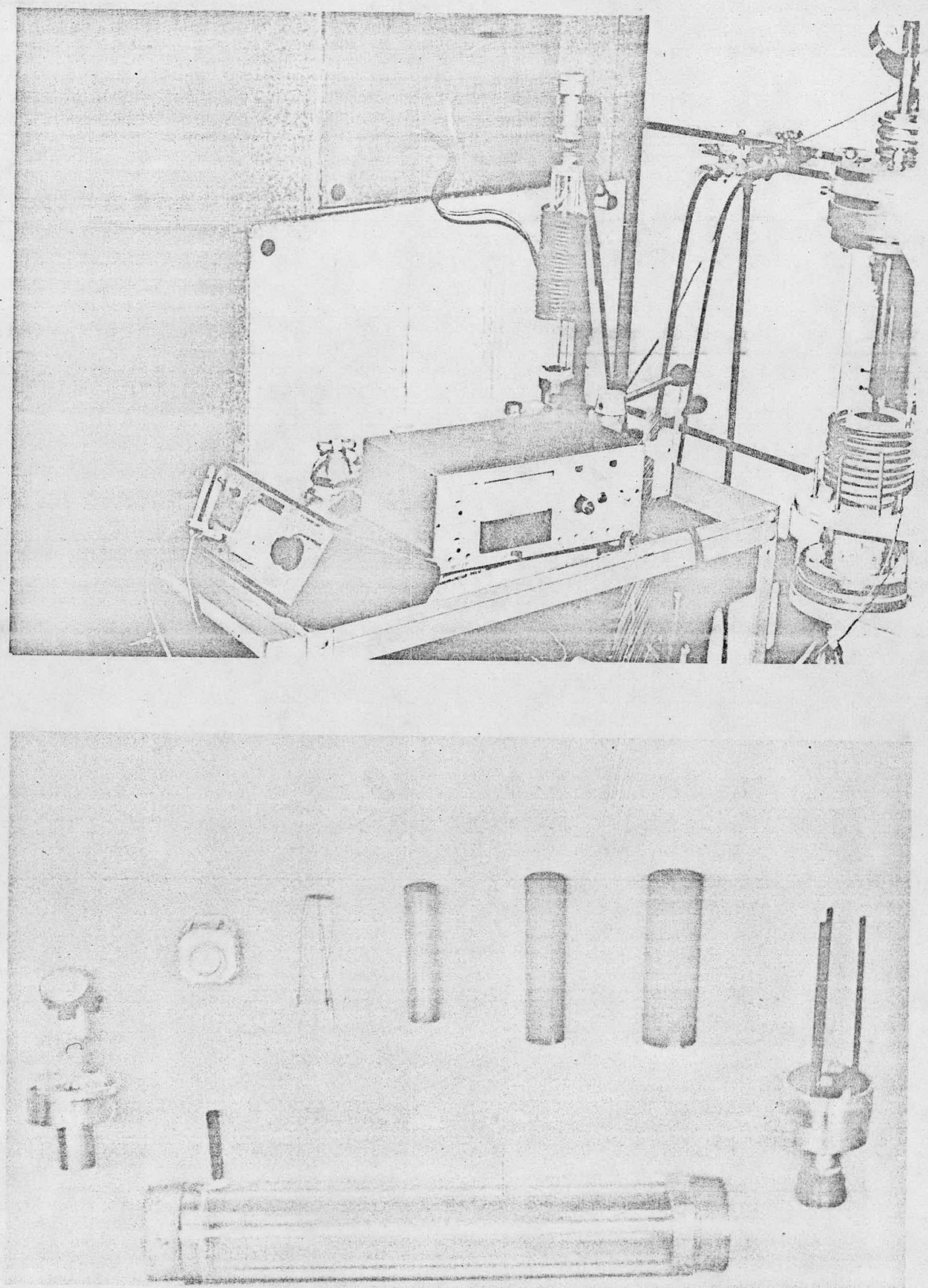

Figure $7 \quad R-F$ Induction Furnace 
III. Densification in Doped $\mathrm{Al}_{2} \mathrm{O}_{3}$

A. Use of Mgo to Densify $\mathrm{Al}_{2} \mathrm{O}_{3}$

In an effort to examine the role of segregants on the densification of $\mathrm{Al}_{2} \mathrm{O}_{3}$, severel commercial aluminas sintered with MgO were examined using AES. In general the samples were cut with a diamond wheel on a wafering machine into a size and shape compatible with the Auger analysis equipment utilized, This usually meant a sample of square or round cross section (with the largest cross-sectional dimensions less than $0.145^{\prime \prime}$ ) $I^{\prime \prime}$ long. The specimens were then placed in an UHV system and intergranular fractures obtained under vacuum. AES and inert-ion sputtering were then used on the exposed grain boundaries to determire the composition of the first few atomic layers of the boundary and to obtalin a profile of species away from that joundary. Figure 8 presents a top view of the vacuum system used in this study.

The commercial aluminas doped with Mgo examined this way Included an alumina manufactured by AFC, a Westinghouse alumina, and a high density General Electric alumina. All three of these materials were theoretically dense and translucent. SEM fractographs from these materials (Figures 9-11) Indicated intergranular fracture and the absence of pores. The Auger spectra from these fractures are presented in Figures 12-14. In addition to the AI and $O$ peaks, a Ca peak was present on the spectra from all three alumina grain boundary fractures. $M g$ if present, would have a serles of peaks from 1100-1200eV. There does not appear. to be any $\mathrm{Mg}$ present. Figure 15 presents a sputter profile of $\mathrm{Ca}$. in the General Electric material. The AFC and Westinghouse materials 


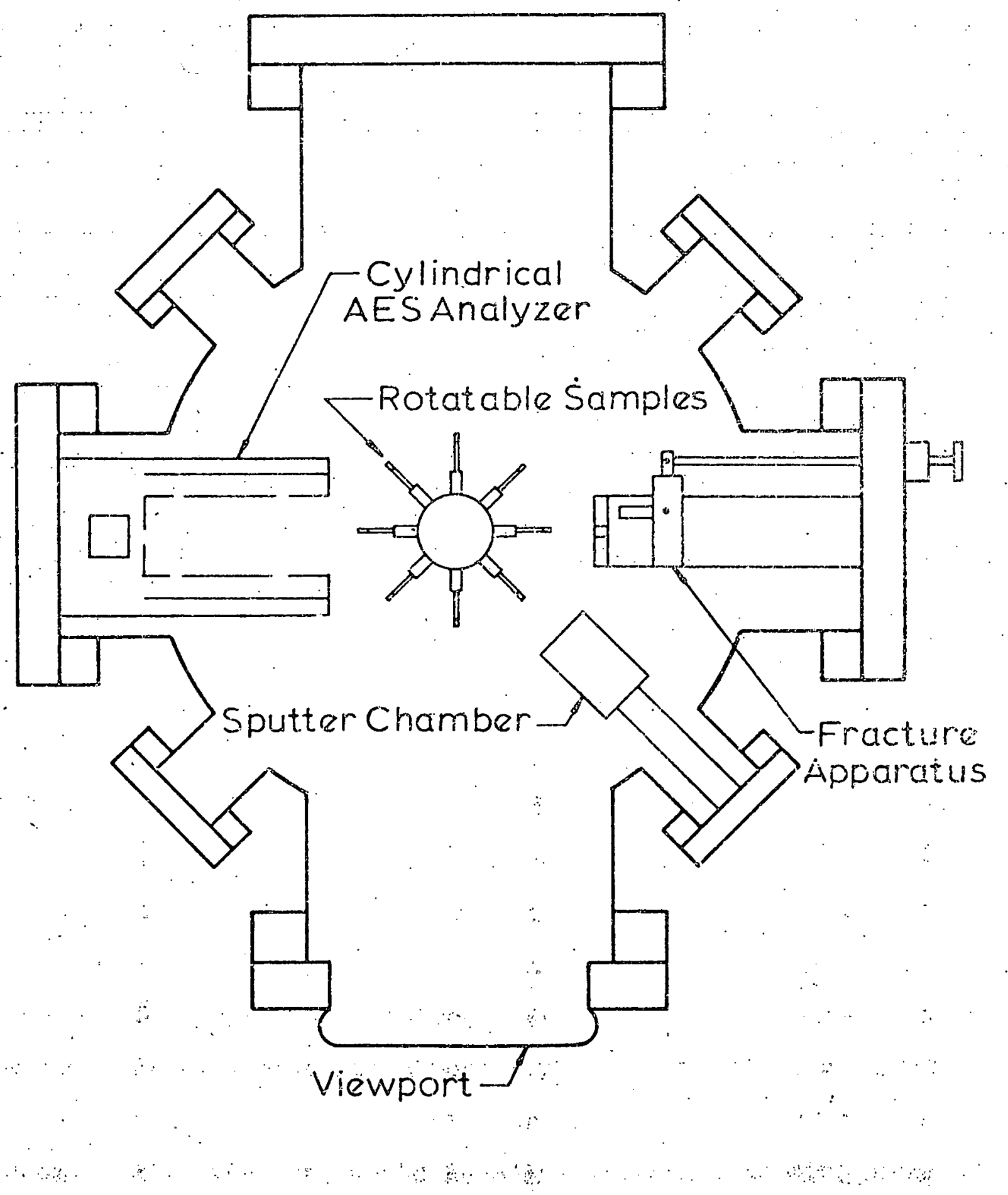

Figure 8 , Top View of UHV System 


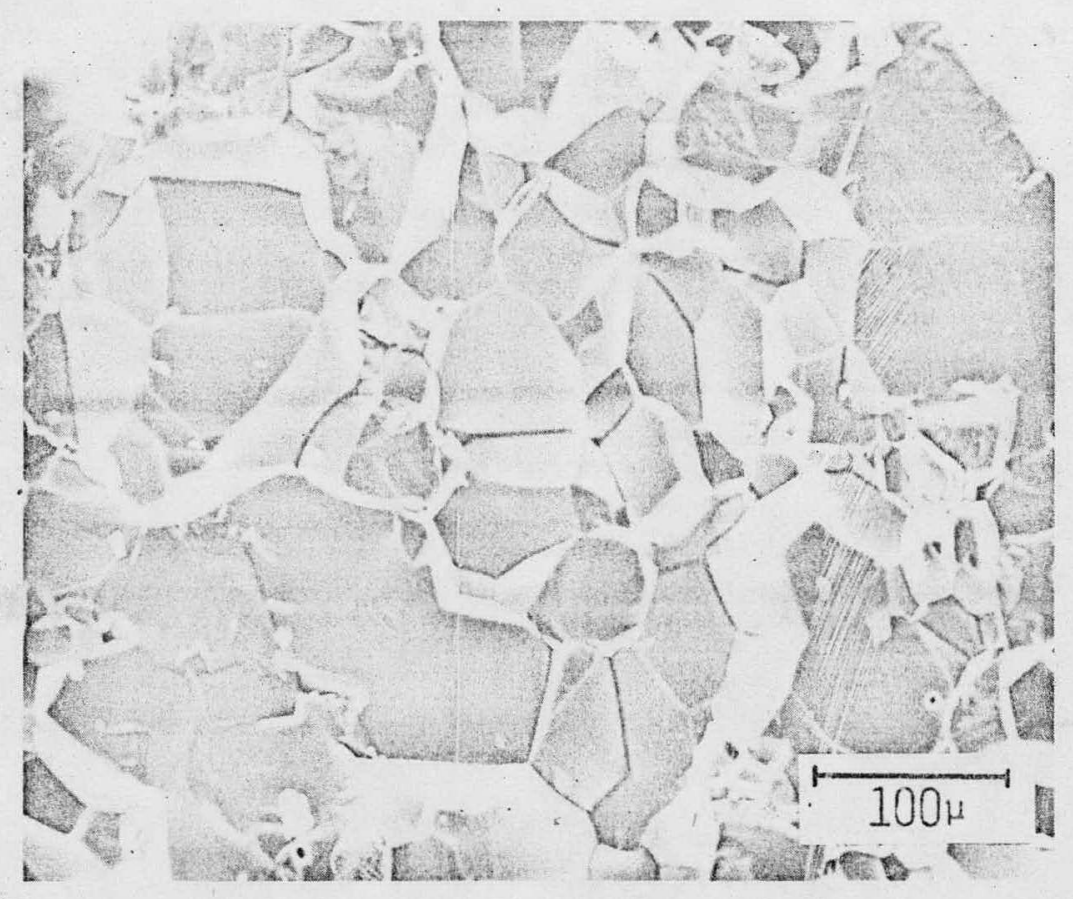

Figure 9 SEM Fractograph of $\triangle F C \quad \mathrm{Al}_{2} \mathrm{O}_{3}$ 


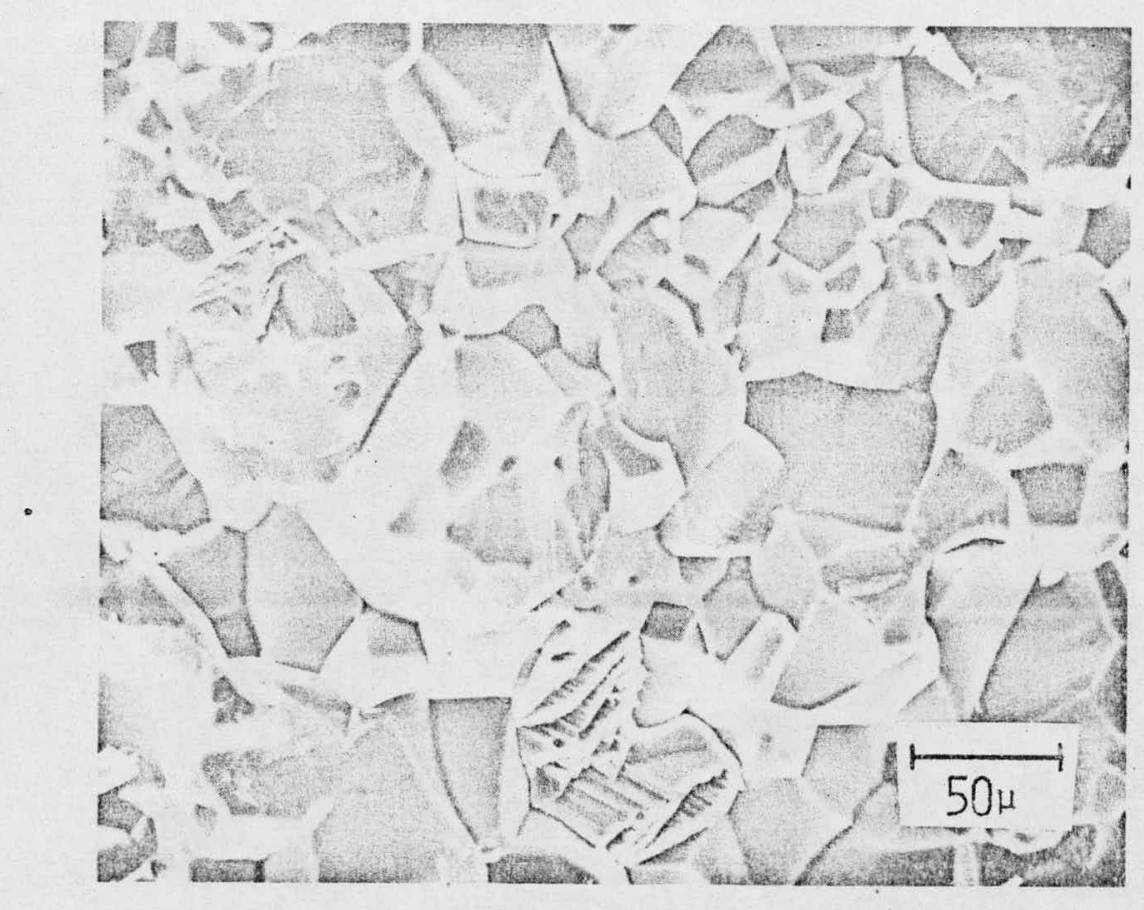

Figure 26 SEM Fractograph of Westinghouse $\mathrm{Al}_{2} \mathrm{O}_{3}$ 


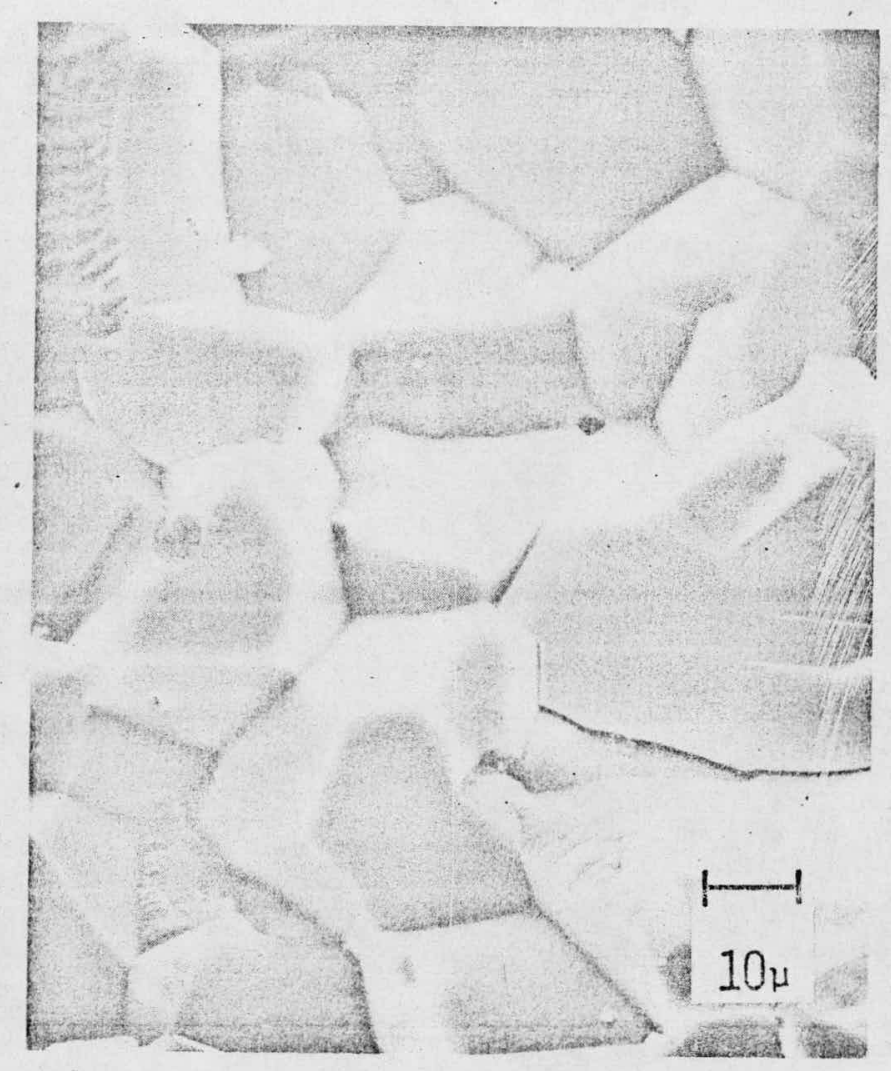

Figure 11 SEM Fractograph of General Electric $\mathrm{Al}_{2} \mathrm{O}_{3}$ 


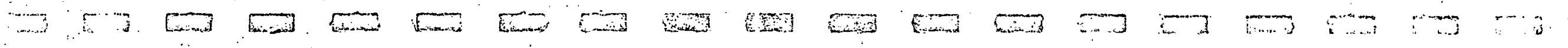

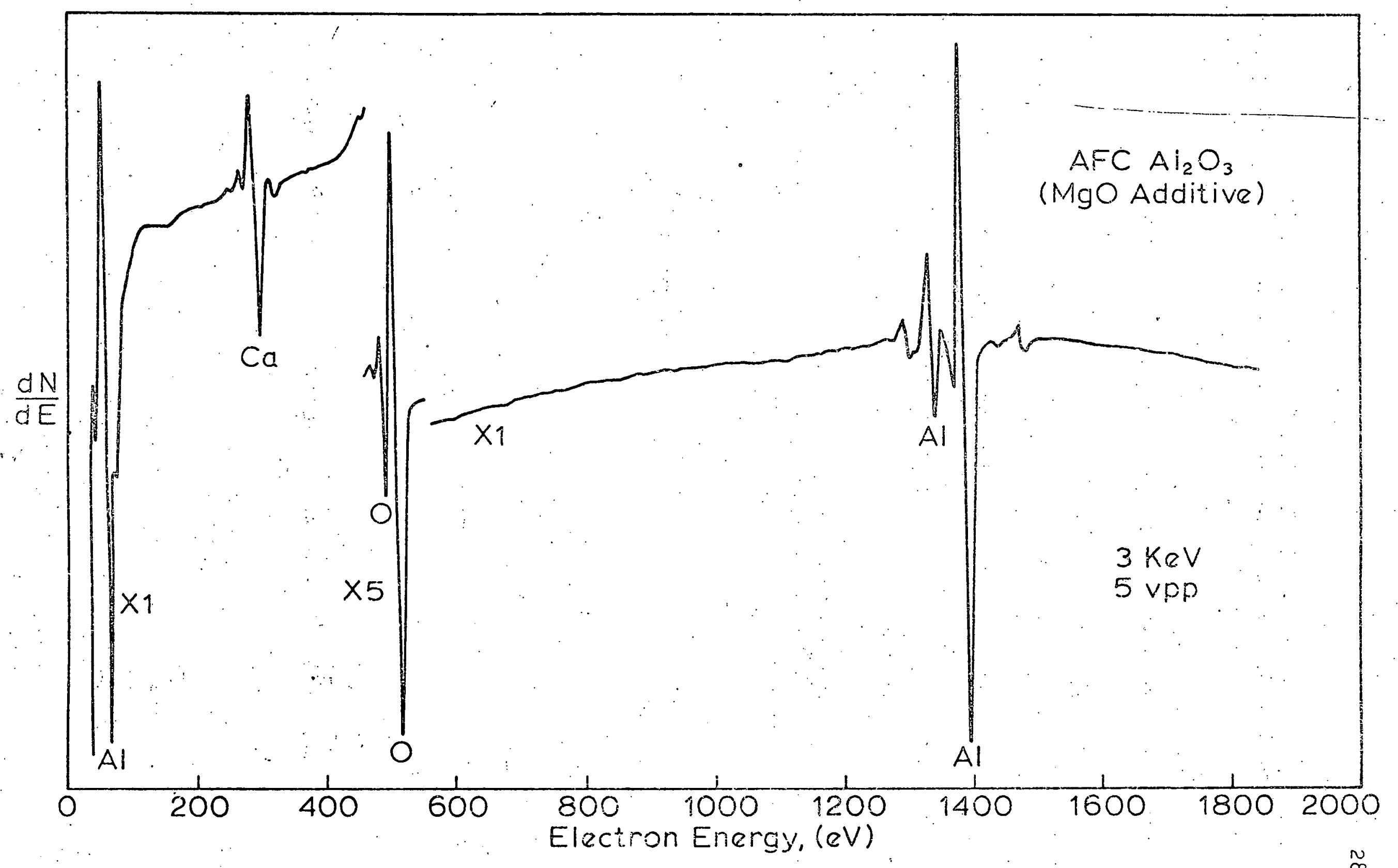

Figure 12 AES Spectrum of AFC $\mathrm{Al}_{2} \mathrm{O}_{3}$ 


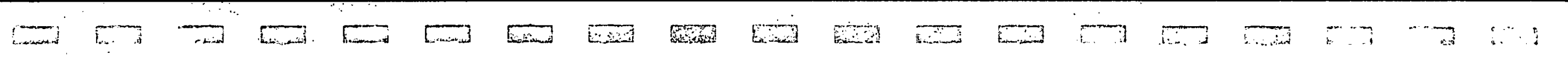

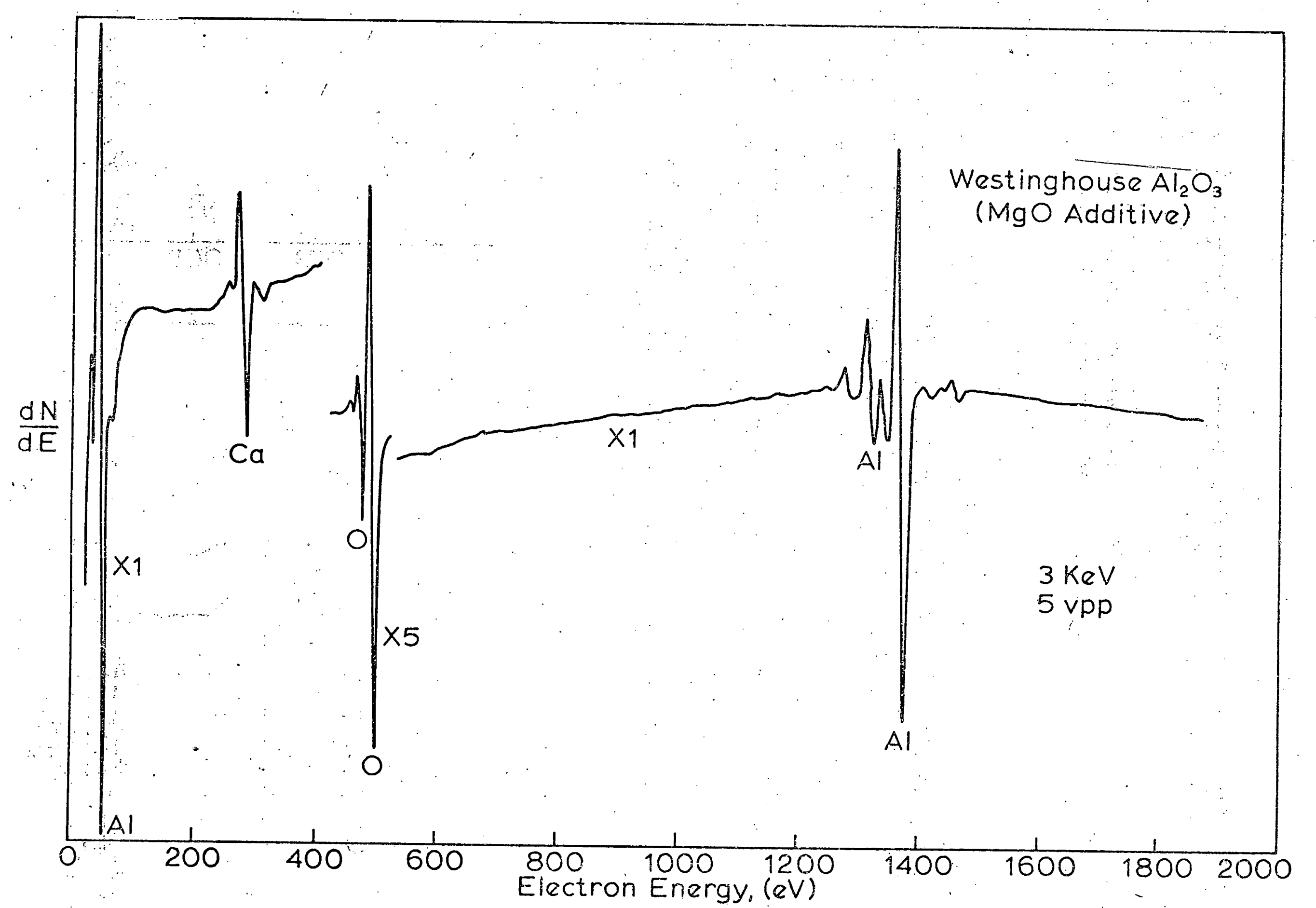

Figure 13 AES Spectrum of Westinghouse $\mathrm{Al}_{2} \mathrm{O}_{3}$ 


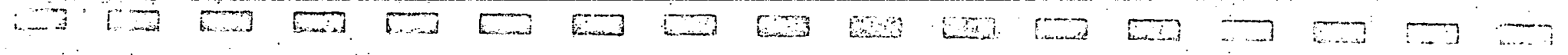

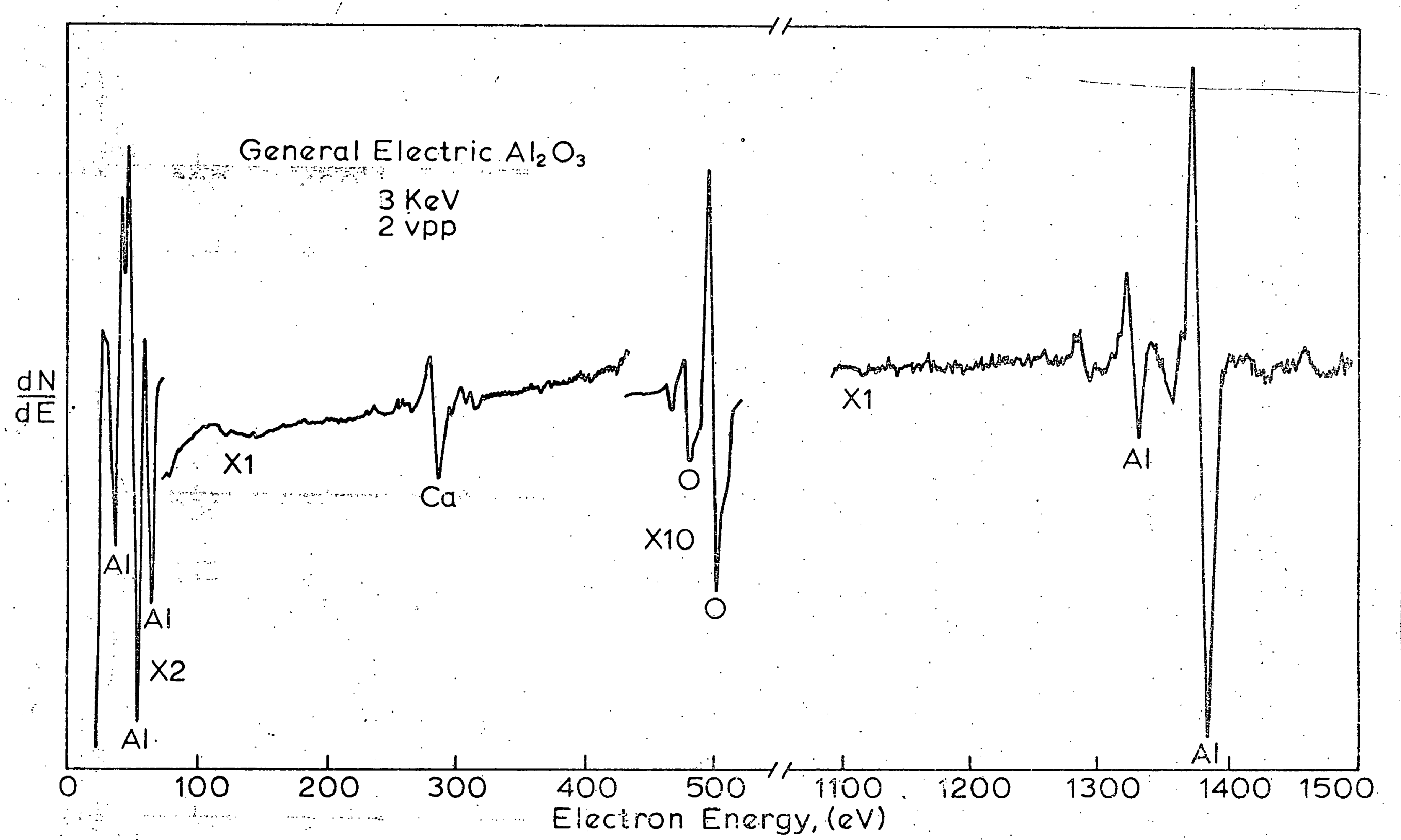

F1gure 14 AES Spectrum of General Electric $\mathrm{Ai}_{2} \mathrm{O}_{3}$ 


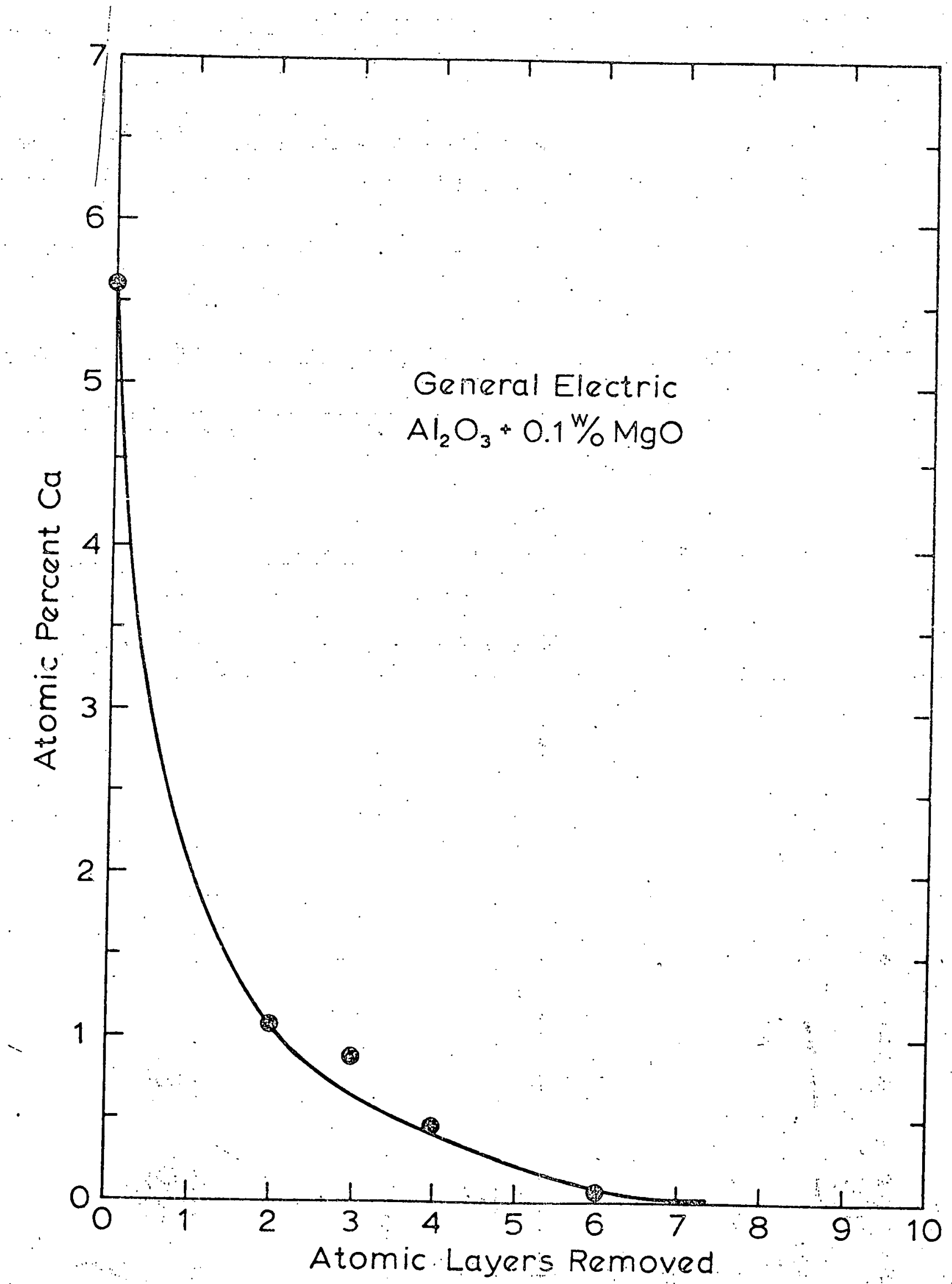

F1gure 15 Sputter Proftle of $\mathrm{Ca}$ in General Electric $\mathrm{Al}_{2} \mathrm{O}_{3}$ 
had similar profiles of $\mathrm{Ca}$ away from the grain boundaries. The results of this portion of the study are summarized in Table 1, which presents the amount in atomlc percent of segregants detected at the boundaries, the density of the materials, and the bulk concentration of detected segregants. The dopant levels presented represent residual leyels after sintering, not nominal additions. Densities were determined using standard $\mathrm{CCl}_{4}$ displacement techniques (see Appendix II) and are reported as percentage of theoretical density (taken to be $3.987 \mathrm{~g} / \mathrm{cc}) .37$

TABLE 1: G. B. Chemistry of Three Commerclal Aluminas

\begin{tabular}{|c|c|c|c|c|}
\hline Material & Dopant & Density & G. B. Chem & Eulk Levels \\
\hline $\mathrm{AFC}$ & $\begin{array}{l}.02^{\mathrm{w}} / 0 \mathrm{MgO} \\
.05^{\mathrm{a}} / 0 \mathrm{Mg}^{+2}\end{array}$ & $99.8 \%$ & $7^{\mathrm{a}} / 0 \mathrm{Ca}^{+2}$ & $90 \mathrm{ppmCa}^{+2}$ \\
\hline $\begin{array}{l}\text { Westing- } \\
\text { house }\end{array}$ & $\begin{array}{l}.01 \mathrm{w} / \mathrm{O} \mathrm{MgO} \\
.025^{\mathrm{a}} / \mathrm{c} \mathrm{Mg}^{+2}\end{array}$ & $100 \%$ & $\begin{array}{l}5^{a} / 0 \mathrm{Ca}^{+2} \\
\end{array}$ & $50 \mathrm{ppmCa}^{+2}$ \\
\hline G. E. & $\begin{array}{l}.075^{\mathrm{w}} / 0 \mathrm{MgO} \\
.2^{\mathrm{a}} / 0 \mathrm{Mg}^{+2}\end{array}$ & $100 \%$ & $6^{a} / 0 \mathrm{Ca}^{+2}$ & $40 \mathrm{ppmCa}^{+2}$ \\
\hline
\end{tabular}

Since no $\mathrm{Mg}$ was detected:at the grain boundaries in any of these materials, as would be expected from previous studies, 8,10 an examination was made of two points. 1) Was the previcus work invalid? 2). Is $\mathrm{Mg}$ detectable on $\mathrm{Al}_{2} \mathrm{O}_{3}$ ?

B. Previous Evidence For Segregation

The most direct evidence from the work of Jorgensen et al for $\mathrm{Mg}$ segregation was obtalned using microhardness techniques. 
Th1s technique involves taking microhardness measurements on a. polished specimen and plotting the microhardness values as a function of distance as a grain boundary is traversed. It has been used by Westbrook and Wood ${ }^{37}$ and Westbrook and Aust 38 to study grain boundary migration in metallic systems, along with the work of Jorgensen et al on ceramics. 8,39

However, basic problems have arisen in the interpretation of observed microhardness profiles. An example of a microhardness profile obtained by Jorgensen and Westbrook from MgO doped $\mathrm{Al}_{2} \mathrm{O}_{3}$ is presented in figure 16. Detectable hardening is observed as far as 10y from the grain boundaries, and this was interpreted as due to segregation of $\mathrm{Mg}$ to the interface. ${ }^{8}$. When this profile is compared to the segregation profile of Ca observed directiy In a similar specimen using AES and inert-ion sputtering (Pigure i5), a discepancy of 4 orders of magnitude in profile spread is observed.

If the hardening Involved a solid solution effect, the two profiles should be of similar spread. 40 Another possible explanation for the hardening can be modeled by the image force produced on a dislocation as it approaches an interface representIng a discontinuity in elastic modulus. The image force can be calculated as a function of distance from the interface. 41 . If - a thin strip of pure MgO $20 \AA$ thick is. inserted between two regions of pure $\mathrm{Al}_{2} \mathrm{O}_{3}$, the resulting force profile (calculated in Appendix $C$ and presented in Figure 43) indicates softening beginning about $75 \&$ from the interface. Unfortunately modulus data for CaO is not available, but even if the modulus for caO were larger than that of $\mathrm{Al}_{2} \mathrm{O}_{3}$ (which would produce a hardening effect), the spread In the profile would be comparable to that of Figure 43. Hence: 

(n) gure

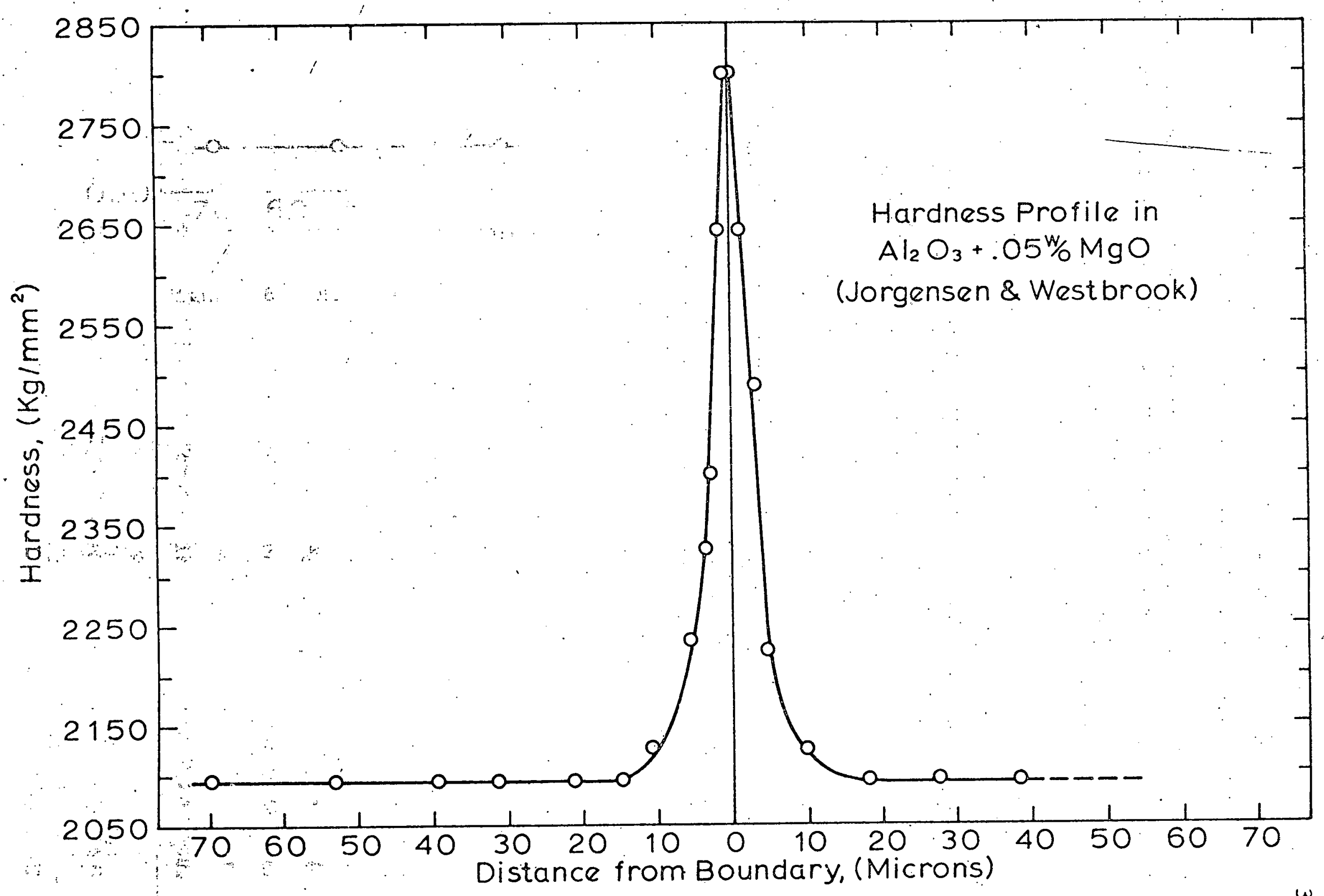

F1gure 16 Microhardness Profile in $\mathrm{Al}_{2} \mathrm{O}_{3}+.1 \mathrm{~W} / 0 \mathrm{MgO}$ 
even this upper limit value (the region of modulus change is not pure $\mathrm{CaO}$ ) falls far short of predicting hardening $10 \mu$ from this interface.

Finally, if the observed shear at the boundary is modeled with a dislocation pile-up mechanism, 40 a calculation of the distance from an interface at which significant hardening is

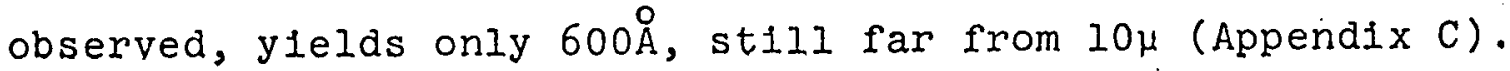

Therefore it appears that interpretation of observed microhardness profiles in light of direct experimental evidence does not imply adsorption of solute at the interface.

Another factor which leads to questions concerning the validity of the solute segregation model is the comparison of continuous grain growth data for pure $\mathrm{Al}_{2} \mathrm{O}_{3}$ and $\mathrm{Al}_{2} \mathrm{O}_{3}+\mathrm{MgO}$. Several sets of this data are plotted in Figure 17. Although obtained from two different investigators and invoiving different temperatures, this data clearly indicates that up to the point at which discontinuous grain growth beglns, there is no detectable difference in rate of grain growth between the material with MgO and that without.5,10 If segregants were inhibiting discontinuous grain growth, they should also inhibit continuous grain. growth. There appears to be no grain growth inhibition relative to pure $\mathrm{Al}_{2} \mathrm{O}_{3}$ which undergoes discontinuous grain growth.

C. Detectability of $\mathrm{Mg}$ on $\mathrm{Al}_{2} \Theta_{3}$

In an effort to examine the second point ralsed earlier concerning detectability of $\mathrm{Mg}$ on $\mathrm{Al}_{2} \mathrm{O}_{3}$, two experiments were run. First; a fresh fracture surface of $\mathrm{Al}_{2} \mathrm{O}_{3}$ was covered with a thin layer of vacuum evaporated $\mathrm{Mg}$. Figure 18 presents the results of an AES examination of the chemistry of this surface. The 


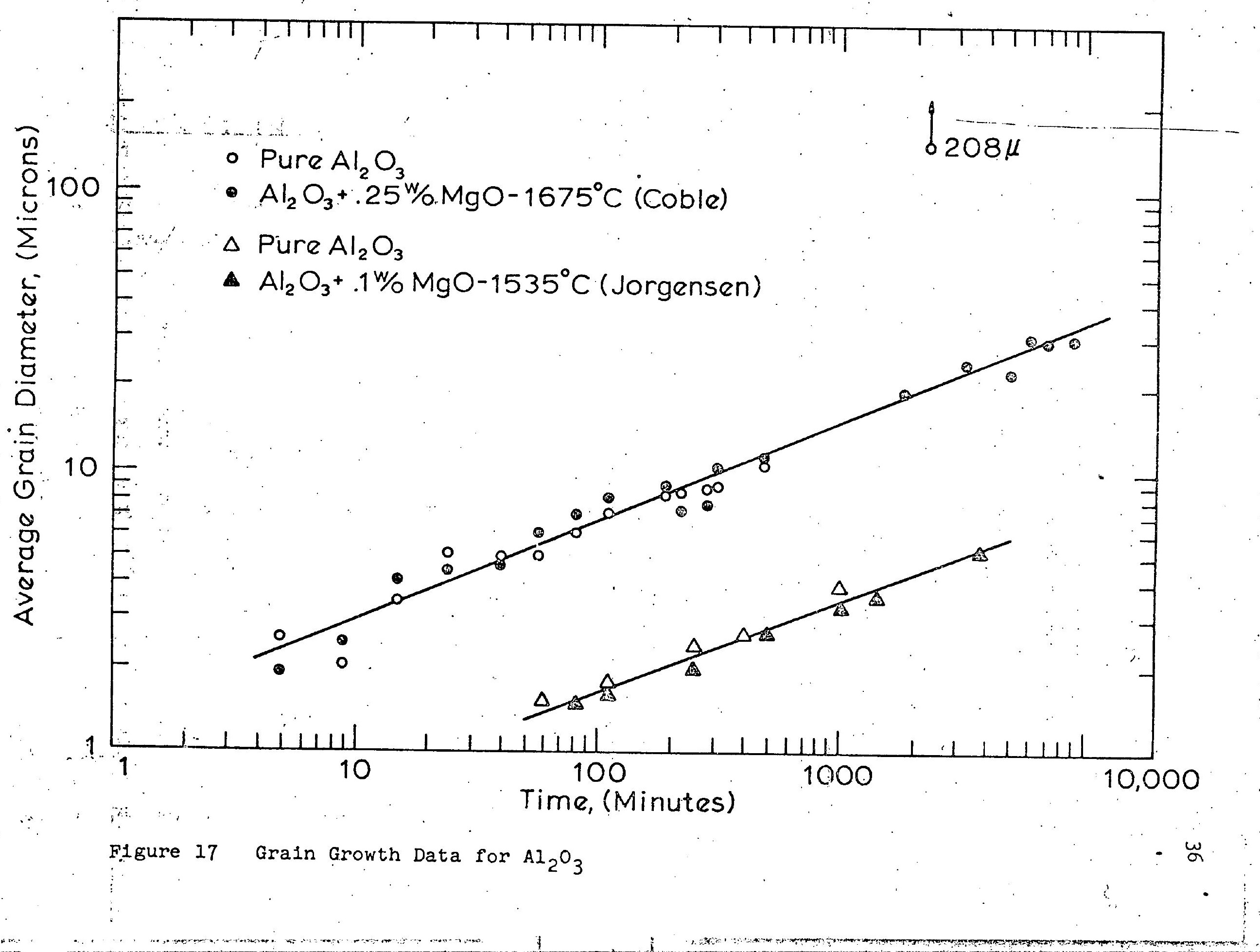


top spectrum is of the $\mathrm{Al}_{2} \mathrm{O}_{3}$ substrate with the freshly evaporated MgO. Both Mg and AI peaks are present and the concentration of $\mathrm{Mg}$ in the first few atomic layers is roughly $25^{\mathrm{a}} / 0$. The middle spectrum shows the same spot after the electron beam had been on the sample for 30 minutes. The Mg concentration is stable under electron bombardment and hence should be stable on the fresh fracture surfaces. The bottom spectrum represents the surface chemistry after 5 atomic layers have been removed with 1nert-1on sputtering. This reduced $\mathrm{Mg}$ concentration is also stable.

The second part of the stabillty question was answered by examining a sample of General Electric $\mathrm{Al}_{2} \mathrm{O}_{3}$ doped w1th . ${ }^{\mathrm{W}} / 0$ MgO and detecting the background Mg level. As indicated in Table 1 , th1s corresponds to $.2^{\mathrm{a}} / 0 \mathrm{Mg}$ wh1ch $1 \mathrm{~s}$ st1ll detectable w1th AES and Figure 19 presents the high energy spectrum from this sample. The small peak labeled $M g$ is the only detectable $M g$ signal and to compare the scale of the peaks, the main Al peak should be multiplied by two. The Mg level detected appeared to be slightly greater than $.2^{\mathrm{a}} / 0$, perhaps $.4^{\mathrm{a}} / 0$, but at such low levels it is difficult to quantify the observed peaks.

The conclusion, however, is that if there was a massive segregation of $\mathrm{Mg}$ to the grain boundaries in these aluminas, 1 t. would be detected.

D. Use of $\mathrm{N} 10$ to Densify $\mathrm{Al}_{2} \mathrm{O}_{3}$

Jorgensen notes that $\mathrm{N} 10$ additions can lead to a theoretically dense: alumina, although the material remalns opaque due to the $\mathrm{N} 1$ ion color centers. ${ }^{8}$ Further, $\mathrm{N} 1$ was thought to be a good additive to study since it is simliar in size to $\mathrm{Mg}$, has the same valence, and was reported to segregate in $\mathrm{Al}_{2} \mathrm{O}_{3} \cdot{ }^{8}$ 
The samples examined were mixed from Linde A alumina, . . w $/ 0$ Baker Reagent grade NiO and $.5 \%$ Carbowax (a ceramic powder binder) by Battelle Columbus Laboratories. The pellets were isostatically pressed at $30,000 \mathrm{psi}$, and fired in an $\mathrm{O}_{2}$ atmosphere in a gas torch furnace for two hours at $1900^{\circ} \mathrm{C}$. Coble notes that $\mathrm{O}_{2}$, vacuum, or $\mathrm{H}_{2}$ is necessary as an atmosphere to achieve theoretical density. ${ }^{4}$ The resulting ceramics were theoretically dense materials and an Auger spectrum from a typical fracture is presented in Figure 20. On the order of $1^{\mathrm{a}} / \mathrm{O} \mathrm{Ca}$ was detected (bulk level 12ppm $\mathrm{Ca}$ ). Inert-ion sputtering indicated that the Ca was located within 5 atomic layers of the grain boundaries in this material. However, very little $(\sim .4 \%$ ) $N$ i was detected at the grain boundaries. Hence it appears that there is no massive segregation of $\mathrm{Ni}$ in Nio doped alumina. This result apparently conflicts with an autoradiograph obtained by Jorgensen and Westbrook indicating a high level of $\mathrm{Ni}$ isotope at grain boundaries in a NiO doped $\mathrm{Al}_{2} \mathrm{O}_{3}$ sample. ${ }^{8}$ However, since only one sample from many examined yielded this result and since it could not be reproduced, the rellability of the result is. In question. 43 Perhaps a nucleation phenomenon produced a $\mathrm{Ni}$ rich second phase near the boundaries or diffusion along the boundaries caused a local bulld-up of $\mathrm{NI}$ at the polished surface. Since the sample was : unavaliable for AES analysis, 1t was impossible to determine what was unique about this particular sample.

E. Grain Boundary Chemistry in Non-Dense Aluminas:

Since it appears obvious that segregated $\mathrm{Ni}$ or $\mathrm{Mg}$ do. not cause the enhanced densification experienced when these lons are used as additives, the next question to be asked concerned the importance of segregated $\mathrm{Ca}$ in densification. 
A sample of pure $\mathrm{Al}_{2} \mathrm{O}_{3}$ sintered at $1900^{\circ} \mathrm{C}$ for $2 \mathrm{hrs}$. In $\mathrm{O}_{2}$ was examined to determine grain boundary chemistry when discontinuous grain growth has occurred. This material was $95 \%$ dense and a fractograph (Figure 21) Indicates discontinuous grains and trapped pores. The Auger spectrum (Figure 22) showed about $I^{2} / 0 \mathrm{Ca}$ at the grain boundaries.

A material doped with . ${ }^{\mathrm{W}} / 0$ CaO similarly falled to achieve theoretical density (96\%) and the Auger spectrum (Flgure 23) showed about $2^{a} / 0 \mathrm{Ca}$ at the grain boundaries.

Hence $\mathrm{Ca}$ appears at grain boundaries of dense and nondense materials and does not appear to affect final density.

F. Use of $\mathrm{Y}_{2} \mathrm{O}_{3}$ to Achieve Dense Alumina ${ }^{\prime}{ }_{2} \mathrm{O}_{3}$ has also been used to achieve a high density $\mathrm{Al}_{2} \mathrm{O}_{3}$. Commercial Sylvania and Coors aluminas contain $Y$ additives and a sample of each of these was examined. The SEM fractographs (Figures 24 and 25) show intergranular failure and both materials were near theoretical density. (Coors - $99.8 \%$ and sylvania 99.9\%): The Auger spectra (Figures 26 and 27) showed some segregated $\mathrm{Y}$ and $\mathrm{Ca}$. Table 2 summarizes the results of AES analysis of these two materials.

TABLE 2: G. B. Chemistry of Two Commercial Aluminas

\begin{tabular}{|c|c|c|c|c|}
\hline Matepial & Dopant & Density & $\therefore$ G. B. Chemistry & Bulk Levels \\
\hline Sylyania & $.02^{\mathrm{w}} / \mathrm{OY}_{2} \mathrm{O}_{3}$ & $99.9 \%$ & $3^{2} / 0, Y$ & $.025^{\mathrm{W}} / \mathrm{OMgO}$ \\
\hline$\because$ & $.02^{\mathrm{a}} / 0 Y$ & & $I^{a} / 0 \mathrm{Ca}$ & $91 \mathrm{ppm} \mathrm{Ca}^{+2}=$ \\
\hline Coors & $.015^{\mathrm{w}} / \mathrm{OY}_{2} \mathrm{O}_{3}$ & $99.8 \%$ & $i .5^{\mathrm{a}} / \mathrm{OY}$ & $.03^{\mathrm{w}} / \mathrm{OMgO}$ \\
\hline & $.015^{\mathrm{a}} / 0 \mathrm{Y}$ & & $1^{a} / 0 \mathrm{Ca}$ & 58ppm $\mathrm{Ca}^{+2}$ \\
\hline
\end{tabular}




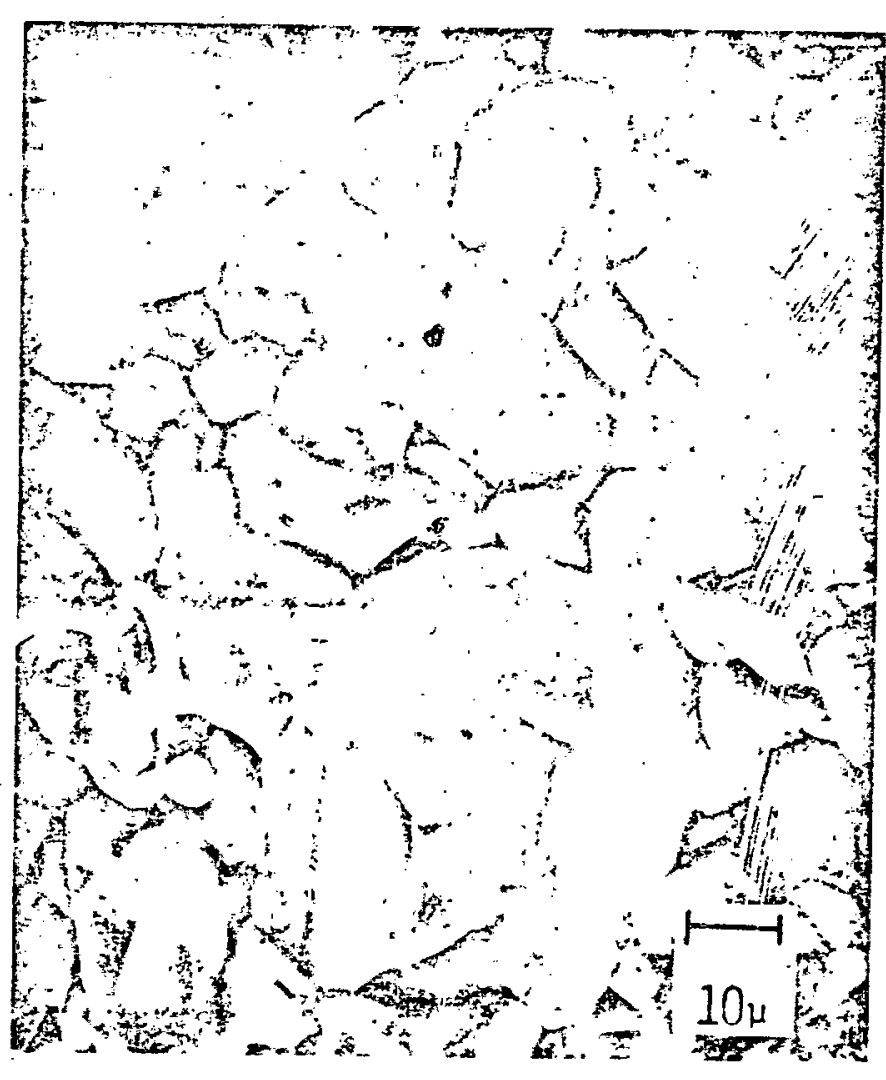

Figure 21 SEM Fractograph of Pure $\mathrm{Al}_{2} \mathrm{O}_{3}$ 
Get

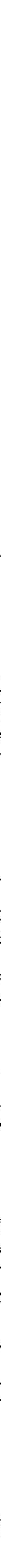




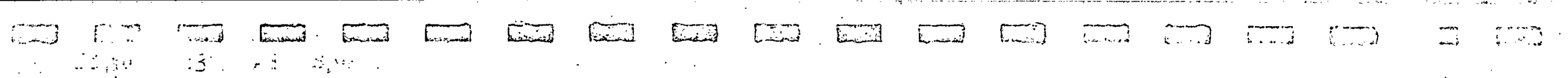

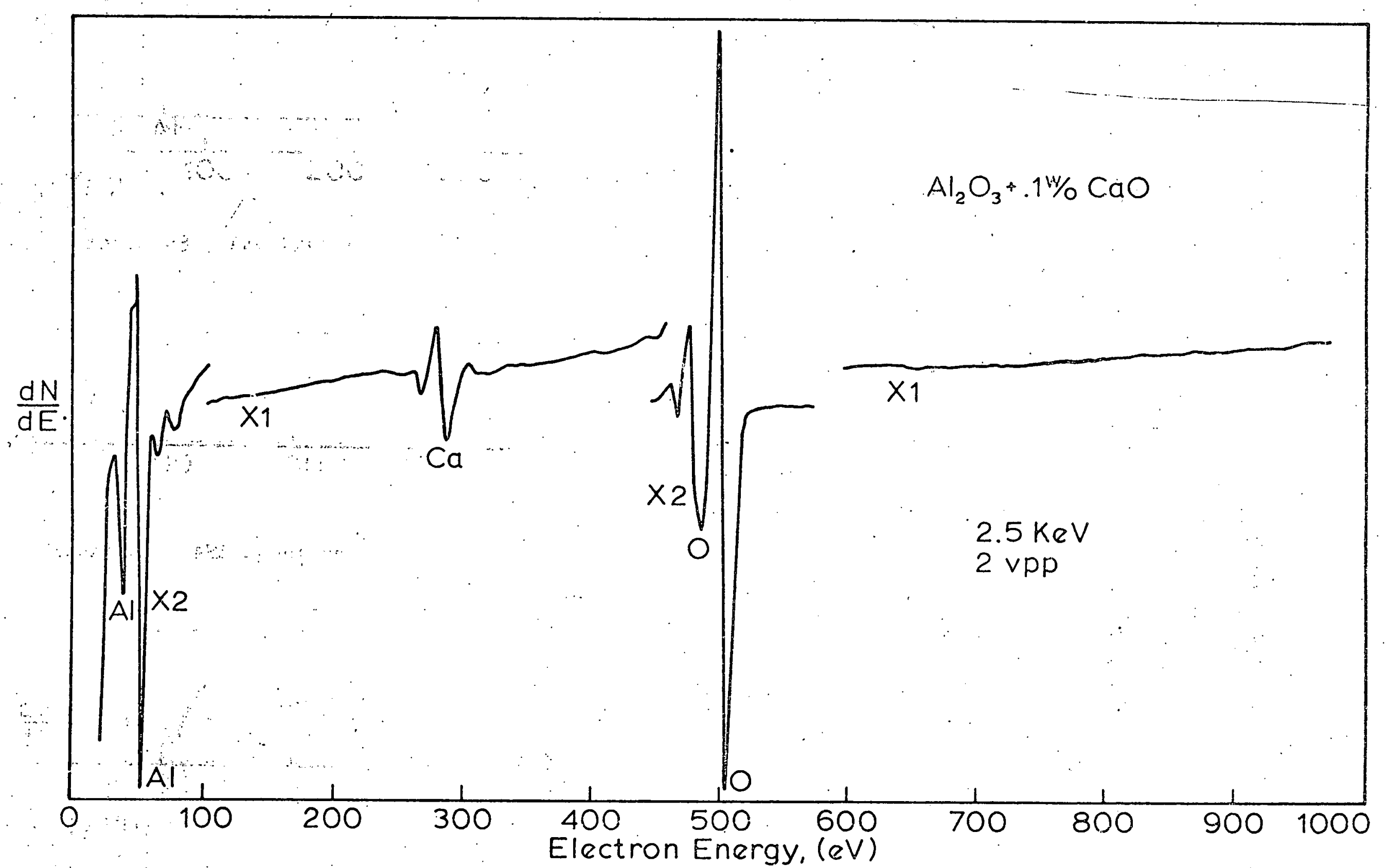

Figure 23 AES Spectrum of $\mathrm{Al}_{2} \mathrm{O}_{3}+. .^{\mathrm{w}} / 0 \mathrm{CaO}$ 


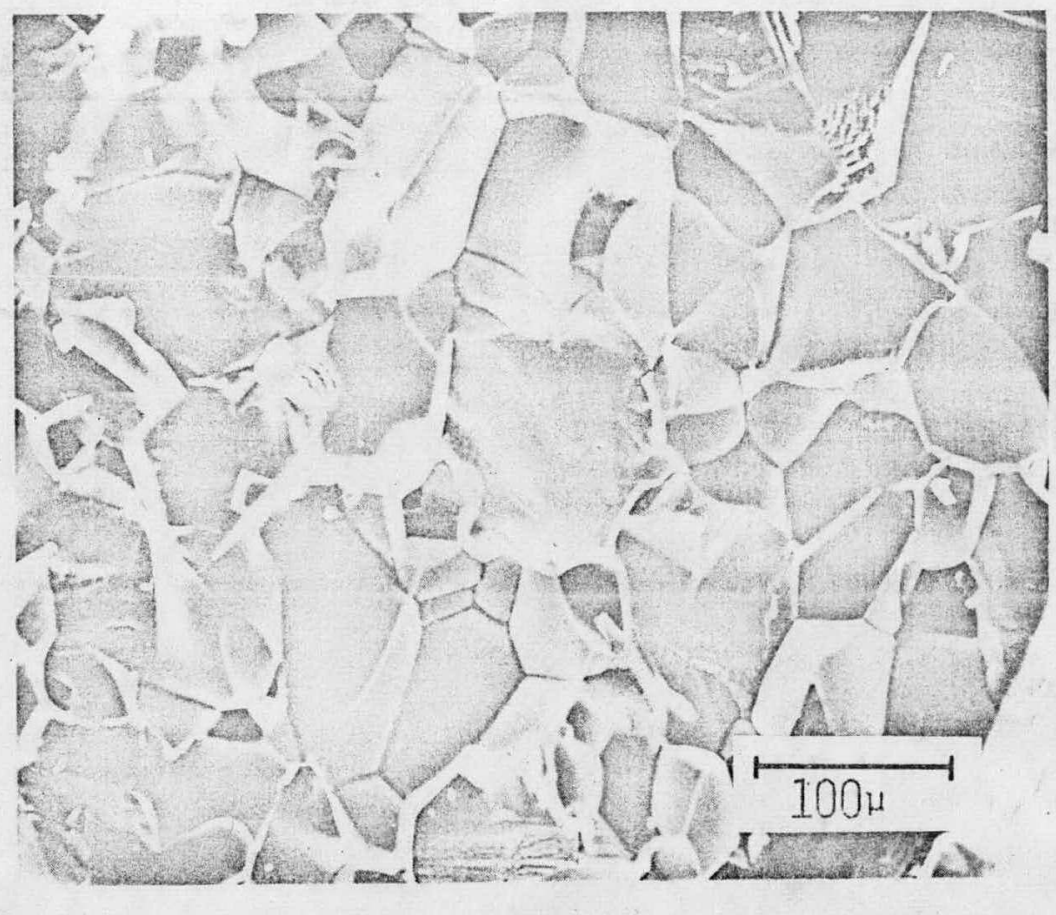

Figure 24 SEIV Fractograph of Sylvania $\mathrm{Al}_{2} \mathrm{O}_{3}$ 


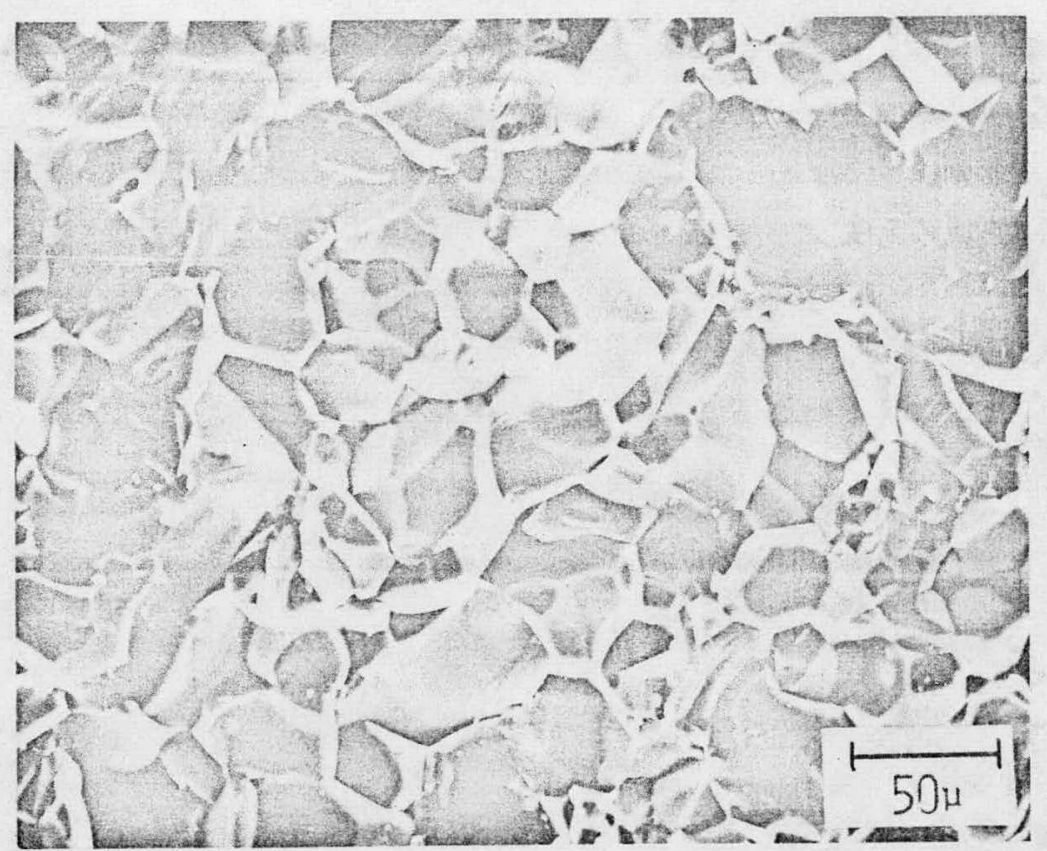

Figure 25 SEM Fractograph of Coors $\mathrm{Al}_{2} \mathrm{O}_{3}$ 

Although it was not possible to obtain non-dense material with $Y$ at the boundaries and therefore eliminate consideration of $\mathrm{Y}_{2} \mathrm{O}_{3}$ as a densification aid, it is interesting to note that these materials had at least as much MgO as the dense materials in Table 1. The other important point is that the $Y$ does segregate and inert-ion sputtering indicated that all segregated species were localized within 5 atomic layers of the grain boundaries.

\section{G. Equilibrium Segregation of Impurities}

The segregation of impurities in the materials examined In this study can be explained by Gibbsian or equilibrium segregation.44-47 The driving force for this segregation involves the reduction in free energy accompanying segregation of a poorly fitting solute species (size misfit or electronic nisfit) from a matrix site to a region of high energy such as a disordered grain boundary. As the temperature of the system Is lowered, more solute is expected to segregate until the boundary becomes saturated or kinetic factors begin to.limit material transport to the boundaries.

A calculation of the amount of a solute expected at the grain boundaries with a given bulk concentration and change in free energy as a function of temperature, is presented in Appendix D.

$$
\mathrm{Cgb}=\frac{C \mathrm{e}^{\mathrm{Q} / \mathrm{RT}}}{1+C \mathrm{e}^{\mathrm{Q} / \mathrm{RT}}}
$$

where $\mathrm{Cgb}=$ grain boundary: concentration of the solute,

$\mathrm{C}=$ bulk concentration of the solute, and

$Q=$ interaction energy (change in free energy)

Th1s form of the equation does not include the vibrational entropy term. An evaluation of: the effect of changes in this. term is inciuded in Appendix D; from.this point on, its effect 
will be ignored and the equation utilized without it. An alternate way to consider the problem of grain boundary segregation has been developed by Cahn and Hilliard. 46 Beginning with Gibbs' equation for variation in boundary tension with chemical potential they arrived at the following equation for an upper limit on the amount of excess solute located at the grain boundary at equilibrium:

$$
\Gamma_{2(1)}^{0}<\frac{\sigma_{1}}{\operatorname{kTT}\left[1+\ln \left(\mathrm{x}_{\mathrm{e}} / \mathrm{x}_{0}\right)\right]}
$$

where $\Gamma_{2(1)}^{0}=\left(\Gamma_{2}-\left(x_{0} /\left(1-x_{0}\right)\right) \Gamma_{1}\right)$, where $\Gamma_{2}$ and $\Gamma_{1}$ are the excess quantities of component 2 and 1 respectively (defined as the differences between the actual amount and that which would be present if the phases were homogeneous up to the grain boundary);

$$
\begin{aligned}
& x_{e}=\text { solubility of component } 2 \text {; and } \\
& x_{0}=\text { bulk concentration of component } 2 .
\end{aligned}
$$

This particular upper limit can be calculated and compared to the experimentally measured excess, defined as:

$$
\Gamma_{2(1)}^{0}=\frac{1}{A}\left(N_{2}-\frac{x_{0}}{\left(1-x_{0}\right)} N_{1}\right)
$$

where $N_{1}=$ number of 1 atoms removed from an area $A$, ard $\mathrm{N}_{2}=$ number of 2 atoms removed from $A$.

By calculating the upper limit of the excess solute from. equation (2) and comparing this value to the observed excess . calculated from equation (3) and sputter data, a particular case can be classified as equilibrium or non-equilibrium segregation. As mentioned earlier, the factors contributing to the driving: force in equilibrium segregation can be broadly described as size misfit or electronic misfit. The size misfit factor can be treated In at least a semi-quantitative fashion; the electronic misfit 
includes such considerations as electro-negativity and valence differences. These are not easy to consider quantitatively.

However in these ionic materials, the valence is often the same $\left(\mathrm{Mg}^{+2}, \mathrm{Ca}^{+2}, \mathrm{Ni}^{+2}\right.$, etc. $)$ and the electro-negativity has no real meaning. Hence to ignore them to the first approximation and deal withi size misfit is appropriate.

McLean has described the elastic strain energy induced in a lattice when a larger solute is introduced onto a substitutional site. 47

$$
W=\frac{24 \pi K G r^{3} \varepsilon^{2}}{3 K+4 G}
$$

where $K=$ bulk modulus of the solute species,

$\mathrm{G}=$ shear modulus of the matrix,

$r=$ radius of the solute in situ, and

$\varepsilon=\left(r_{1}-r_{0}\right) / r_{0}$ is the strain induced in the lattice $\left(r_{1}=\right.$ radius of the isolated solute and $\dot{r}_{0}=$ radius of the unoccupied site)

Since this model was derived using a finite sphere of the solute material inserted into an infinite continuum of the base material and uses bulk modull and shear moduli for individual ions its rigorous validity is subject to question. However, the important point and a valid one, is that the misfit strain energy is proportional to the square of the strain, $1 . e$.

$$
W \cdot \alpha \quad \varepsilon^{2}=\left(\frac{r_{1}-r_{0}}{r_{0}}\right)^{2}
$$

- From this, an estimate can be made of the interaction energy, Q, for a solute for which there is not enough data to calculate $Q$, by simply using a ratio of $\varepsilon^{2}$ and a $Q$ for a known system. H. Experimental Verification of Segregation Models on $\mathrm{Al}_{2} \mathrm{O}_{3}$ In an attempt to explore the points set out in the previous section, experiments were devised utilizing the casegregation 
noted in the General Electric high density $\mathrm{Al}_{2} \mathrm{O}_{3}$. Samples were machined from a rod of high density G.E. $\mathrm{Al}_{2} \mathrm{O}_{3}$ doped with $.1^{\mathrm{W}} / 0$ Mgo to obtain theoretical density.

The samples were heated to a given temperature, held for 5 hours to ensure equilibrium, and quenched with a blast of He gas. Although it was Impossible to obtain the actual cooling rates, the samples were optical for only a few seconds, far too short a period of time for any significant material transport to occur. Three temperatiures were used, $1700^{\circ} \mathrm{C}, 1800^{\circ} \mathrm{C}$, and $1900^{\circ} \mathrm{C}$. After the quench, the samples were fractured and the grain boundary chemistry obtained with AES. Inert ion sputtering was used to obtain depth profiles of the observed segregants and indicated that the $\mathrm{Ca}$ was localized to within 5 atomic layers of the fracture surface (grain boundaries).

Figure 28 presents Auger spectra from these three quenches. The only variation detected was that of the Ca peak. The Ca percentages at the grain boundaries were: $1700^{\circ} \mathrm{C}-5.6^{\mathrm{a}} / 0,1800^{\circ} \mathrm{C}-$ $4.2^{\mathrm{a}} / \mathrm{o}$, and $1900^{\circ} \mathrm{C}-2.8^{\mathrm{a}} / \mathrm{o}$. The bulk concentration of $\mathrm{Ca}$ was $40 \mathrm{ppm}$ and the solubility is assumed to be close to that vaiue. Appendix E contains a calculation of the upper limit for equilibrium segregation of $\mathrm{Ca}$ in $\mathrm{Al}_{2} \mathrm{O}_{3}$ and shows that the observed: amounts are: within the limit. It also presents a calculztion of - a Q :value for each of the quenched specimens. These values are all close to $28,500 \mathrm{cal} / \mathrm{mole}$. Figure 29 is a plot of equation (37) using $: Q=28,500 \mathrm{cal} / \mathrm{mole}$; and $C=0.0040$. Superimposed on this curvesare plotted the three experimentally determined points: The fit is very good.

To determine if $\mathrm{Mg}, \mathrm{Ni}$, or $\mathrm{Y}$ should segregate, a calculation is presentea in. Appendix $E$ to estimate $Q$ values for these species. 


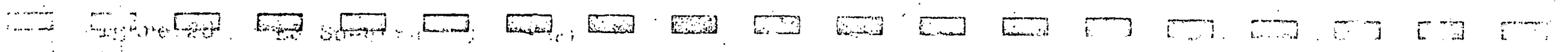

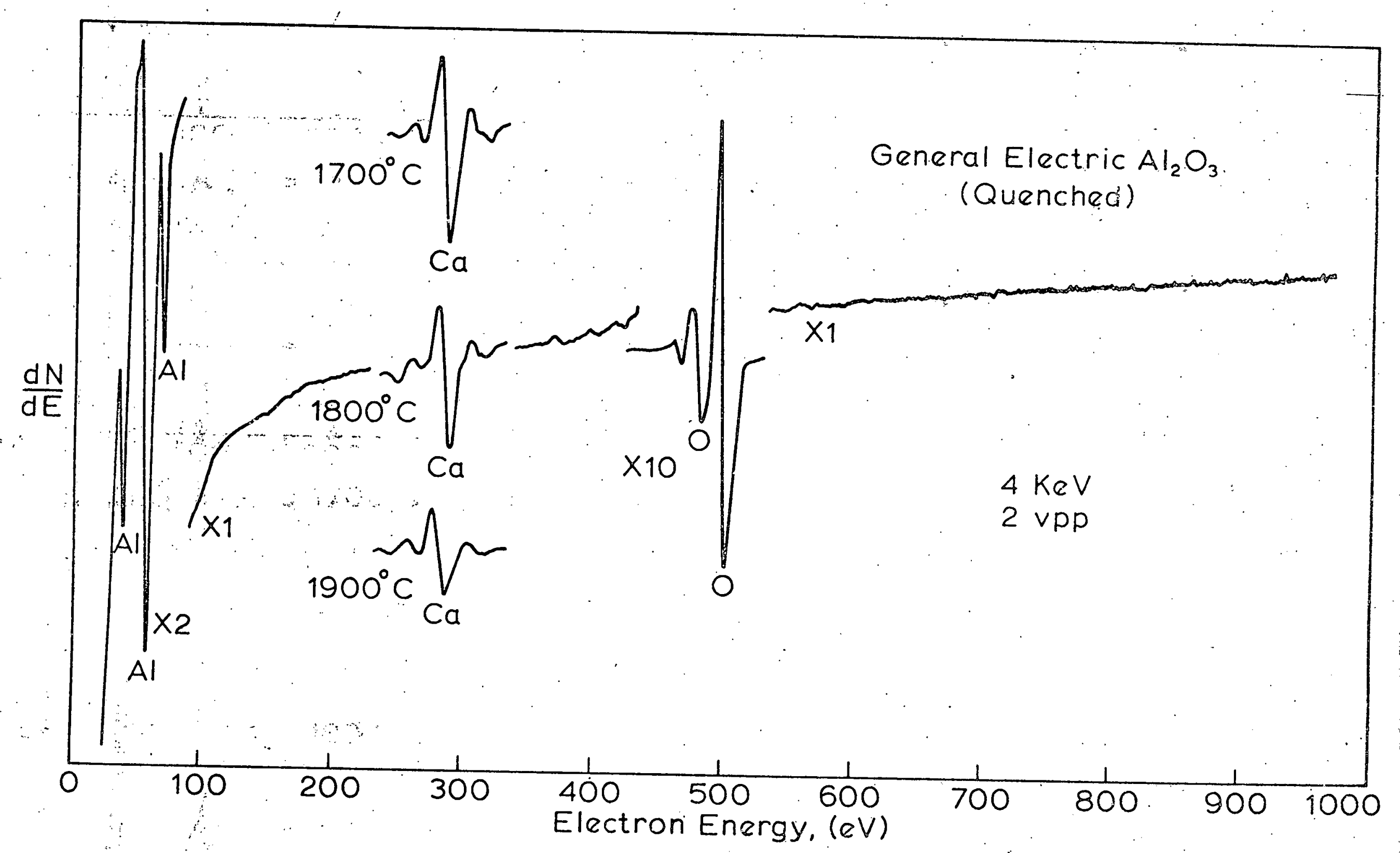

F1gure 28. AES Spectrum of Quenched $\mathrm{Al}_{2} \mathrm{O}_{3}$ 


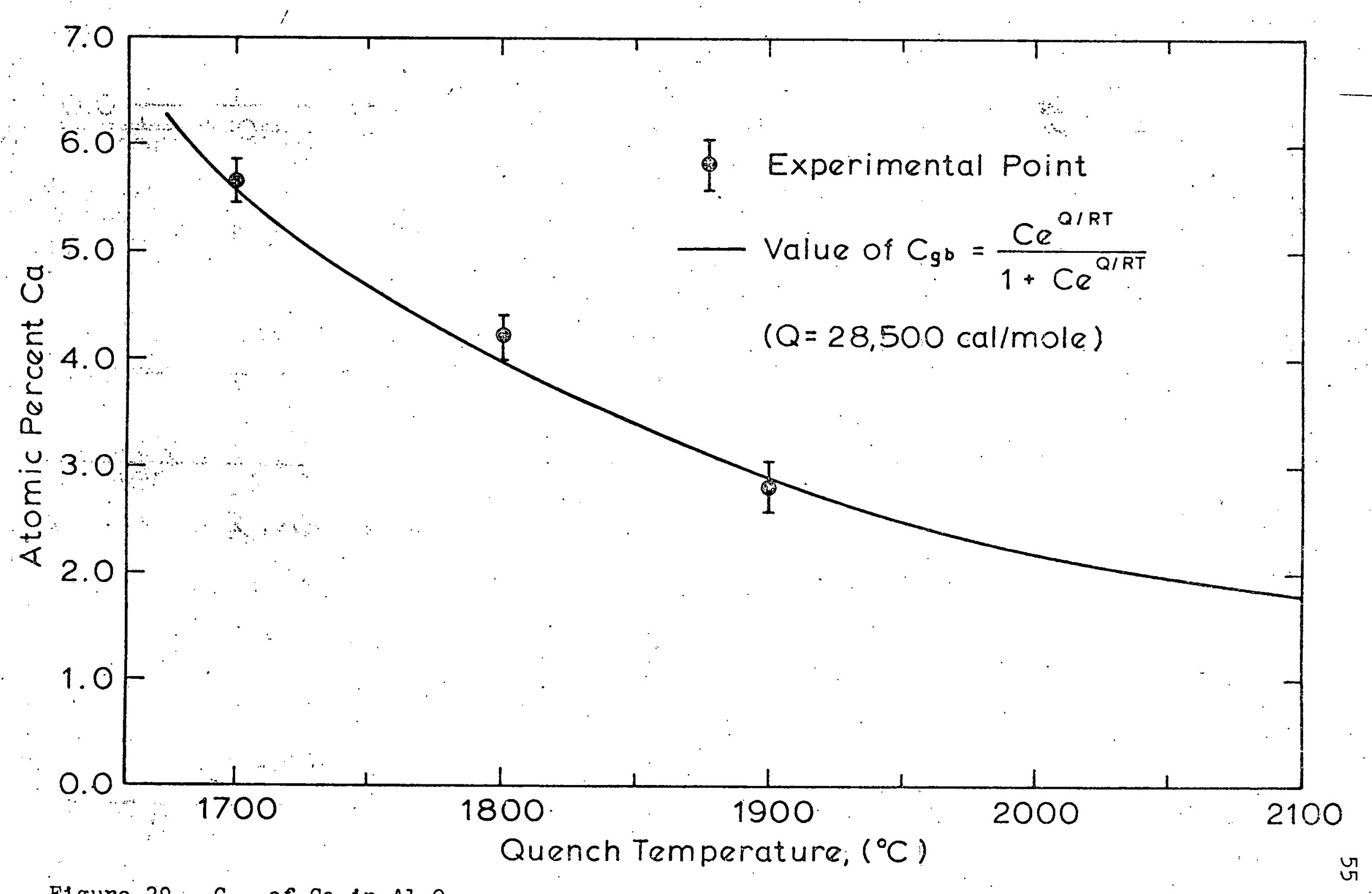

F1gure 29. $\mathrm{C}_{\mathrm{gb}}$ of $\mathrm{Ca}$ in $\mathrm{Al}_{2} \mathrm{O}_{3}$ 
To do this, the $Q$ value for $\mathrm{Ca}$ is multiplied by $\left(\varepsilon_{\mathrm{x}}^{2} / \varepsilon_{\mathrm{ca}}^{2}\right)$. where $\varepsilon_{\mathrm{x}}$ is the misfit due to the desired species and $\varepsilon_{\mathrm{ca}}$ is the $\mathrm{Ca}$ misfit. The $Q$ values determined are listed in Table 3 .

TABLE 3: Misfit Energies for Varlous. Solutes in $\mathrm{Al}_{2} \mathrm{O}_{3}$

Species. Ionic Radius $\underline{\varepsilon}$ Q(cal/mole)

\begin{tabular}{|c|c|c|c|c|c|}
\hline $\mathrm{Ca}^{+2}$ & $.99 \AA$ & & 1.0 & 28,500 (experimentally & determined) \\
\hline $\mathrm{Mg}^{+2}$ & $.65 \AA$ & 8 & .32 & 2,550 (ratio value) & \\
\hline $\mathrm{Ni}^{+2}$ & $.72 \AA$ & & .44 & 5,470 (ratio value) & \\
\hline$y^{+3}$ & $.93 \AA$ & & .86 & 21,800 (ratio value) & \\
\hline
\end{tabular}

Hence Ca would be expected to segregate before any other species, $\mathrm{Y}$ next, followed by $\mathrm{N} i$ and finally $\mathrm{Mg}$. Appendix $\mathrm{E}$ also contains a set of calculations which indicate how much $\mathrm{Mg}$, $\mathrm{N} 1$, or $\mathrm{Y}$ shoulci segregate at $1700^{\circ} \mathrm{C}$, given the $Q$ values above. Table 4 summarizes these results:

TABLE 4: Expected Segregation of Impurities at $1700^{\circ} \mathrm{C}$ in $\mathrm{AI}_{2} \mathrm{O}_{3}$

Species Bulk Level $\quad$ G. B. Concentration Expected

$\begin{array}{ccc}\mathrm{Mg}^{+2} & .2^{\mathrm{a}} / 0 \mathrm{Mg}^{+2} & .4^{\mathrm{a}} / 0 \mathrm{Mg}^{+2} \\ \mathrm{NI}^{+2} & .15^{\mathrm{a}} / 0 \mathrm{NI}^{+2} & .6^{\mathrm{a}} / 0 \mathrm{NI}^{+2} \\ \mathrm{Y}^{+3} & .02^{\mathrm{a}} / 0 \mathrm{Y}^{+3} & 4.3^{\mathrm{a}} / 0 \mathrm{Y}^{+3}\end{array}$

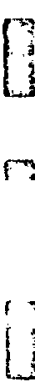

The expected grain boundary concentration of $Y$ wili be modifled due to the co-segregation of $\mathrm{Ca}$ to that boundary, büt I.t. is important to note that the $Y$ will segregate heavily and there will be no massive segregation of either Mg or $\mathrm{Ni}$ (all of 
which is as observed in the previous results). Hence all of the observed segregation is consistent with the equilibrium segregation models presented.

I. Proposed Model for Densification of $\mathrm{Al}_{2} \mathrm{O}_{3}+\mathrm{MgO}$

Although the observed segregation has been accounted for, the question of how $\mathrm{MgO}$ aids $\mathrm{Al}_{2} \mathrm{O}_{3}$ densification remains. The obvious possiblity that Ca segregates to the grain boundaries and inhibits discontinuous grain growth must be discarded, since Ca was also observed on the grain boundaries of both CaO doped and pure $\mathrm{Al}_{2} \mathrm{O}_{3}$. Neither material was close to theoretical density and both had $\mathrm{Ca}$ levels close to the levels observed in the NiO doped material and another in-house prepared $\mathrm{Al}_{2} \mathrm{O}_{3}+. .^{\mathrm{w}} / \mathrm{O} \mathrm{MgO}$. All of thiese material had $C a$ levels at the boundaries near $1-2^{a} / 0$. and the only difference was theoretical density in the samples doped with $\mathrm{MgO}$ or $\mathrm{NiO}$, while the others were not fully dense. The conclusion reached is that $\mathrm{Ca}$ at the grain boundaries is not sufficient for achieving theoretical density in sintered $\mathrm{Al}_{2} \mathrm{O}_{3}$. This result is consistent with the grain growth data presented earlier indicating that there were no substantial differences between rates of grain growth in pure $\mathrm{Al}_{2} \mathrm{O}_{3}$ and $\mathrm{MgO}$ doped $\mathrm{Al}_{2} \mathrm{O}_{3}$ unt11 discontinuous grain growth began. (Figure 17).

$\because$ The model involving second phase pinning by splnel particles must: also be rejected. Although certain materials doped with MgO ana sintered to theoretical density can show second phase particles distributedthroughout the ceramic, 48 other materlals and in fact the outer .015 inches of these "samplies are also theoretically" dense and free of second phase particles. Hence second phase particles are not necessary. . 
As mentioned earlier there does not appear to be enough $\mathrm{MgO}$ added to form a liquid phase and if present during sintering, it should also be present after annealing and quenching.

This leaves the solid solution theory for enhanced sintering as another alternative. This theory was first proposed by Coble 5 and later supported by Bruch ${ }^{9}$. Their contributions will be used in this treatment and enlarged upon.

\section{J. Modification of Solvent Defect Structure}

When a solute ion of different valence is introduced into an ionic material modification of the defect structure can occur.49,50 If for example, a divalent impurity such as $\mathrm{Mg}^{+2}$ is substituted for a trivalent cation such as $\mathrm{Al}^{+3}$, one oxygen vacancy. will be created for every $2 \mathrm{Mg}^{+2}$ ions substicuted into $\mathrm{Al}_{2} \mathrm{O}_{3}$. In a material doped with $.2^{\mathrm{a}} / 0 \mathrm{Mg}^{+2}$ ions, $.1^{\mathrm{a}} / 0$ or $10^{-3}$ atom fraction oxygen vacancies are introduced. An expression for the anion diffusivity of $\mathrm{Al}_{2} \mathrm{O}_{3}$ indicates the importance of the vacancy concentration (assuming diffusion occurs by a vacancy mechanism).49

$$
\mathrm{D}=\mathrm{D}_{\mathrm{O}} \mathrm{N}_{\mathrm{Va}} \mathrm{W}_{\mathrm{T}}
$$

$$
\begin{aligned}
\text { where } \mathrm{D}_{\mathrm{O}} & =\text { pre-exponential constant, } \\
\mathrm{N}_{\mathrm{Va}} & =\text { concentration of vacant anion sites, and } \\
\mathrm{W}_{\mathrm{T}} & =\text { jump frequency. }
\end{aligned}
$$

For intrinsic behavior (i.e.., for pure materlals with only thermally induced vacancies);. the temperature dependence of $\mathrm{N}_{\mathrm{Va}}$ and $\mathrm{W}_{\mathrm{T}}$ incan be expressed in terms of enthalples of vacancy formation, $\Delta \mathrm{H}_{\mathrm{S}}$,: and movement from a site to a vacancy, $\Delta \mathrm{H}_{\mathrm{m}}$ :

$$
\text { (intrinsic) } D=D_{0} e^{-\Delta H_{s} / R T} e^{-\Delta H_{m} / R T}
$$

If on the other hand, a contribution is made to $\mathrm{N}_{\mathrm{Va}}$ through another mechanism, the total $N_{V a}$ will be the sum of the thermaily 
Induced vacancies and the other vacancies:

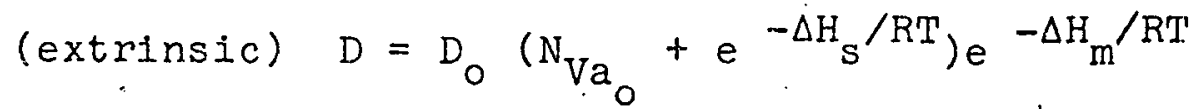

When $\mathrm{N}_{\mathrm{Va}}$ is much larger than the thermaliy induced vacancy concentration in a.given temperature range, the only temperature dependence of $D$ is the jump frequency and the material is said to exhibit extrinsic diffusion. To illustrate the effect of $10^{-3}$ vacancies on the diffusion coefficient, it is necessary to obtain a value of $\Delta \mathrm{H}_{\mathrm{S}}$ for $\mathrm{Al}_{2} \mathrm{O}_{3}$. This value is not readily obtainable, but order of magnitude estimates can be made. Cutler notes that this value is near $5 \mathrm{eV} /$ atom for $\mathrm{MgO} .50$ Shewmon notes that the value for $\mathrm{NaCl}$ is near $2 \mathrm{eV} .{ }^{49}$ Further, an estimate of $\Delta \mathrm{H}$ can be made using the approximation:49

$$
\frac{\Delta \mathrm{H}}{\mathrm{T}_{\mathrm{m}}} \simeq \frac{36 \mathrm{cal}}{\mathrm{O}_{\mathrm{K}}}
$$

This is a standard rule for vacancy creation in metals, and a value of $3.4 \mathrm{eV} /$ atom is obtained for $\mathrm{Al}_{2} \mathrm{O}_{3}$. Table 5 contains values of the thermally induced vacancy concentration using $\Delta H$ values from $2 \mathrm{eV}$ up to $6 \mathrm{eV}$ at $1900^{\circ} \mathrm{C}$ for $\mathrm{Al}_{2} \mathrm{O}_{3}$.

Table 5: Thermally Induced Vacancy Coricentration

\begin{tabular}{llll}
$\frac{\Delta \mathrm{H}_{\mathrm{S}}}{2 \mathrm{eV} / \text { atom }}$ & $\frac{\mathrm{T}\left(\mathrm{O}_{\mathrm{K}}\right)}{2173}$ & $\frac{\exp \left(-\mathrm{H}_{\mathrm{s}} / \mathrm{RT}\right)}{1.6 \times 10^{-5}}$ \\
$4 \mathrm{eV} /$ atom & 2173 & $2.4 \times 10^{-10}$ \\
$6 \mathrm{eV} /$ atom & 2173 & $3.8 \times 10^{-15}$ \\
\hline
\end{tabular}

It is obvious that even if $\Delta \mathrm{H}_{\mathrm{s}}$ is $2 \mathrm{eV} / \mathrm{atom}, 10-3$ vacancies introduced by MgO doping will render the diffusion coefficient extrins $1 \mathrm{C}$ well past $1900^{\circ} \mathrm{C}$ where the $\mathrm{Al}_{2} \mathrm{O}_{3}$ is sintered. Hence if $\Delta \dot{H}_{S}$ is 2 ev/atom and the introduced vacancy concentration is $10^{-3}$, 
the diffusivity of oxygen in $\mathrm{Al}_{2} \mathrm{O}_{3}$ will jump 2 orders of magnitude at $1900^{\circ} \mathrm{C}$. If $\Delta H_{S}$ is higher (which is likely), the diffusivity could jump 7 orders of magnitude or more.

The conclusion is that extrinsic behavior of $\mathrm{Al}_{2} \mathrm{O}_{3}$ due to "artificial" vacancies can alter the diffusivity of the anion species in a very marked manner. This would be expected to alter sintering behavior as vell, if the anion species has the rate controlling diffusivity.50,51 Since the effective rate of material transport through the bulk involves the effective diffusivity,

$$
\text { Deff }=\frac{D_{0} D_{A}}{D_{0}+D_{A}}
$$

this rate of transport would be expected to increase if the rate controlling self diffusivity was increased substantially.

And indeed the $0^{-2}$ diffusivity is rate controling for volume diffusion in $\mathrm{Al}_{2} \mathrm{O}_{3} \cdot 52 \%$. Hence if the $0^{-2}$ diffusivity is Increased, the rate of material transport would increase, and the material should sinter faster. This is also observed in the results of density versus time determinations by Coble ${ }^{5}$ and Bruch $^{9}$, both of which are presented in Figure 30. The plots compare density versus time for samples of pure $\mathrm{Al}_{2} \mathrm{O}_{3}$ and samples doped with $\mathrm{MgO}$. It is obvious from the plots, that at all times, the material with MgO exhibits greater density (less porosity). Hence it is concluded that the presence of $\mathrm{Mg}^{+2}$ (or $\mathrm{Ni}^{+2}$ ) in solid solution in $\mathrm{Al}_{2} \mathrm{O}_{3}$ can enhance final stage sintering through a vacancy modification mechánism.

\footnotetext{
* Palladino and. Coble report that the $\mathrm{AI}^{+3}$ controlling in polycrystalline $\mathrm{Al}_{2} \mathrm{O}_{3}$ and diffusivity is rate

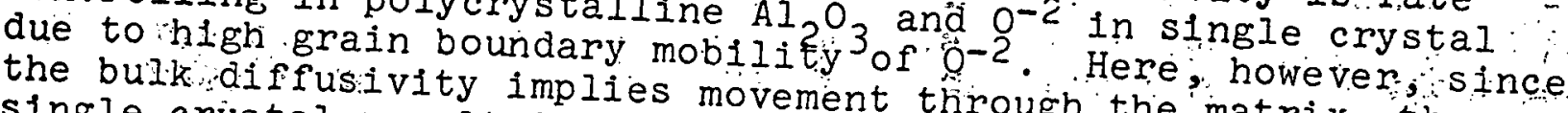
single crystal result is appropriate and o- $0^{2}$ the matrix, the during final stages of sinteringate and $\mathrm{O}^{-2}$ is rate controling: observed mode of material transport. 52 . bulk diffusion is the
} 


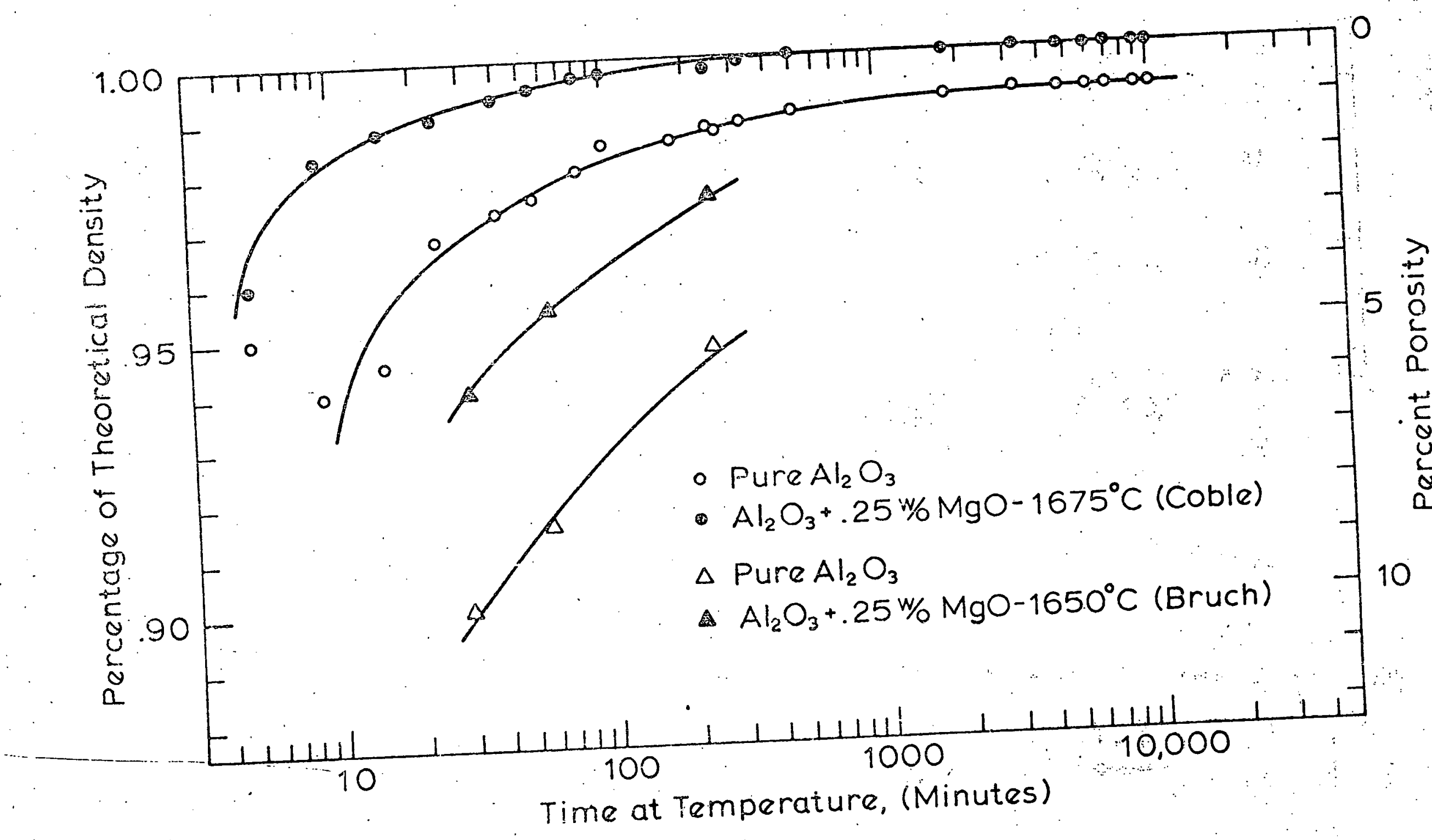

Figure $30^{\circ}$ Density of $\mathrm{Al}_{2} \mathrm{O}_{3}$ Versus TIme at Temperature 
K. Effect of $\mathrm{ME}^{+2}$ or $\mathrm{N1}^{\text {t2 }}$ on Discontinuous Grain Growth

The reason for the lack of discontinuious grain growth in $\mathrm{Al}_{2} \mathrm{O}_{3}$ sintered with $\mathrm{MgO}$ is related to the enhanced sintering effect of the additive and the nature of discontinuous grain growth. By its nature, discontinuous grain growth (secondary recrystallization) can only occur in a material in which continuous grain growth is inhibited.53-56 In $\mathrm{Al}_{2} \mathrm{O}_{3}$, this restraint is supplied by the pore phase. If for example, an alumina exhibits the sort of grain structure presented in Figure 3ia, normal grain growth is stopped by the pores. If due to random fluctuations, however, a region is deficient in pores, a few grains can grow at the expense of the surrounding grains until they become several times the size of the "normal." grains. These abnormal-grains (Figure 3Ib) can now grow in a more rapid manner, since the restraint to noimal grain growth (1.e. pore phase) is no longer a restraint to growth for grains with so many sides and such favorable curvature (i.e. energetics of growth favor multislded grains with relatively flat or concave boundaries). Once a critical size is reached, the Zener drag produced by the pores can no longer inhibit the growth of this grain and it rapidly consumes the "normal" grains surrounding it, all of which are. still restrained by the pore phase.53,54

This critical size can be calle a "nucleus" and in some: aspects the problem is analogous to nucleation of a second phàse, although mathematicaliy more difficult to model. Unlike preclpltation, it is a completely hetergeneous phenomenon (i.e. dependent on 1nhomogeneaties for occurrence) and the random fluctuations that produce it can only carry the embryo to critical size; they cannot redissolve it. 56 


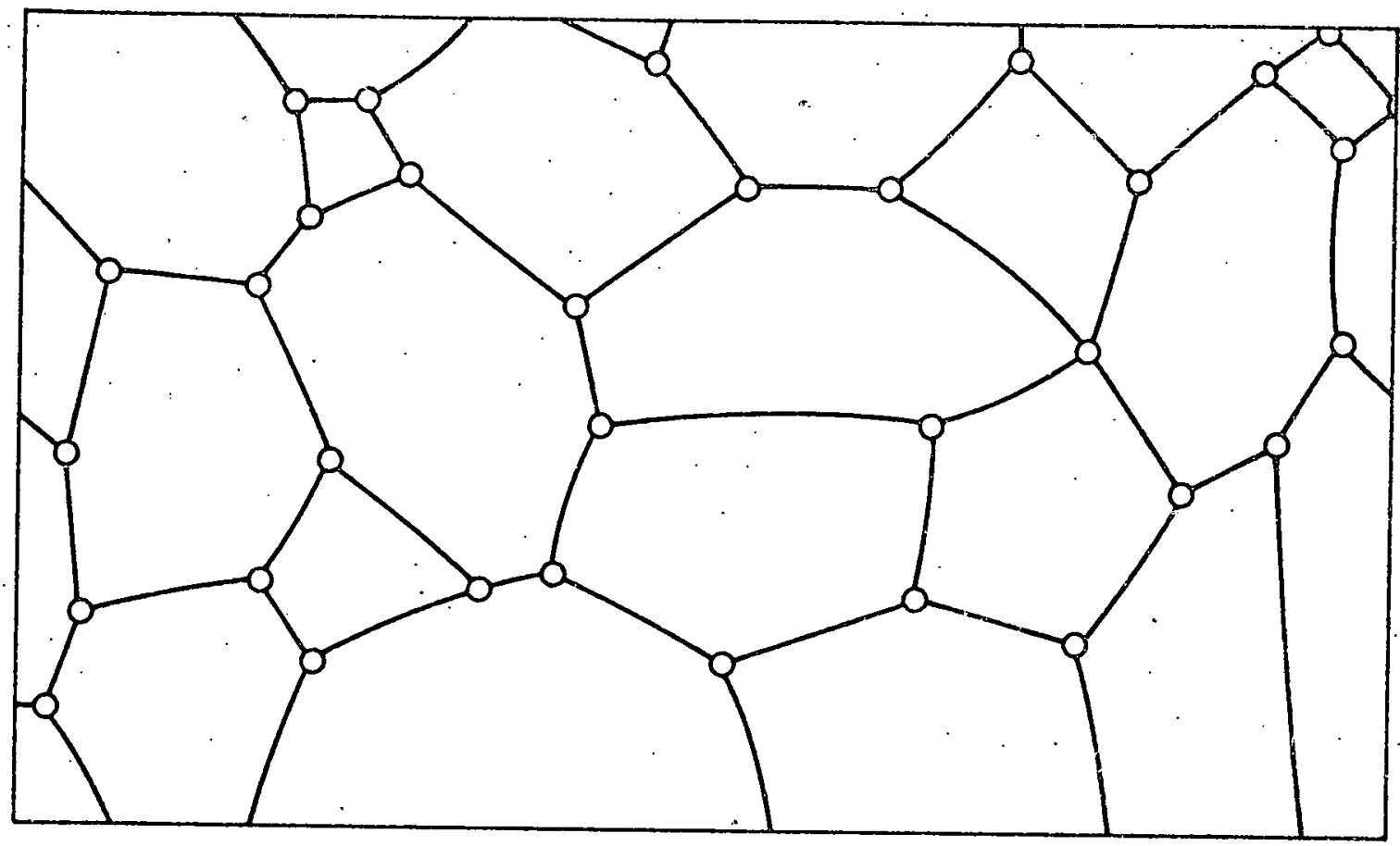

a. Normal Growth Inhibited by Pores

b. Discontinuous Growin Nucleating

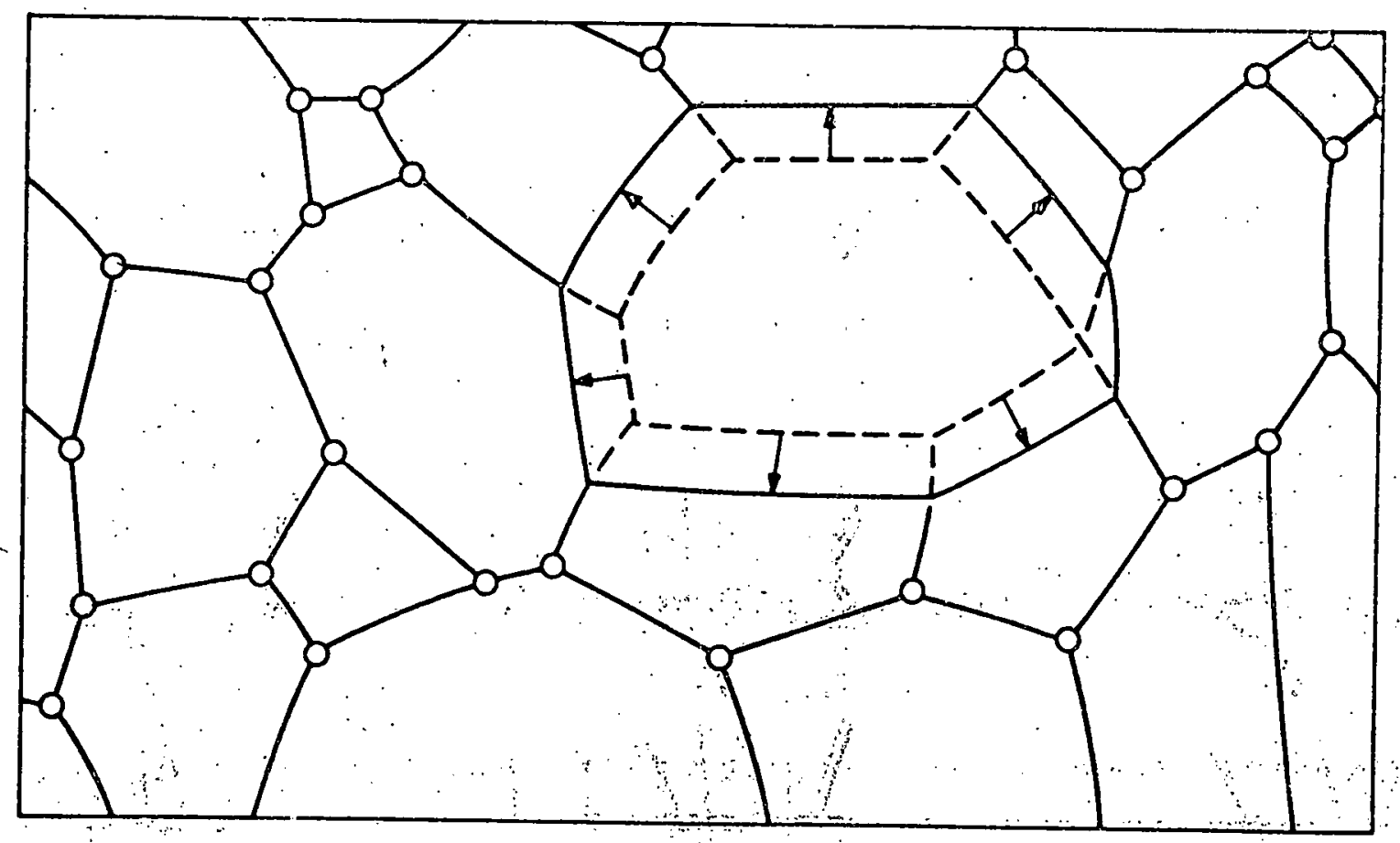

F1gure 31 Discontinuous Grain Growth 
In general, ff the innibition to continuous grain growth (i.e. pore phase) is removed slowly enough as to allow the growth of a few grains at a rate comparable to this rate of removal, it has been found in metallic systems that these few large grains can gain an enormous advantage energetically over normal grains still inhibited by the pore phase. If on the other hand, the rate of inhibition removal is high compared to the rate of grain growth, the result will be uniform sized small grains with a growth rate similar to that of grains with no inhibition. All of the above is dependent on temperature, type, size, and distribution of inhibition. 54 Ultimately, the decision whether discontinuous grain growth will occur or not and the time necessary for its appearance depends on the above mentioned factors.

The "iricubation" time for discontinuous grain growth, describes the period of time during which fluctuations of temperature and/or obstruction combine to create a critical grain which is no longer slowed by the Zener drag inhibiting normal grain growth. Measurements of this incubation time are easy to make, but extremely difficult to interpret. It was found that in high purity silver inhibited by second phase inclusions, the growth of secondary grains proceeded at a slower rate than normal grain growth in uninhibited material until the grain was 13 times the size of a normal grain. At that point the rate of growth was" independent of size. 54 Other studies established that there is a. strong dependence on normal grain size in the incubation time for discontinuous grain growth 55

Therefore, since the evidence indicates that:

1). $\mathrm{Al}_{2} \mathrm{O}_{3}$ densifies faster. with $\mathrm{MgO}$ than w1thout (1.e. the "inhibition" - pore phase - is removed more quickly) due 
to enhanced rate of material transport.

2) A finfte time is necessary for nucleation of a discontinuous grain (Incubation time).

3) Discontinuous grain growth does not occur in $\mathrm{Mg}$ doped $\mathrm{Al}_{2} \mathrm{O}_{3}$

4) Grain boundary segregants if present do not alter normal grain growth appreclably and are present in doped, theoretically dense materials, as well as samples in which porosity remains trapped in discontinuous grains.

and 5) Second phase particles do not have to be present to obtain theoretical density.

It is concluded thatdiscontinuous grain growth is not inhibited in doped alumina, but rather the material achieves theoretical density (i,e. all inhibition - pore phase - is removed) before discontinuous grains can nucleate. Because of the extrinsic behavior of the rate controling diffusivity due to the MgO introduced vacancies, doped $\mathrm{Al}_{2} \mathrm{O}_{3}$ sinters faster than pure $\mathrm{Al}_{2} \mathrm{O}_{3}$. Further, figure 30 indicates that discontinuous grain growth occurs in pure material over an order of magnitude in time after the: doped material is fully dense (and all tendency for abnormal growth. Is removed). Since the nucleation time for discontinuous grain growth would not be expected to change much in doped material, lit can be concluded that the doped alumina is already theoretically dense long before discontinuous gralns can achleve critical size.

L. Conclusions of Doped $\mathrm{Al}_{2} \mathrm{O}_{3}$ Stuãy

1. $\mathrm{Ca}^{+2}$ and $\mathrm{Y}^{+3}$ segregate heavily to grain boundaries in $\mathrm{Al}_{2} \mathrm{O}_{3}$. when present. 
2. $\mathrm{Mg}^{+2}$ and $\mathrm{Ni}^{+2}$ if present at all at grain boundaries are relatively weak segregants.

3. All of the observed segregation can be understood and explained in a quantitative manner from equilibrium segregation theory.

4. Segregants are neither necessary, nor sufficient to obtain theoretical density in high purity $\mathrm{Al}_{2} \mathrm{O}_{3}$.

5. Sintering is enhanced in final stages by the presence of vacancy creating divalent ions in soiution in $\mathrm{Al}_{2} \mathrm{O}_{3}$ $\left(\mathrm{Mg}^{+2}, \mathrm{Ni}^{+2}\right)$.

6. Discontinuous grain growth is avoided, not inhibited by $\mathrm{MgO}$ and $\mathrm{NiO}$ through an increase in the rate of removal of the Inhibition (pore phase) responsible for the abnormal growth.

7. The effect of $\mathrm{Y}^{+3}$ on density is questionable, but both $\mathrm{Y}_{2} \mathrm{O}_{3}$ doped materials examined had sufficient Mgo to achieve theoretical density in spite of other additives. 


\section{Role of Additives in Hot Pressing Mgo \\ In order to establish the role of additives and impurities}

an the densification of hot pressed MgO, a study was begun on the relationship between grain boundary chemistry and density of MgO. As mentioned earlier, use of a few weight percent LiF or NaF additive markedly improve hot press ahlitty of Mgo. Typically hot-pressed at $1300^{\circ} \mathrm{C}$ when pure, $\mathrm{MgO}$ can be hot pressed with additives at $1000^{\circ} \mathrm{C}(\mathrm{LiF})$ or $1100^{\circ} \mathrm{C}(\mathrm{NaF}) .12,13,15,57$ Further, although room temperature fracture strength is not good, it can be markedly improved by annealing at a temperature higher than the hot pressing temperature.

\section{A. Hot Pressed MgO With No Additives}

Two samples of $\mathrm{MgO}$ hot pressed without additives were examined. The first represented the as-hot pressed state and the second represented a similar material that had been given a subsequent $1150^{\circ} \mathrm{C}$ anneal. Both samples gave totally intergranular fracture (FIgs. $32 \mathrm{a}$ and $32 \mathrm{~b}$ ) and the grain boundary chemistries were similar, although with different anounts or segregants i. - (F1g. 33). $\therefore$ The as-hot pressed materials exhibited about $9 \% / 0 \mathrm{Ca}$ and $2^{a} / 0 \mathrm{~T} 1$ at the boundaries while the annealed sample showed $5^{\mathrm{a}} / \mathrm{O} \mathrm{Ca}$ and $2^{\mathrm{a}} / 0 \mathrm{TI}$. In both cases the species were segregated to within 3 atomic layers of the grain boundaries.

In general it is expected that if one material is annealed at a lower temperature than another; the driving forces for equilibrium segregation would increase, causing a build up of the segregant at the boundary. However; both the kinetic limitations" of diffusion at low temperature, as well as the bulk concentration: dependence of the relationship for the expected segregation, Indicate that there can be exceptions. In this particular case, 
Hot-Pressed MgO No Additives

a

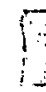

1

8

ing

2
5
5

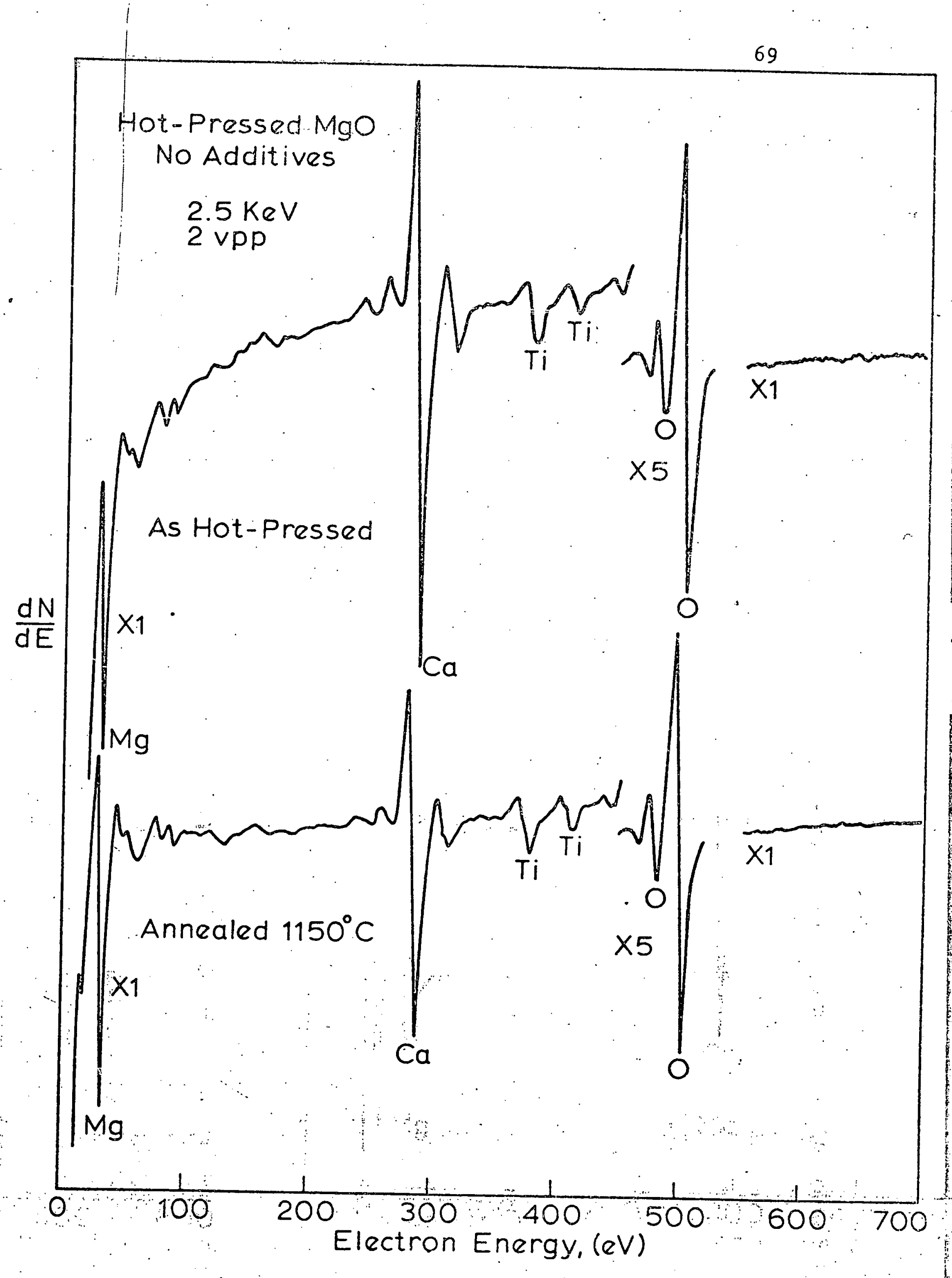


the two samples were from different lots of material, hence had different levels of bulk Ca impurities and the amount necessary to attain equilibrium in the $1150^{\circ} \mathrm{C}$ sample was less than the amount that was needed to attain it in the $1300^{\circ} \mathrm{C}$ (as hot pressed) sample. Hence the observed segregation is still consistent with the equilibrium segregation model presented earlier.

\section{B. MgO Hot Pressed With LiF}

Two lots of MgO hot pressed with 2 W/O LiF were examined to determine the location of the residual additives. Bulk chemical analysis indicated that around $.9 \mathrm{~W} / 0$ fluorine remained in the bodies after hot pressing, but only trace amounts of Li.57 SEN fractographs of the first lot of MgO are presented in Figure 34. Figure $34 \mathrm{a}$ is the as-hot pressed fracture surface, $34 \mathrm{~b}$ is of the same material given a subsequent $1315^{\circ} \mathrm{C}$ anneal and $34 \mathrm{c}$ is after a $1540^{\circ} \mathrm{C}$ anneal. The corresponding AES spectra from these fracture surfaces are presented in Figure 35.' In the as-hot pressed state the MgO grain boundaries contain a significant amount of fluorine. The $F$ peak was unstable with time under electron bombardment and decayed rapidly. However, an estimate for the original concentration of between $30-40 \% \mathrm{~F}$ in the first few layers is within reason. No Ifthium was detected, which is consistent with the above mentioned - lack of LI In bulk chemical analysis: A calculation of the amount of $F$ accounted for by the observed grain boundary concentration is contained in Appendix F. The results indicate that all of the residual $F$ In the $M g O$ is accounted for at the grain boundarles: This coupled with the fact that these materials are cooled relatively guickly from hot" pressing temperatures (In contrast to the slow cooling of the sintered $\mathrm{Al}_{2} \mathrm{O}_{3}$ discussed earlier) indicates 

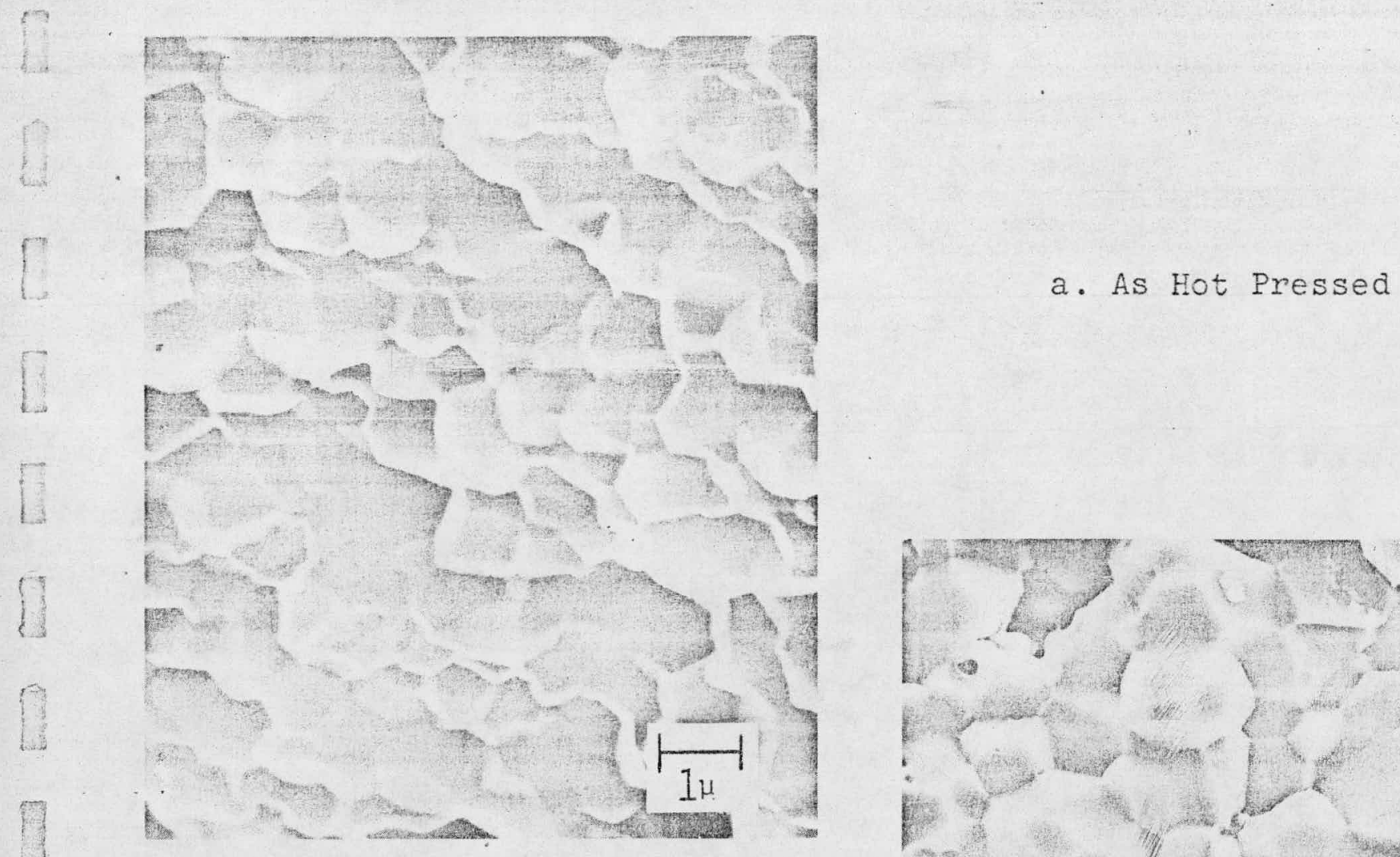

Lis

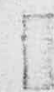

1

P

(

(2)

b. Annealed At $1315^{\circ} \mathrm{C}$

2

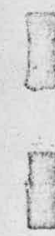

1

1

I
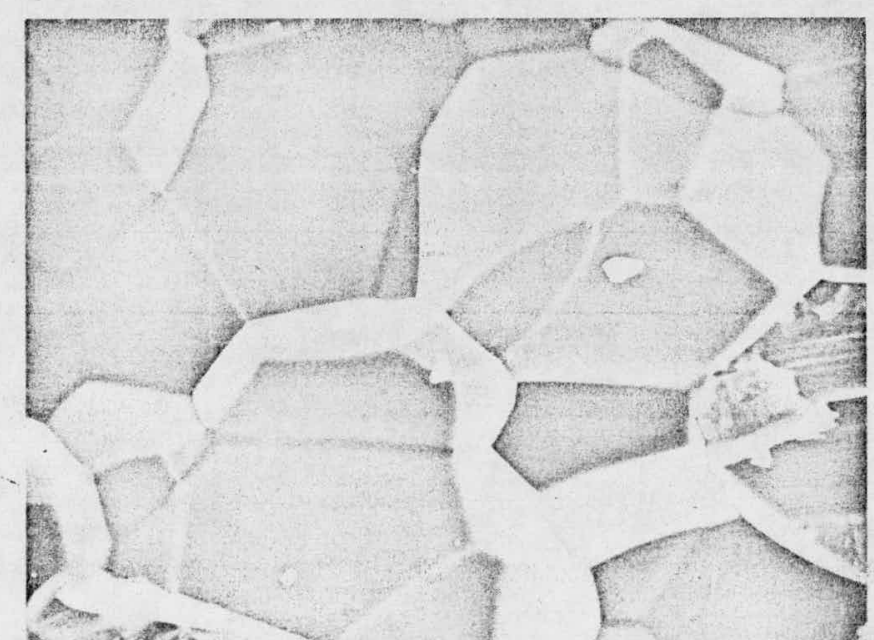

s 30
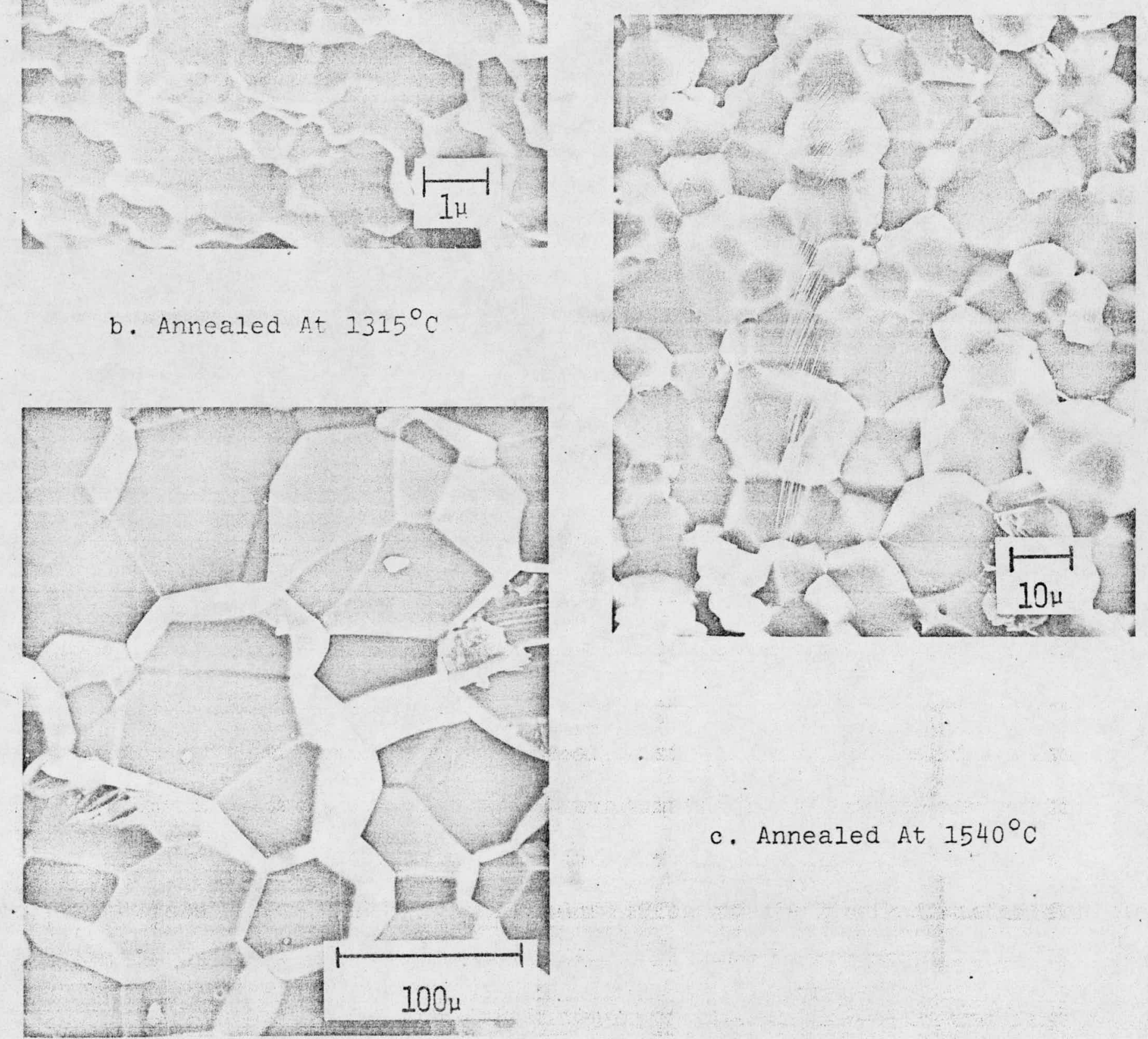

Figure 34 SEM Fractographs of Lot I MgO Hot Pressed 


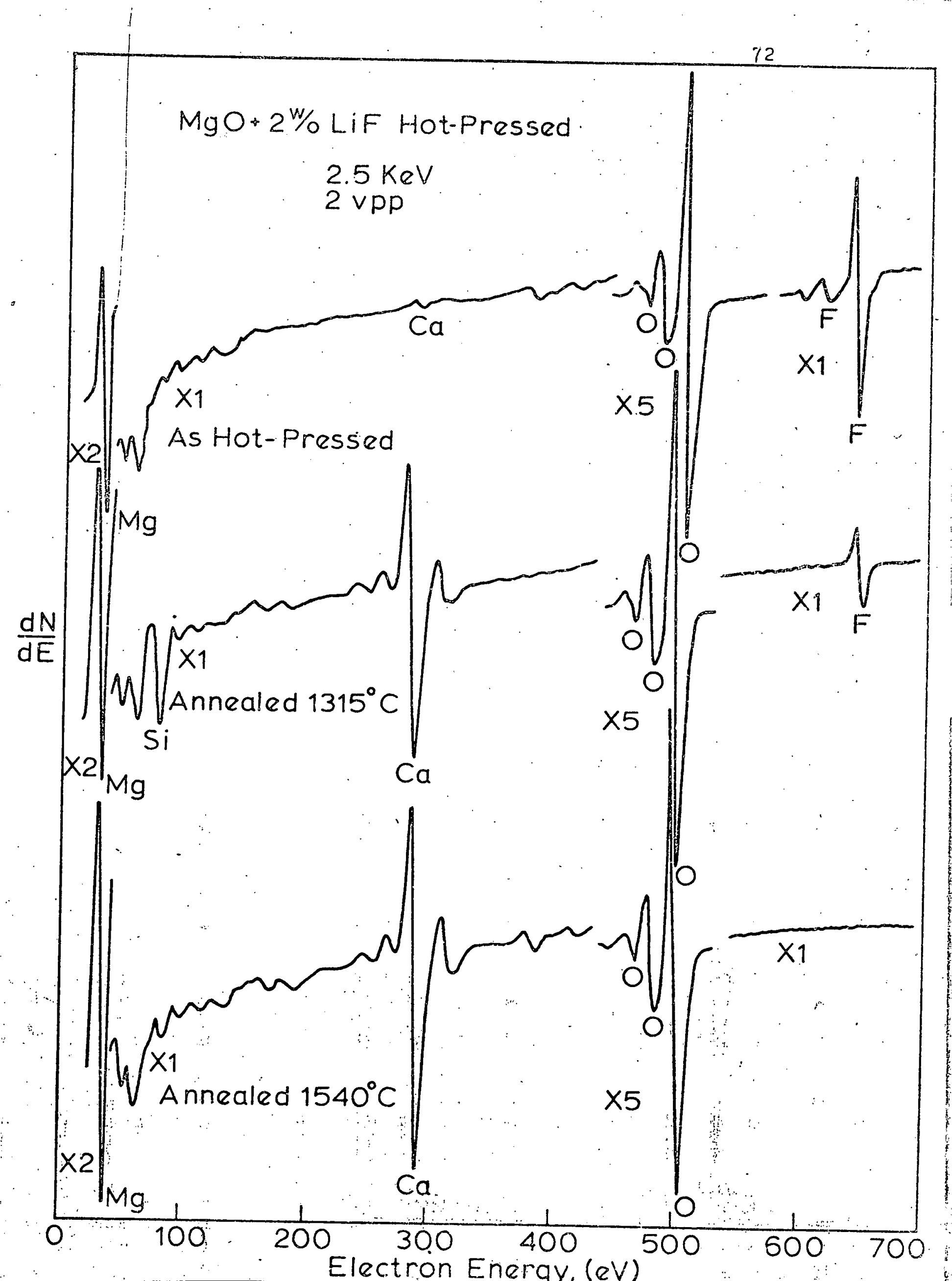


pressing, although the $L i$ apparently is lost due to volatilization during the process. The apparent contradiction in residual Li leveis noted when these results are compared to those of carnall is aftributed to the fact that his specimens were at least 10 times as thick as the ones used in this study. ${ }^{14}$ The limiting step in the volatilization process would be expected to be the transport of the Li from the interior of the sample to the surface. Samples with dimensions large compared to diffusion distances would be expected to retain more $L i$ than those with dimensions comparable to these diffusion distances.

After annealing at $1315^{\circ} \mathrm{C}$, the fluorine level at the boundary has dropped by a factor of 4 and $\mathrm{Ca}$ and $\mathrm{Si}$ peaks have appeared. After a $1540^{\circ} \mathrm{C}$ anneal, no fluorine is detected and the Ca peak has become larger, while the $\mathrm{Si}$ is gone. The Ca concentration increased from about $4^{\mathrm{a}} / 0$ to $5^{\mathrm{a}} / 0$ and the $\mathrm{Si}$ concentration at $1340^{\circ} \mathrm{C}$ was about $2^{\mathrm{a}} / 0$. Another series of MgO samples doped with LIF produced similar results. Figure 36 presents SEM fractographs and Figure 37 gives the Auger spectra. Again substantial $F$ was detected at the grain boundary, a small amount $(2 \mathrm{a} / \mathrm{o})$ of $\mathrm{Ca}$, and a trace of $\mathrm{Ti}$. After annealing at $1150^{\circ} \mathrm{C}$ the fluorine is down and the Ca has increased to about $4^{\mathrm{a}} / 0$.

All of the above can be explained on an equilibrlum segregation -basis. The is residual additive from the hot pressing process and since it is located in the region of disorder (grain bourdaries) there is no driving force for the segregation of the $\mathrm{Ca}$ to this lnterface during hot pressing. Puring annealing however; two competitive processes are occurring. First the fluorine is being bolled out of the sample at the higher temperatures. The boundary sites again become avaliable for relocation of poorly 


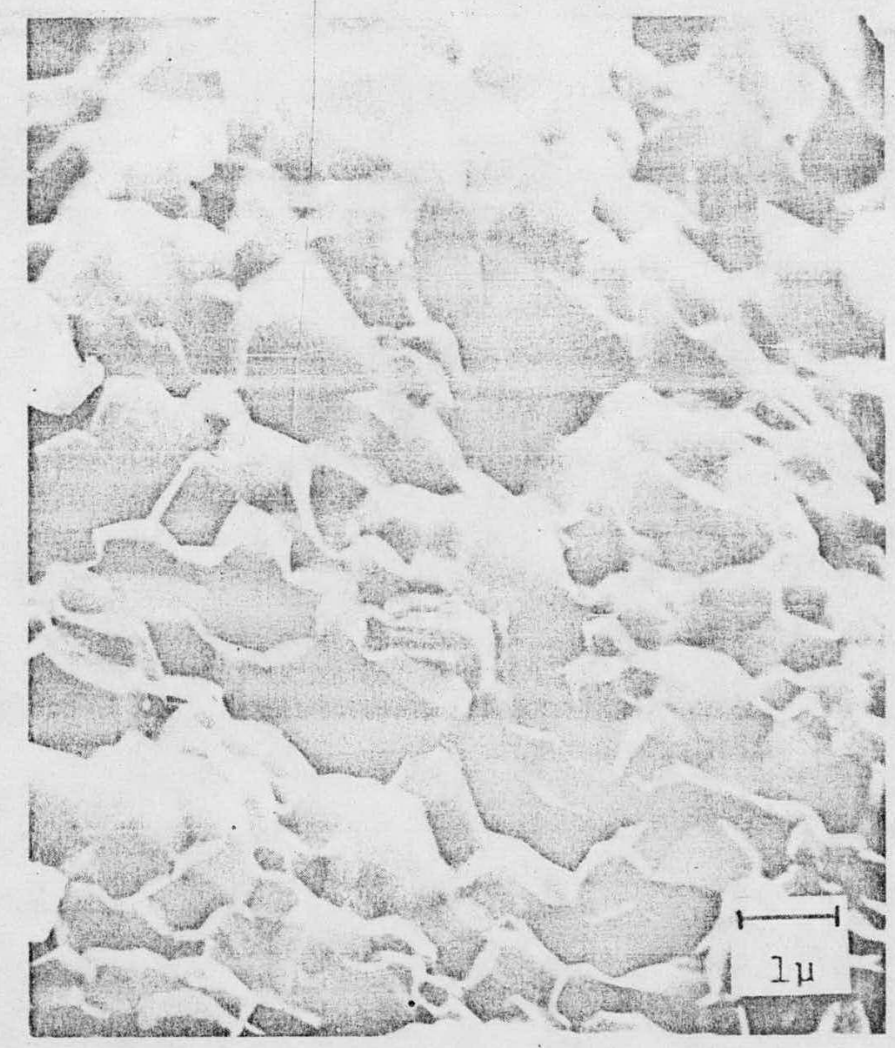

\section{a. As Hot Pressed}

b. Annealed At $1150^{\circ} \mathrm{C}$

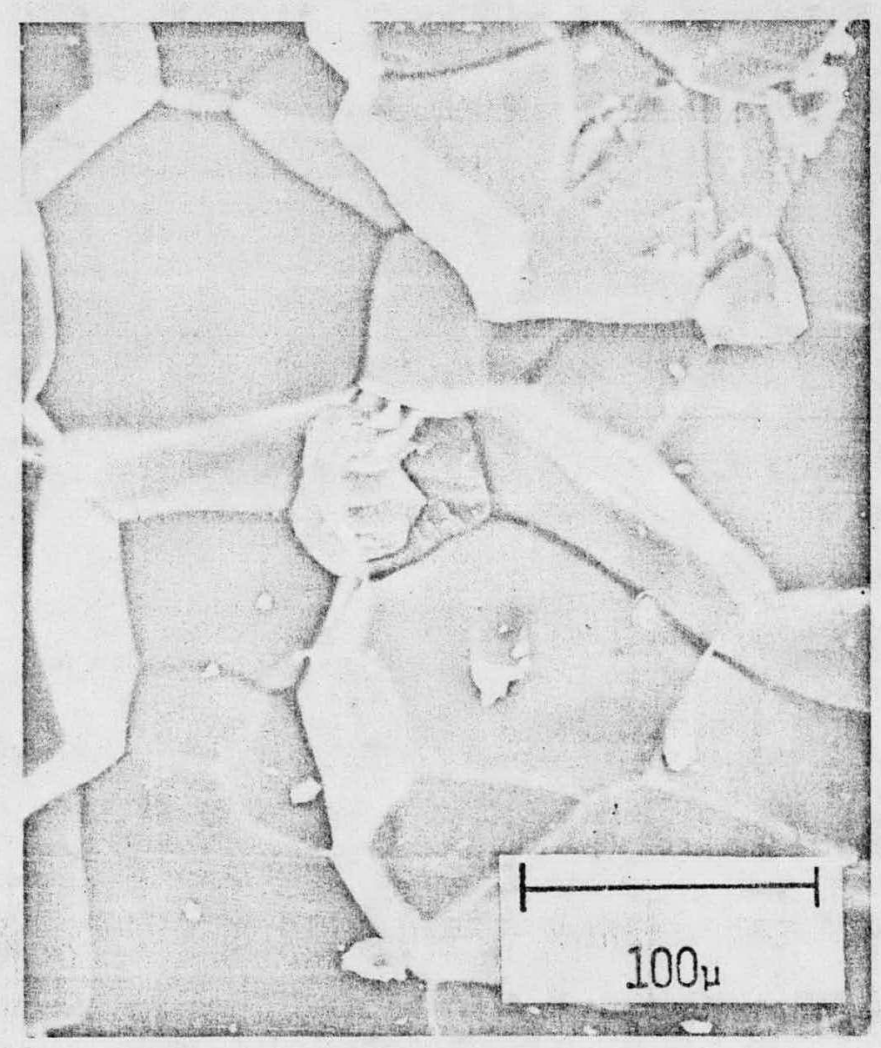

Figure 36 SEM Fractographs of Lot II MgO Hot Pressed With $2 \%$ LiF 


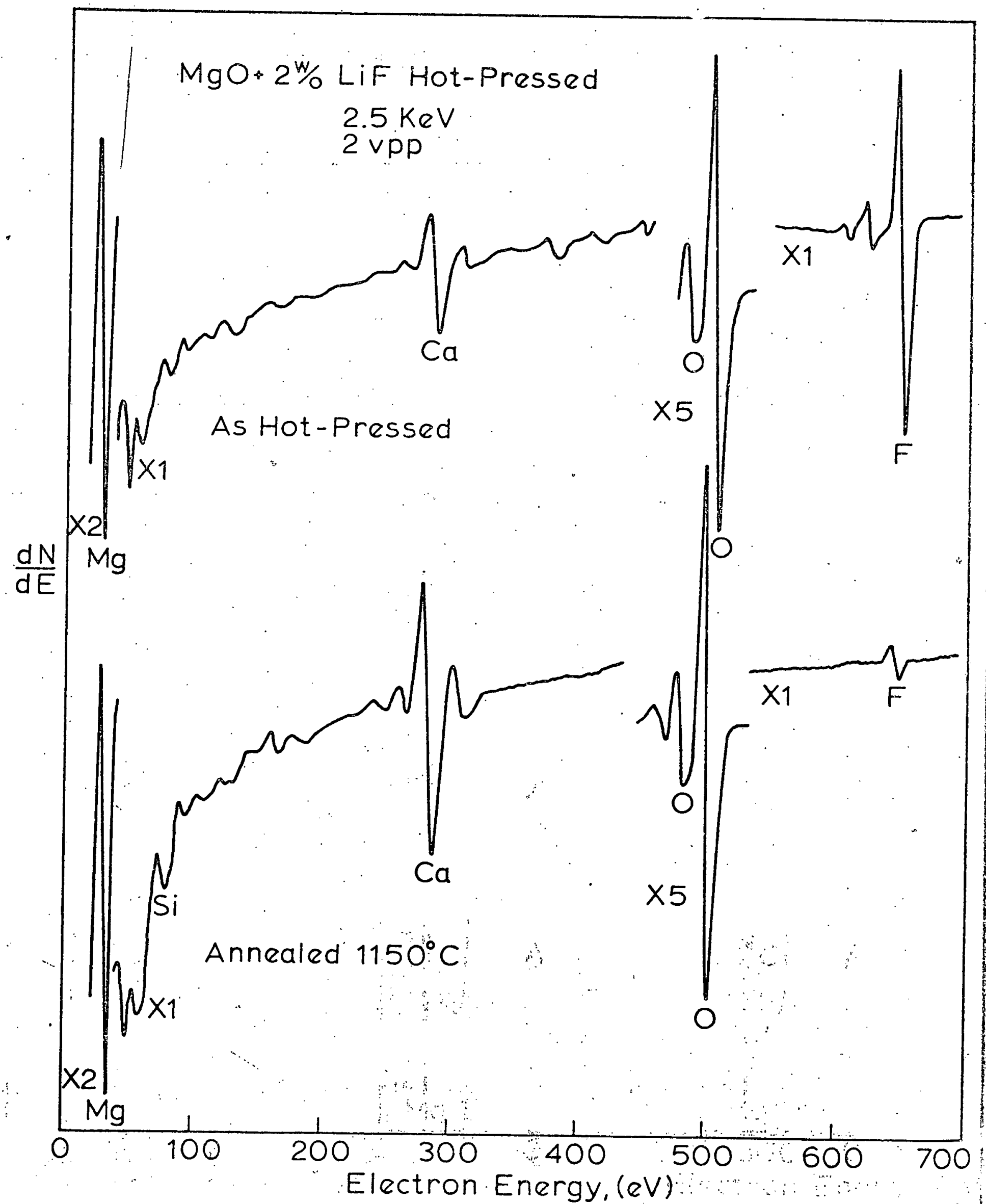


fitting solutes (such as $\mathrm{Ca}, \mathrm{Si}$, or $\mathrm{Ti}$ ). The number of sites avaliable for cations will be determined by the free energy of the interfacial region, which in turn is determined by the composition of the region. The $\mathrm{Si}$ appears at $1315^{\circ} \mathrm{C}$ and then disappears at $1540^{\circ} \mathrm{C}$, because it is ariven to the boundary at the lower temperature, but then is redissolved in the matrix.at the higher temperature. It should indeed be possible (although the limited amount of material available in this study did not allow it) to anneal the $\mathrm{MgO}$ at even higher temperatures and quench the $\mathrm{Ca}$ back into the bulk; hence the concentration of $\mathrm{Ca}$ at the boundaries should decrease as was observed for the $\mathrm{Ca}$ in $\mathrm{Al}_{2} \mathrm{O}_{3}$ quenching experiments presented earlier.

That the observed grain boundary chemistry is indeed sharacteristic of an equilibrium condition is substantiated by analyzing a sample of $\mathrm{MgO}$ hot pressed with $.3^{\mathrm{W}} / 0 \mathrm{LIF}$, which had been annealed at $1000^{\circ} \mathrm{C}$ for 60 hours* instead of the $1 / 2-1$ hour anneals given these samples. The results are presented in Figure 38 and Indicate that the residual fluorine is apparentiy an : equilibrium condition, as is the segregation of $\mathrm{Ca}$, not fust a point on the way to total elimination of $\mathrm{F}$ and/or $\mathrm{Ca}$ from the sample. The 60 hour anneal allows sufficient time for elimination of all the fluorine if $1 t$ were kinetically controlled: An Indication of the rate of movement of the fluorine 1s:the rapid. loss of the species in $1 / 2$ hour at $1315^{\circ} \mathrm{C}$ as in the previous $1 \mathrm{y}$ mentioned sample. Hence the grain boundary chemistries represent the end point of an equilibrium process.

C. Hot Pressed MgO With NaF

A series of $\mathrm{MgO}$ samples hot pressed at $1100^{\circ} \mathrm{C}$ with $2^{\mathrm{W}} / 0$ 


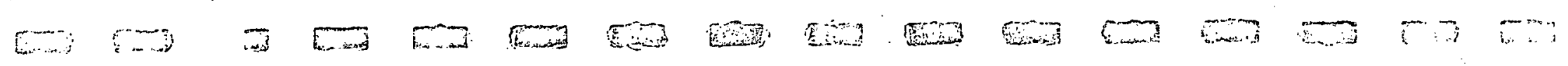

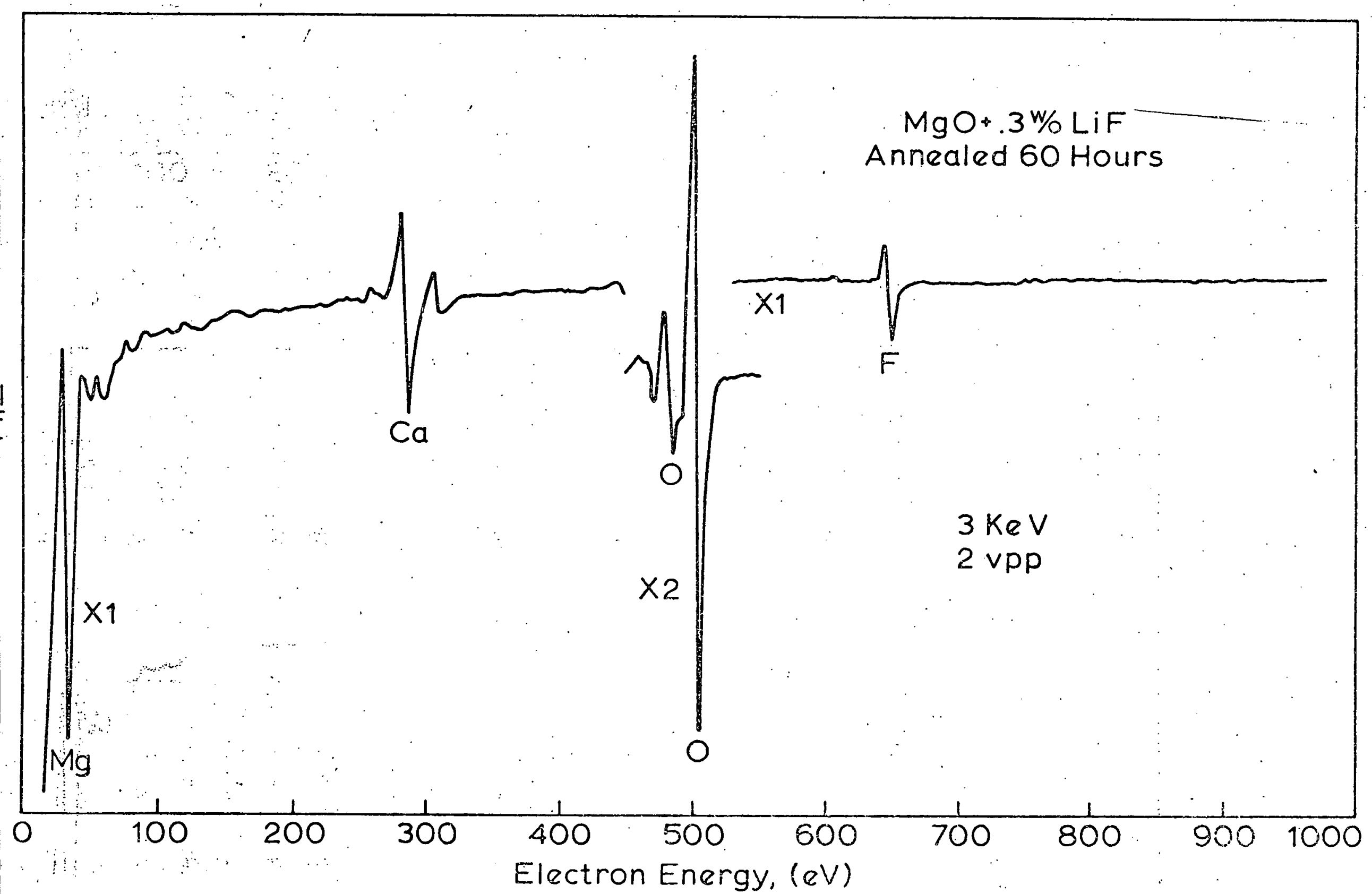


NaF were examined to determine the effect of doping with this. additive. The as-hot pressed material was close to theoretical density, but was not translucent. Bulk analyses indicated cation additive remained as well as residual fluorine $\left(.22^{\mathrm{W}} / 0\right.$ $\mathrm{Na}$ and $\left..9^{\mathrm{W}} / \mathrm{O} \mathrm{F}\right)$. Annealing at $1370^{\circ} \mathrm{C}$ improved the optical properties, but the material was still not as transparent as the IL doped materials. SEM fractographs (Figure 39) indicate total Intergranular fracture in both specimens and the presence of residual porosity. AES analysis (FIgure 40) indicated residual $\mathrm{F}$ and $\mathrm{Na}$ in the as-hot pressed material, and loss of the additives and segregation of about $4^{a} / 0 \mathrm{Ca}$ and $3^{a} / 0 \mathrm{Si}$ after annealing. The levels of $\mathrm{Ca}$ and. SI are both consistent with the results obtained earlier at $1315^{\circ} \mathrm{C}$ for the LiF doped material. The . retention of tre $\mathrm{Na}$ is consistent with the bulk chemical analysis and presumably occurs due to the greater stability of $\mathrm{Na}$ then Li in MgO at these temperatures. In all of the materials examined, the grain boundary chemistry variation did not extend over 5 atomic layers from the boundary.

D. Hot Pressing of $\mathrm{Al}_{2} \mathrm{O}_{3}$ and $\mathrm{MgAl}_{2} \mathrm{O}_{4}$ With LIF.

A sample of $\mathrm{Al}_{2} \mathrm{O}_{3}$ hot pressed at $1100^{\circ} \mathrm{C}$ with $2^{\mathrm{W}} / 0 \mathrm{LIF}$ and a sample of $\mathrm{MgAl}_{2} \mathrm{O}_{4}$ (Spinel)* hot pressed at $1600^{\circ} \mathrm{C}$ with:

$1.5 \mathrm{~W} / \mathrm{L}$ LF were also examined to determine location of residual additives.

The $\mathrm{Al}_{2} \mathrm{O}_{3}$. AES results (FIgure 4l) Indicated residual $\mathrm{F}$, but no cation Impurities . The $\mathrm{MgAl}_{2} \mathrm{O}_{4}$ results (FIgure 42 ) indicated. much less residual $F$, but no.cations'. These results agree with the Mgo results and also with bulk analyses indicating less \#. Sample Obtained From. D. Sellers, Coors Porcelain Co., Golden, Colo. 


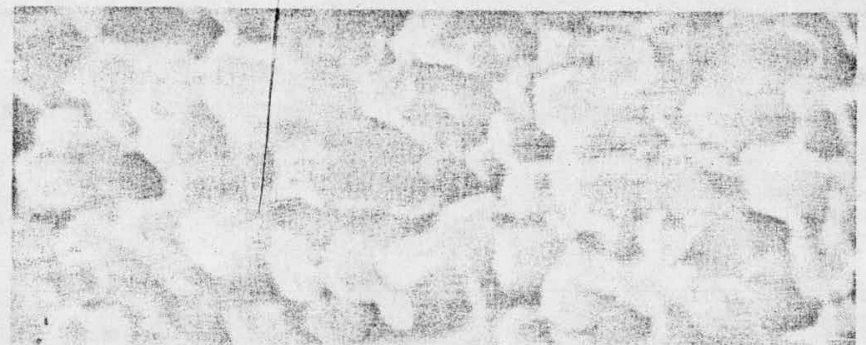

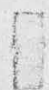

1

I

E

II
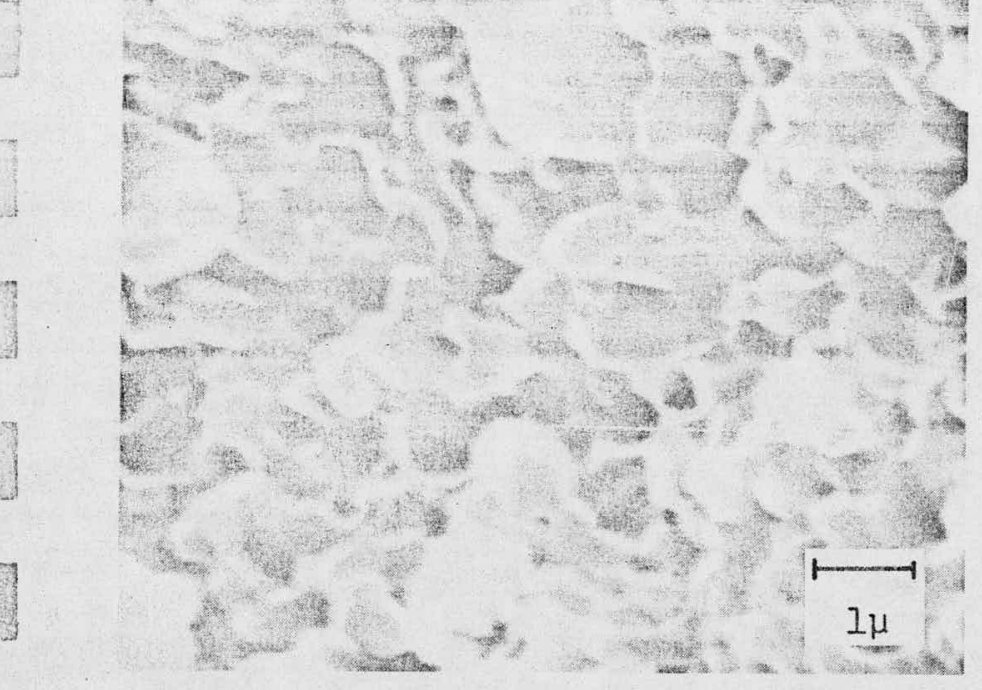

है

1.

I.

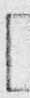

1

1

b. Annealed At $1370^{\circ} \mathrm{C}$ a. As Hot Pressed

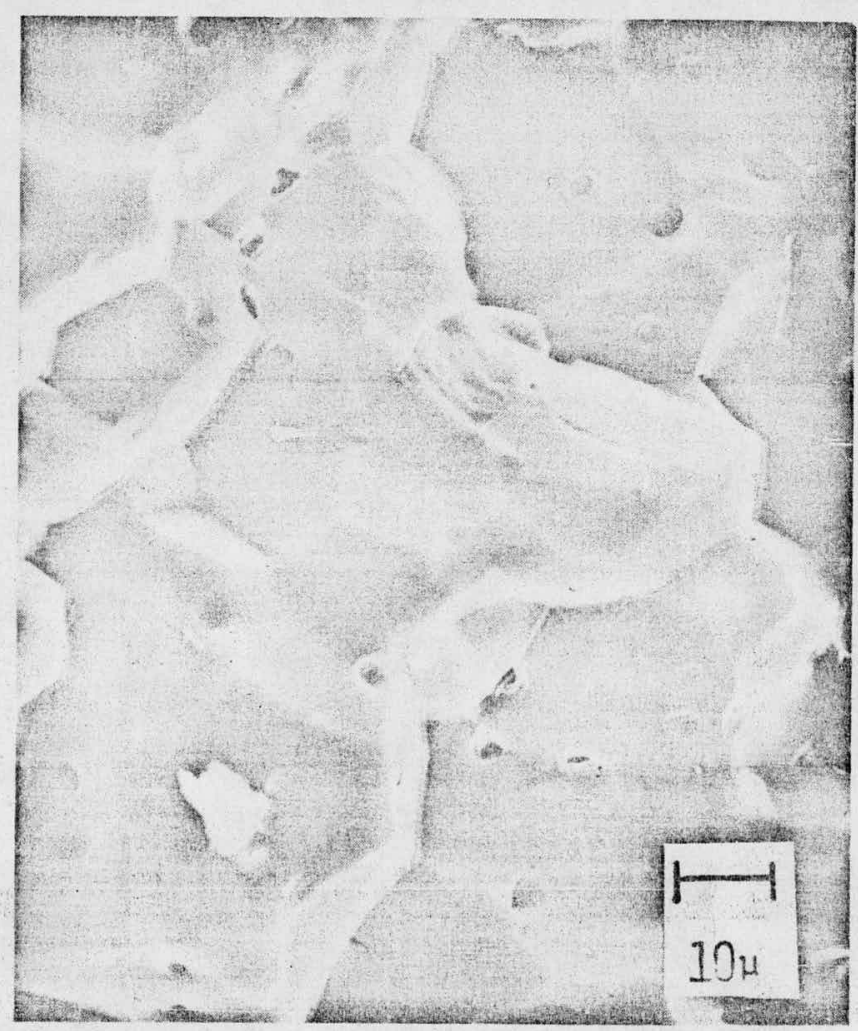




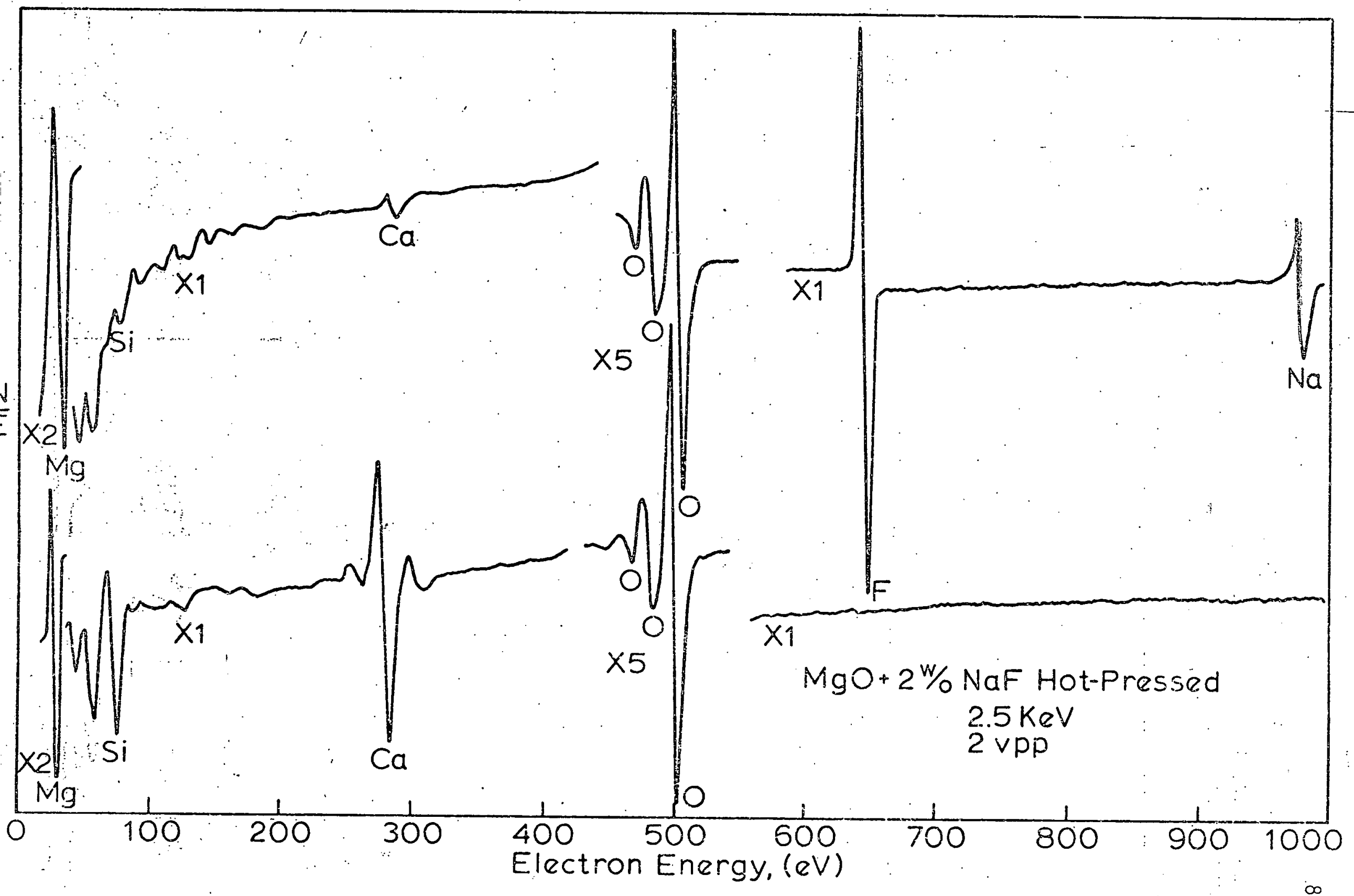

Figure 40 AES Spectra of Mg Hot Pressed with 2w/o NaP 

retained $F$. This in turn, is consistent with the higher temper-. atures and lower quantities of additives used for the spinel.

E: Analysis of Results in Terms of Densification

The observed residual additives offer unequivocal

evidence that the additives affect the grain boundaries of the hot pressed material. These results further support the theory of Iiquid phase hot pressing assistance in fábrication of MgO with additives.16;17 Residual. grain boundary additives and their loss on annealing are consistent with lower fracture strength in $\mathrm{MgO}^{15}$ as well as lower strength and greater tendency for intergranular failure in $\mathrm{MgO}$ and $\mathrm{MgAl}_{2} \mathrm{O}_{4} \cdot 58$

Hence liquid phase assistance (formation of a liquid phase between particles and enhanced diffusivity through this liquid phase) is proposed as the model for densification enhancement and is supported by the findings of this study.

F. Conclusions of Hot Pressed MgO Study.

1. Ca, TI, and $\mathrm{Si}$ impurities segregate to the grain boundaries In MgO during hot pressing and/or annealing.

2. The presence of $F$ and $\mathrm{Na}$ at the grain boundaries in MgO hot pressed with additives is unequivocally demonstrated, hence supporting proposed densification (e.g. liquid phase) mechanlsms and alteration of mechanical behavior. Greater retention of $\mathrm{F}$ and loss of $\mathrm{Li}$ or $\mathrm{Na}$ and $\mathrm{F}$ are corroborated.

3. Smaller quantities of $F$ also were shown to be present at the grain boundaries of spinel and $\mathrm{Al}_{2} \mathrm{O}_{3}$ hot pressed with $\mathrm{LiF}$. The lower quantities of $F$ are consistent with the volatility of the additive and higher temperatures used in fabrication of these materials: 
4. All additives and impurities were found to generally occupy only a few atomic layers along the boundaries. 
V. Appendices
A. A Calculation of Sputter Removal Rates
B. Use of $\mathrm{CCl}_{4}$ Displacement to Measure Porosity
C. Calculation of Image Stress From a Segregant
D. Calculation of Grain Boundary Concentration of a Segregant
E. Calculation of Interaction Energies and Upper Limits for Segregants in $\mathrm{Al}_{2} \mathrm{O}_{3}$
F. Calculation of Residual Fluorine Levels in MgO
G. Further Study of Equilibrium Segregation 
Appendix A: A Calculation of Sputter Removal Rates

The important parameters determining the removal rate from

a surface undergoing inert-ion sputtering are:

1. $I_{\beta}=$ The ion beam current (number of coulombs of charge striking the surface per second).

2. $E_{S}=$ Sputtering energy (difference in potential between the anode and the target imparts this potential energy to an electron or singly charged ion).

3. $Y_{S}=$ Sputter yield (experimentally determined ratio of substrate atoms removed per incident ion - depends on energy, type of ions, and type of substrate).

4. $\rho_{\ddot{A}}=$ Surface atom density (Number of substrate atoms per unit. area of surface in first atomic layer - the number $10^{15}$ atoms $/ \mathrm{cm}^{2}$. will be used).

5. $A=$ Area of beam incident on surface.

The rate of removal in monolayers per second is:

$\dot{R}=I_{\beta}\left(\frac{\text { coulomb }}{\mathrm{sec}}\right) \times \frac{1 \text { electronic charge }}{1.6 \times 10^{-19} \text { coulomb }} \times \frac{1 \times \mathrm{e}^{+} \text {ion }}{1 \text { electron charge }} \times$ $\mathrm{Y} \frac{\text { (number of atoms removed) }}{1 \mathrm{Xe}^{+} \text {ion }} \times \frac{1}{\mathrm{\rho}_{\mathrm{A}}} \times \frac{\mathrm{l}}{\mathrm{A}}=\frac{\mathrm{Y} I(\mu \mathrm{A})}{\mathrm{A}\left(\mathrm{cm}^{2}\right)} \times$ $10^{-6} \times \frac{10^{19}}{1.6} \times 10^{-15}=\frac{6.25 \times 10^{-3}}{\mathrm{~A}\left(\mathrm{~cm}^{2}\right)} \times Y \times I(\mu \mathrm{A})$

If for example, the typical sputter conditions of $E_{S}=500 \mathrm{eV}$ and $I=I \mu \mathrm{A}$ were used on a specimen of square cross section $(.100 " x .100 ")$,

$R=\frac{6.25 \times 10^{-3}}{(.254 \mathrm{~cm} \times .254 \mathrm{~cm})} \times Y=10^{-2} \times 10^{-2} \times Y$

From private communication, ${ }^{34}$ it was learned that $\mathrm{Y}_{\mathrm{Al}_{2} \mathrm{O}_{3}}(500 \mathrm{eV})$ $\simeq Y_{\mathrm{MgO}}(500 \mathrm{eV}) \simeq .2$

Therefore, $\mathrm{R}_{\mathrm{AI}_{2} \mathrm{O}_{3}}=\mathrm{R}_{\mathrm{MgO}}=0.02$ atom layers $/ \mathrm{sec}$ 
Appendix B: Use of $\mathrm{CCl}_{4}$. Displacement to Measure Porosity

Use was made of a single crystal (sapphire) as a standard

for theoretically dense $\mathrm{Al}_{2} \mathrm{O}_{3}$ : AlI samples were suspended by a

thin wire and their welght measured in air and $\mathrm{CCl}_{4}$. The wire

alone was then weighed in air and in $\mathrm{CCl}_{4}$.

$W W w=$ We1ght of the wire wet

Wwd = Weight of the wire dry

$W \times w=$ welght of the unknown sample wet

Wxd = welght of the unknown sample dry

Wsw $=$ weight of the sapphire wet

Wsd = weight of the sapphire dry

$\rho=$ density of $\mathrm{CCl}_{4}$ (function of temperature)

Percentage of theoretical density = Mass of unknown

$\frac{\text { volume of unknown }}{\frac{\text { Mass of sapphire }}{\text { volume of sapphire }}} \times 100=$

$\frac{\frac{I}{\rho} \cdot \frac{W_{x d}-W_{w d}}{\left(W_{x d}-W_{w d}\right)}-\left(W_{x w}-W_{w W}\right)}{\frac{I}{\rho} \frac{W_{s d}-W_{w C i}}{\left(W_{s d}-W_{w d}\right)}-\left(W_{s w}-W_{W W}\right)} \times 100$

$$
\text { FT.D. }=100 x \frac{\left(w_{x d}-w_{w d}\right)\left[\left(w_{s d}-w_{w d}\right)-\left(w_{s w}-w_{w w}\right)\right]}{\left(w_{s d}-W_{w d}\right)\left[\left(w_{x d}-W_{w d}\right)-\left(w_{x w}-w_{w w}\right)\right]}
$$

Note that the final form does not depend on $\rho$ which is troublesome to use since it is so temperature and impurity sensitive. 
Appendix C: Calculation of Image Stress from A Segregant

From Fleischer, a dislocation of Burgers vector $b$, a distance

$x$ from a thin region of width $\delta$ and change in modulus $\Delta G$, will be under an image stress: 42

$$
\tau=\frac{\Delta G}{\delta \pi}\left(\frac{\delta}{x+\delta}\right) \frac{b}{x}
$$

Examine a pure MgO strip $20 \AA$ wide at a grain boundary:

$$
\begin{gathered}
\tau=\frac{(13-15)}{8 \pi} \times 10^{11} \frac{\text { dynes }}{\mathrm{cm}^{2}} \cdot\left(\frac{20 \AA}{x+20 \AA}\right) \frac{5 \AA}{x} \\
\tau=-8 \times 10^{9} \frac{\text { dynes }}{\mathrm{cm}^{2}}\left(\frac{100}{x+200}\right) \cdot \frac{1}{x}
\end{gathered}
$$

$\tau$ Is plotted versus $x$ in Figure 43. Cbviously, it is negligibie beyond $100 \AA$. The answer for $\mathrm{MgO}$ is always negative, implying that the presence of $\mathrm{MgO}$ at the boundary should lead to a softening. Data is not available for the modulus of CaO, but the important; varlables in the above equation are the width of the segregated region, $\delta$, and the distance from the region, $x$. Hence the segregated $\mathrm{CaO}$ could not extend the hardening out much farther than the MgO softening extends.

If a multiple dislocation modeI is considered (i.e. a pile up at. the interface) an estimate of distance can be made based on the back stress on the last dislocation in a plle-up.41

$$
\tau_{0}=\frac{\mathrm{Gbn}}{\pi \mathrm{L}}
$$

where $n=$ number of dislocations in the pile-up,

$\mathrm{b}=$ Burgers vector,

$G=$ shear modulus of the material; and

$L=$ distance from pinned disiocation to the last one in the pile-up.

If $n$ is assumed to be $10^{2}-10^{3}$ dislocations, $G=15 \times 10^{3}$ psi, $b=5 \AA$, and the ultimate tensile strength is used for $\tau_{0}$ 


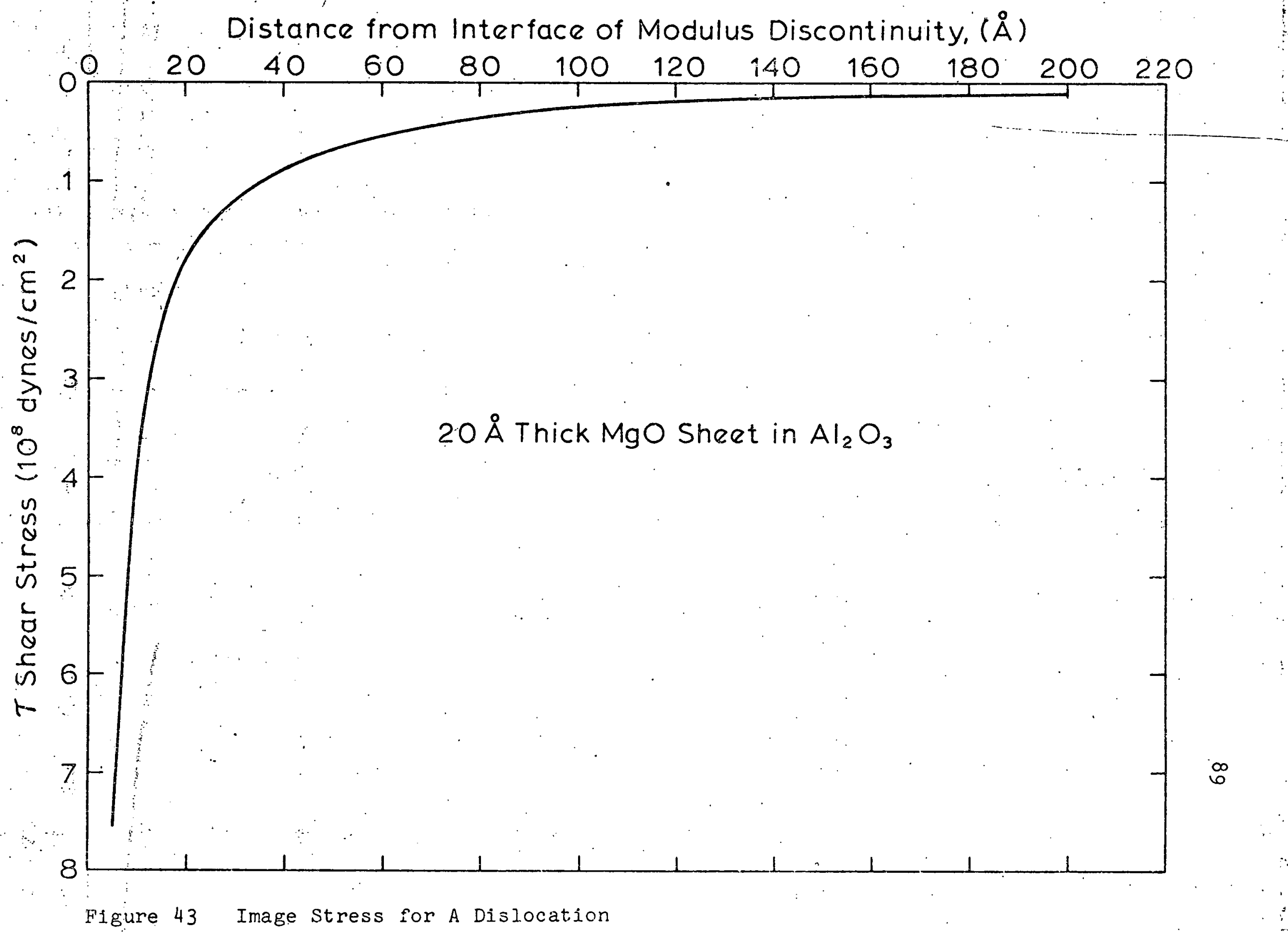


(yleld stress should be used, but is unavaliable for $\mathrm{Al}_{2} \mathrm{O}_{3}$ ), an .. estimate can be made of how far from the boundary a stress of yleld strength proportions could be felt:

$$
\begin{array}{rlrl}
L=\frac{15 \times 10^{3} \mathrm{psi}}{40 \times 10^{3} \mathrm{psi}} & \frac{(5 \AA)}{\pi} \mathrm{n}=.6 \mathrm{n} \AA \\
\text { If } \mathrm{n}=10^{2} & \mathrm{~L}=60 \AA \\
\text { or if } \mathrm{n}=10^{3} & L=600 \AA
\end{array}
$$


Appendix D: "Calculation of Grain Boundary Concentration of a Segregant

The following derivation is based on a treatment given in McLean's: text on grain boundaries. ${ }^{7}$

Assume that there are $N$ undistorted lattice sites with $P$ solute atoms distributed throughout and $n$ distorted lattice sites containing $p$ atoms. The $n$ sites would correspond to areas of disorder such as grain boundaries and the $\mathrm{N}$ sites refer to normal lattice positions. If the distortion energy (both size and electronic misfit) of a misfiting solute atom on an $\mathrm{N}$ site is given by $E$ and on an $n$ site is given by $e$, the total free energy of the system is given by:

$$
F=H-T S=p e+P E-T\left[S_{\text {pos }}+S_{\text {vib. }}\right]
$$

Further, the positional entropy can be expressed by using statistical thermodynamics: ${ }^{4}$

$$
S_{\text {pos. }}=k \text { In } n ! N !-k \text { ln }(n-p) ! p !(N-P) ! p !
$$

The vibrational entropy can also be expressed utilizing a harmonic oscillator approach (Einstein statistical thermodynamics):59

$$
S_{\text {vib. }}=p k\left(\ln \frac{k T}{h v}+1\right)+p k\left(\ln \frac{k T}{h v}+1\right)
$$

where $v=$ Einstein frequency of oscillation of solutes on distorted sites and

$v^{\prime}=$ Einstein frequency of oscillation on undistorted sites. (Assume the frequencies are independent of $T$ at high temperatures)

Therefore:

$$
\begin{aligned}
F= & p e+P E-T\{k \ln n ! N !-k \ln (n-p) ! p !(N-P) ! P !+ \\
& \left.\vdots p\left(\ln \frac{k T}{h \nu}+1\right)+P k\left(\ln \frac{k T}{h \nu}+1\right)\right\}
\end{aligned}
$$

To get the equilibrium (i.e. minimum) value, the total..

differential is taken and set equal to zero with $p$ and $P$ variables: 


$$
\left.(N-P)] d P+\left[\ln \frac{k T}{h v}+1\right] d p+\left[\ln \frac{k T}{h v}+1\right] d P\right\}
$$

But since $p+P=$ constant (i.e. conservation of total solute),

$$
d p=-d P
$$

and $\quad d F=(e-E)+k T \ln \frac{p}{n-p}-\ln \frac{P}{(N-P)}+\ln \frac{k T}{h \nu}$

$$
\left.-\ln \frac{k T}{h !},\right\}=0
$$

Solving for (E-e),

$$
(E-e)=k T \text { In }\left[\left(\frac{p}{n-p}\right) \times\left(\frac{N-P}{P}\right)\left(\frac{v^{\prime}}{v}\right)\right]
$$

Let $\mathrm{C}_{\mathrm{gb}}=\mathrm{p} / \mathrm{n}$ (concentration in the distorted region),

$C=P / N$ (concentration in the undistorted region), and

$Q=(E-e) / N_{0}$ where $N_{0}=$ Avogadros number.

$$
Q=R T \ln \left(\frac{p}{n-p} \times \frac{N-P}{P} \times \frac{\nu^{\prime}}{\nu}\right)
$$

or:

$$
\exp (Q / R T)=\left(\frac{p}{n-p}\right)\left(\frac{N-P}{P}\right)\left(\frac{\nu^{\prime}}{\nu}\right)=\left(\frac{C}{g b}\right) \times\left(\frac{I-C}{C}\right)\left(\frac{\nu^{\prime}}{\nu}\right)
$$

Solving for $\mathrm{C}_{\mathrm{gb}}$. gives for the concentration at the grain bouidary at equilibrium at temperature $\mathrm{T}$ :

$$
C_{g b}=\frac{e^{Q / R T}}{\frac{v^{\prime}}{v}\left(\frac{1-C}{C}\right)+e^{Q / R T}}
$$

multiply through by $C$,

$$
c_{g b}=\frac{C e^{Q / R T}}{\frac{v^{\prime}}{v}+C e^{Q / R T}}
$$

Since the Debye temperature, $\theta$, is equal to $\mathrm{h \nu}_{\mathrm{m}} / \mathrm{k}$ where:

$v_{m}$ is the maximum frequency, the ratio $\nu / v^{\prime}$ can be approximated by,

$$
\frac{\nu^{\prime}}{\nu}=\frac{\theta^{\prime}}{\theta}
$$

Since at temperatures above room temperature, $\nu \simeq \nu_{m}$ (1.e. where $T>>\theta)$

Hence an alternate way to write the frequency term is: 


$$
C_{g b}=\frac{C e^{Q / R T}}{\frac{\theta^{1}}{\theta}+C e^{Q / R T}}
$$

But Debye temperatures as a function of order/disorder are no more readily avallable than frequencies; hence an estimate must be made as to the size of the $v^{\prime} / v$ term.

From the Einstein theory, the energy of a group of harmonic oscillators all having the same frequency, is:60,61

$$
E=\frac{N h \omega}{e(h \omega / k T)-I}=\frac{N h v}{e(h v / k T)-I}
$$

At high temperatures $(T>>\theta)$, most osciliators have the same frequency $\nu_{m}$ and the term $e(h \nu / k T)<1$. Hence for $T \gg>\theta$

$$
E \propto \cdot v_{m}
$$

Also, the potential energy of cohesion of an ionic material (1.e. coulomblc forces) can be related to ion separation: 62

$$
\text { E } \propto \frac{I}{r}
$$

Hence the maximum frequency can be related to 1on.separation:

$$
\nu_{m} \propto \frac{1}{r}
$$

The assumption concerning $T>>\theta$ is valid in this instance since although no data was available for $\mathrm{Al}_{2} \mathrm{O}_{3}$, most ionic materials have $\theta<300^{\circ} \mathrm{K}$, while the temperature range of interest in this study is $T \geqslant 1900^{\circ} \mathrm{K}$. Hence $\theta / T<\frac{1}{6}$ and $e^{1 / 6} \simeq .002$, which is much smaller than 1 .

If the assumption is now made that the $\mathrm{Ca}^{+2}$ ion is compressed to fit the unaltered octahedral interstice in $\mathrm{Al}_{2} \mathrm{O}_{3}$ usually occupied by $\mathrm{Al}^{+3}$, the distorted size of the $\mathrm{Ca}^{+2}$ Ion wiIl be the size of the site.

$$
r_{\text {distorted }}=.5 \AA
$$


Further if the $\mathrm{Ca}^{+2}$ ion at the grain boundary is assumed to pe "free" (1.e. not compressed at all) and allowed to fill a site as large as 1 ts free lonic radius,

$$
r_{\text {undis torted }}=.99 \AA
$$

Hence the lower $l$ imlt value on the ratio between the two frequencies can be calculated.

$$
\frac{V^{\prime}}{V}(\text { lower Ilmit })=\frac{.5 \AA}{.99 \AA} \simeq \frac{1}{2} .
$$

The actual value will be closer to one, since the $\mathrm{Ca}^{+2}$ ion In the distorted site w1ll expand the lattice somewhat and an ion at the grain boundary is not "free", but will be compressed somewhat.

Therefore, since the spread in values of $\frac{v^{\prime}}{v}$ will be:

$$
\frac{1}{2}<\frac{v^{\prime}}{v}=1
$$

It appears Justifiable to use one as an approximation.

The final form for the $c_{g . b}$. equation and the form in which it will be used, is:

$$
c_{\text {g.b. }}=\frac{C e^{Q / R T}}{I+C e^{Q / R T}}
$$


Appendix E: Calculations of Interaction Energies and Upper Linits for Segregants in $\mathrm{Al}_{2} \mathrm{O}_{3}$

A. Calculation of $Q$ for Ca in $\mathrm{Al}_{2} \mathrm{O}_{3}$

Utilizing equation (37) from Appendix $D$, a relation for $Q$ asi a function of $C_{g b}$ and $C$ can be obtained.

$$
\begin{aligned}
& C_{g b}=\frac{C e^{Q / R T}}{1+C e^{Q / R T}} \\
& Q=R T \ln \left[\frac{C_{g b}}{\left(1-C_{g b}\right)} \times \frac{1}{C}\right]
\end{aligned}
$$

In the quenched General Electric alumina $\mathrm{C}=40 \mathrm{ppm}=$ $4 \times 10^{-5}$

$\underline{1700^{\circ} \mathrm{C}}$

$$
\begin{aligned}
& \mathrm{c}_{\mathrm{gb}}=5.6^{\mathrm{a}} / 0=.056 \\
\mathrm{Q}\left(1700^{\circ} \mathrm{C}\right)= & \left(1.98 \frac{\mathrm{cal}}{\mathrm{mole} \mathrm{o}^{\circ} \mathrm{K}}\right)\left(1973^{\circ} \mathrm{K}\right) \times \ln \left[\frac{.056}{(1-.056)} \times \frac{1}{\left(4 \times 10^{-5}\right.}\right] \\
& =28,500 \frac{\mathrm{cal}}{\mathrm{mole}}
\end{aligned}
$$

$\underline{18.00^{\circ} \mathrm{C}}$

$1900^{\circ} \mathrm{C}$

$$
\begin{aligned}
C_{g b} & =4.2^{\mathrm{a}} / 0=.042 \\
Q\left(1800^{\circ} \mathrm{C}\right)= & \left(1.98 \frac{\mathrm{cal}}{\mathrm{mole} \mathrm{K}}\right)\left(2073^{\circ} \mathrm{K}\right) \times \ln \left[\frac{.042}{(1-.042) \times \frac{1}{\left(4 \times 10^{-5}\right)}}\right. \\
= & 28,700 \frac{\mathrm{cal}}{\mathrm{mole}}
\end{aligned}
$$$$
c_{g b}=2.8^{a} / 0=.028
$$$$
\begin{aligned}
Q\left(1900^{\circ} \mathrm{C}\right) & =\left(1.98 \frac{\mathrm{cal}}{\mathrm{mole}}\right)\left(2173^{\circ} \mathrm{K}\right) \times \ln \left[\frac{.028}{(1-.028)} \times \frac{1}{\left(4 \times 10^{-5}\right)}\right] \\
& =28,350 \mathrm{caI}
\end{aligned}
$$$$
\text { mole }
$$

B. Calculation of $\mathrm{Q}$ for $\mathrm{Mg}, \mathrm{NA}$, and $\mathrm{Y}$ in $\mathrm{Al}_{2} \mathrm{O}_{3}$

$$
\text { Given: } r_{\mathrm{Mg}}=.65 \AA
$$




$$
\begin{aligned}
& r_{\mathrm{N1}}=.72 \AA \\
& r_{Y}=.93 \AA \\
& r_{\mathrm{Ca}}=.99 \AA \\
& r_{A I}=.50 \AA \\
& \text { and } Q_{\text {cal }}=28,500 \mathrm{cal} / \mathrm{mole} \\
& Q_{M g}=\frac{\varepsilon_{m g}^{2}}{\varepsilon_{c a}^{2}} \times \grave{Q}_{c a}=\frac{\left(\frac{.65-.50}{.50}\right)^{2}}{\left(\frac{.99-.50}{.50}\right)^{2}} \times(28,500 \mathrm{cal} / \mathrm{mole}) \\
& =2,550 \mathrm{cal} / \mathrm{mole} \\
& Q_{N 1}=\frac{\varepsilon_{N i}^{2}}{\varepsilon_{c a}^{2}} \times Q_{c a}=\frac{\left(\frac{.72-.50}{.50}\right)^{2}}{\left(\frac{.99-.50}{.50}\right)^{2}} \times(28,500 \mathrm{cal} / \mathrm{mole}) \\
& =5,479 \mathrm{cal} / \mathrm{mole} \\
& Q_{Y}=\frac{\varepsilon_{Y}^{2}}{\varepsilon_{c a}^{2}} \times Q_{c a}=\frac{\left(\frac{.93-.50}{.50}\right)^{2}}{\left(\frac{.99-.50}{.50}\right)^{2}} \times(28,500 \mathrm{cal} / \mathrm{mole}) \\
& =21,800 \mathrm{cal} / \mathrm{mole}
\end{aligned}
$$

C. Calculation of Expected Grain Boundary Concentrations In the General Electric material, there is $.2^{2} / 0 \mathrm{Mg}^{+2}$. Hence, using the $\mathrm{Q}_{\mathrm{Mg}}$ above and equation (37) at $1700^{\circ} \mathrm{C}$, $M g: c_{g b}=\frac{(.002) \exp [2550 /(1973)(1.98)]}{1+(.002) \exp [2550 /(1973)(1.98)]}=.4^{\mathrm{a}} / 0 \mathrm{Mg}$

For the $\mathrm{N} 1 \mathrm{O}$ doped $\mathrm{Al}_{2} \mathrm{O}_{3}$ at $1700^{\circ} \mathrm{C}$,

$\mathrm{N1:C \textrm {gb }}=\frac{(.0015) \exp [5470 /(1973)(1.98)]}{1+(.0015) \exp [5470 /(1973)(1.98)]}=6^{2} / 0 \mathrm{N1}$ And finaliy in the Sylvanta $\mathrm{Al}_{2} \mathrm{O}_{3}$, the $\mathrm{Y}^{+3}$ level was $.02^{\mathrm{a}} \%$, $Y: C_{g b}=\frac{(.0002) \exp [21800 /(1973)(1.98)]}{1+(.0002) \exp [21800 /(1973)(1.98)]}=4.3^{2} \% \mathrm{Y}$ 
D. Calculation of Segregation Upper Limit of Ca in $\mathrm{Al}_{2} \mathrm{O}_{3}$ An upper limit value for $\mathrm{Ca}^{+2}$ segregation in the General Electric $\mathrm{Al}_{2} \mathrm{O}_{3}$ quenched from $1700^{\circ} \mathrm{C}$ can be calculated from: 46 $\left.\Gamma^{0}<1\right)<\frac{\sigma_{1}}{k T\left[1+\ln \left(x^{3} / x_{0}\right)\right]}$

$\sigma_{1}=$ surface (grain boundary energy) of $\mathrm{Al}_{2} \mathrm{O}_{3}=$ $65 \mathrm{ergs} / \mathrm{cm}^{2}$ (This value was determined by grain boundary: grooving techniques) 63

Assume $x_{e}=x_{0}=.00004 \mathrm{Ca}$ in the General Electric material

$$
\therefore \Gamma_{2(1)}^{0}<\frac{65 \mathrm{erg} / \mathrm{cm}^{2}}{1.38 \times 10^{-16} \frac{\mathrm{erg}}{\mathrm{O}_{\mathrm{K}}}\left(1973^{\circ} \mathrm{K}\right)}=2.4 \times 10^{14} \frac{\text { atoms }}{\mathrm{cm}^{2}}
$$

The excess observed experimentally can be calculated from Figure 14:46

$$
\begin{aligned}
& \Gamma_{2(1)}^{0}=\frac{1}{A}\left[N_{2}-\frac{x_{0}}{1-x_{0}} N_{1}\right] . \\
& x_{0}=4 \times 10^{-5} \text {, so } \frac{x_{0}}{1-x_{0}} \simeq 4 \times 10^{-5} .
\end{aligned}
$$

This w1ll make the second term in the brackets above insignificant, hence :

$$
\Gamma_{2(I)}^{0} \simeq \frac{I}{A} \dot{N}_{2}
$$

From Figure 14, the following tabulation glves the percentage Ca In each of the atomic layers a from the grain boundary:

Layers Removed

at gob.

2. Iayers
$\% \mathrm{Ca}$

$5.6 \%$

$1.08^{2} / 0$ number of ions $/ \mathrm{cm}^{2}$

$$
2\left(.056 \times 10^{-15}\right)
$$

$2\left(.01 \times 10^{15}\right)$ 
Layers Removed

3 layers

4 layers

6 layers

*1 layer

*5 layers

$\begin{array}{ll}\frac{\% \mathrm{Ca}}{89^{\mathrm{a}} / 0} & \frac{\text { number of } 10 \mathrm{~ns} / \mathrm{cm}^{2}}{2\left(.009 \times 10^{1.5}\right)} \\ .39^{\mathrm{a}} / 0 & 2\left(.004 \times 10^{15}\right) \\ .1^{\mathrm{a}} / 0 & 2\left(.001 \times 10^{15}\right) \\ 3.3^{\mathrm{a}} / 0 & 2\left(.033 \times 10^{15}\right) \\ .25^{\mathrm{a}} / 0 & 2\left(.0025 \times 10^{15}\right)\end{array}$

$23.1 \times 10^{13} \frac{\text { atoms }}{\mathrm{cm}^{2}}$

The factor of two enters into the calculation since there are really two sides to the segregation profile, not one as the sputter profile would tend to indicate.

Hence the calculated excess is:

$$
\Gamma_{2(1)}^{0}=23.1 \times 10^{13} \frac{\text { atoms }}{\mathrm{cm}^{2}}
$$

and the upper limit is

$$
\Gamma_{2(I)_{U . L .}^{0}}^{0}<24 \times 10^{13} \frac{\text { atoms }}{\mathrm{cm}^{2}}
$$

$\therefore$ Since, $23 \times 10^{13} \frac{\text { atoms }}{\mathrm{cm}^{2}}<24 \times 10^{13} \frac{\text { atoms }}{\mathrm{cm}^{2}}$

the segregation is within the thermodynamic limits of equilibrium segregation.

It should be noted that, the value of $\sigma_{g b}$ used appears to be extremely low. KIngery found that the surface energy of $\mathrm{Al}_{2} \mathrm{O}_{3}$ at $1805^{\circ} \mathrm{C}$ was $905 \frac{\mathrm{erg}}{\mathrm{cm}^{2}} \cdot 64$ The grain boundary energy should be somewhat lower, but $65 \frac{\mathrm{ergs}}{\mathrm{cm}^{2}}$ appears excessively low. Any Increase $1 n \sigma_{g b}$ would Just inereasethe upper limit value and give a greater difference between the calculated excess and the limit value.

*interpolated value between two experimental points. 
Appendix F: Calculation of Residual Fluorine Levels In MgO

To calculate the amount of. fluorine at the grain boundaries, It is necessary to obtain the ratio of the number of lons at the grain boundary to the bulk.

Starting with $1 \mu$ diameter spherical grains (Figure 34 indicates that the as-hot pressed grain size is about $1 \mu$ ), the area of the grain is:

$$
A=\frac{4 \pi d^{2}}{4}=\pi \times 10^{-12} \mathrm{~m}^{2}
$$

Further, the volume is:

$$
\mathrm{V}=\frac{4}{3} \pi \frac{\mathrm{d}^{3}}{8}=\frac{\pi}{6} \times 10^{-18} \mathrm{~m}
$$

The total number of lons on the grain boundary area is (assume $\left.10^{15} \frac{\text { 1ons }}{\mathrm{cm}^{2}}\right):$

$$
\mathrm{N}_{\mathrm{A}}=\frac{10^{15}}{\mathrm{~cm}^{2}} \times \pi \times 10^{-12} \mathrm{~m}^{2} \times \frac{10^{4} \mathrm{~cm}^{2}}{1 \mathrm{~m}^{2}}=\pi \times 10^{7} \text { ions }
$$

In the grain (assume $10^{22} \frac{\text { ions }}{\mathrm{cm}^{3}}$ ):

$$
\mathrm{N}_{\mathrm{v}}=\frac{10^{22}}{\mathrm{~cm}^{3}} \times \frac{\pi}{6} \times 10^{-18} \mathrm{~m}^{3} \times \frac{10^{6} \mathrm{~cm}^{3}}{1 \mathrm{~m}^{3}}=\frac{\pi}{6} \times 10^{10} \text { ions }
$$

Hence: the atom fraction of ions in a monolayer at the grain boundary is

$$
\therefore \mathrm{x}_{\mathrm{A}}=\frac{\pi \times 10^{7}}{\frac{\pi}{6} \times 10^{10}}=6 \times 10^{-3}=.006
$$

If an assumption is now made concerning the percentage of the grain boundary sites found to be occupled by $\mathrm{F}^{-1}$ ions; an estimate of the atom fraction of fluorine that this represents can be made.

Assume that $40 \%$ of the sites in the first 5 layers away from the boundary are occupled:by fiuorine lons:

$$
x_{A}=.006 \times .4 \times 5=.012
$$


This means that there is $1.2^{a} / 0 \mathrm{~F}^{-1}$ at the grain boundaries of the MgO. Bulk analysis indicates that in similar samples, $.9^{\mathrm{w}} / \mathrm{\rho}$ or $1.8^{\mathrm{a}} / 0 \mathrm{~F}^{-1}$ remains after hot pressing. Hence the conclusion is reached that most if not all of the resfdual fluorine additives are at the gratn boundaries in the hot pressed MgO. 
Appenaix G: Further Study of Equilibrium Segregation

The results of this investigation of densification in $\mathrm{Al}_{2} \mathrm{O}_{3}$ and $\mathrm{MgO}$, have revealed new possibilities and opportunities to study equilibrium segregation to interfaces. The basic model utilized describes adequately the behavior observed in the $\mathrm{Al}_{2} \mathrm{O}_{3}-\mathrm{Ca}{ }^{+2}$ system and is consistent with the segregation or lack of segregation of other cation species $\left(\mathrm{Mg}^{+2}, \mathrm{N1}^{+2}\right.$, and $\left.\mathrm{Y}^{+3}\right)$.

The basic equation which relates the grain boundary concentration of a segregant to the other system variables is :

$$
c_{g b}=\frac{C e^{Q / R T}}{1+C e^{Q / R T}}
$$

where all of the terms are as defined previous zy.

Use of this equation in the current study produced consistency In the interpretation of the experimental data and the values obtained implied that the $\mathrm{Ca}^{+2}$ segregation in $\mathrm{Al}_{2} \mathrm{O}_{3}$ is equilibrium in nature. A further test of the nature of the segregation would involve establishing the reversibility of the observed segregation. This indeed has been done for the $\mathrm{Ca}^{+2}$ segregation observed in $\mathrm{MgO}$ hot pressed without additives. Auger samples were annealed at $1500^{\circ} \mathrm{C}$ for 5 hours to ensure equilibrium at temperature. One specimen was then quenched in ice brine and a second furnace cooled to allow segregation of $\mathrm{Ca}$ to occur. The Auger data indicated $2^{a} / 0 \mathrm{Ca}$ at the grain boundaries of the quenched specimen and $6 \%$, in the furnace cooled specimen. This clearly establishes that the $\mathrm{Ca}$ is not boiling out of the sample at high temperature, but rather is incorporated into the: MgO lattice.

Further studies are planned to establish similar irrefutable 
evidence of reversibility in the $\mathrm{Al}_{2} \mathrm{O}_{3}$ system as well and to study the effect of bulk composition on both $Q$ and $C_{g b}$. The $Q$ value reported in this work is an average $Q$ for a given grain boundary. It is reasonable to expect that there are high energy (large amount of disorder) as well as low energy (small amount of disorder) sites at the grain boundary. Hence it possible that $Q$ is concentration dependent and the driving force for segregation will change as the high energy sites are depleted by segregation. Experimentally in this study, no method of distinguishing between $Q$ values was found; hence the $Q$ values reported are "average" values. It would be of interest to study the concentration dependence of $Q$.

Finally it should be noted that it is possible to utilize the observed segregation to study solubility limits of segregants. For example by doping $\mathrm{Al}_{2} \mathrm{O}_{3}$ to various levels of $\mathrm{Ca}^{+2}$, the segregation behavior could be studied and the discontinuity in the increase in segregation noted when the amount of $\mathrm{Ca}$ in the bulk exceeds the solubility limit. At that point, equation (37) Indicates that the increase in $\mathrm{C}_{\mathrm{gb}}$ occurring as the overall bulk level is increased would remain fixed at the value corresponding to $C$ equal to the solubility limit. Further $C a$ additions would preclpitate out and would not contribute to the segregation. The system would maintain only the soluble amount of $\mathrm{Ca}$. In solution. 
VI References

1. W. D. Kingery, "Introduction to Ceramics", Wiley and Sons, N. Y., 361 (1960).

2. J.W. Cahn, Acta Met., 10,789 (1962).

3. K. Lïcke and K. Detert, Acta Met., 5, 628 (1957).

4. E. S. NachIin, Trans. AIME, 224, 1153 (1962).

5. R. L. Coble, J. Appl. Phys., 32, 793 (196i).

6. R. L. Coble, J. Amer. Ceram. Soc., 45, 123 (1962).

7. R. L: Coble, "Transparent Alumina and Method of Preparation", U. S. Patent \#3,026,210, March 20, 1962.

8. P. J. Jorgensen and J. H, Westbrook, J. Amer. Ceram. Soc., 47, 332 (1964).

9. C. A. Bruch, Am. Ceram. Soc. Bull, 41, 799 (1962).

10. P. J. Jorgensen, J. Amer. Ceram. Soc, , 48, 207 (1965).

11. R. W. Rice, Paper presented at $64 \mathrm{th}$ Annual Meeting of the Amelican Ceramic Society, New York, 1962.

12. R. W. Kice, NRL Report 7334, 1971.

13. R. W. R1ce, J. Amer. Ceram. Soc,, 54, 205 (1971).

14. E. Carnall, Jr., Mat. Res. Bull,, 2, 1075 (1967):

15. R. W. Rice, Proc. Brit. Ceram. Soc., 20, 329 (1972).

16. E. Smethurst and D. W. Budworth, Tran. Brit: Ceram, Soc., 71, 45 (1972).

17. P. E. Hart, R. B. Atkin, and J.AA. Pask, J. Amer Ceram, Soc:, $53,83(1970)$.

18. W. C. Johnson, D. F. Stein, and AT. Joshi, Canadian J. of Spec., 17,88 (1972).

I9. C. C. Chang, Surf: Sci., 25, 53\%(1971)

20. $\therefore$. Berrin and R. C. Sundahl," "Characterization of "Ceramics". eds. L. Hench and R. W. Gould, Marcel Dekker, Inc., 
New York, 1972.

21. U. S. Department of Commerce, "X-Ray Wavelengths and $\mathrm{X}$-Ray Atomic Energy Levels", National Bureau of Standards, 54 (1967).

22. J. J. Lander, Phys̃. Re., 91, 1419 (1968).

23. I. A. Harris, J. Appl. Phys., 39, 1419 (1968).

24. R. E. Weber and W. T. Peria, ibid, 38, 4355 (1.967).

25. P. W. Palmberg, G. K. Bohn, and J. C. Tracy, Appl. Phys. 'Letters, 15, 254 (1969).

26. P. W. Palmùizg and. T. N. Rhodin, Phys. Rev., 91, 1419 (1968).

27. R. E. Weber and A. I. Johnson. J. Appl. Phys., 40, 314 (1969).

28. W. C. Johnson, M. S. Thesis, Univ, of Minn., 1971.

29. P. W. Palmberg, G. E. RIach, R. E. Weber, and N. C. MacDonald, "Handbook of Auger Electron Spectroscopy", Physical Electronias Industries, Inc., I972.

30. D. Rosenberg and G. K. Wehner, J. Appl. Phys. 33, 1842 (1962).

31. N. Laegre1d and G. K. Wehner, J. Appl. Phys, 32, 365 (1961).

32. G. K. Wehner, Phys. Rev., 108, 35 (1957).

33. G. K. Wehner, Phys. Rev., I12, 1120 (1958).

34. M. Tarng, Private Communication, Univ of Minn.

35. S. Knight, Private Communication, Mich. Tech. Univ.

36. L. R. McCre1ght, Am. Ceram. Soc. Bull., 30, 127 (1951).

"Alumina As a Ceramic Matêrial", edited by W. H. Gitzen, published by Amer. Ceram. Soc., Columbus, Oh10, 1970.

37.. J. H. Westbrook and D. L. Wood, Native, 192, 1280.(1961):

38. J.H. Westbrook and K. T. Aust, Acta. Met., 1I, 116I. (1963).

39. P. J. Jorgensen and R. C. Anderson, J Am. Ceram. Soc.; $50 ;$ 553 (1967). 
40. D. Hull, "Introduction to Dislocations", Pergamon Press, London ( 1969 ).

41. R. L. Fle1scher, G. E. Report \#6I-RI-2676M, 1961.

42. R. L. Coble, J. Am. Ceram. Soc., 45, 123 (1962).

43. P. J. Jorgensen, Private Communication.

44. M. 'C. Inman and $\dddot{H}, \mathrm{R}$. Tipler, Acta Met., 6, 73 (1.958).

45. J. W. Gibbs, Collected Works, Yale Univ. Press, 1948.

46. J. W. Cahn and J. E. Hilliard, Acta Met., I, 219 (1959).

47. J. McLean, Grain Boundaries in Metals, Clarendon Press. 1951.

48. R. Gịdings, Private Communication, General Electric Corporation.

49. P. G. Shewmon, "Diffusion in Solids", McGraw-H1ll, N.Y. (1963).

50. I. B. Cutler, "High Temperature Oxides", part III, edited by A. M. Alper, Academic Press, N. Y., pages 129-182 (1970).

51. Coble and Burke, Progr. Ceram. Sc1., $\underline{3}, 197$ (1963).

52. A. E. Paladino and R. L. Coble, J. Am. Ceram. Soc., 46, $13 \overline{3}$ (1963).

53. P. A. 'Beck, Ph1.1. Mag. Supp., 3, 245 (1954).

54. P. A. Beck, M. L. Holzworth, and P. R. Sperry, AIME Technical Publication $2475,1948$.

55. P. A. Beck, J. C. Kremer, L. J."Demer, and M. L. Holzworth, Trans. Amer. Inst. Metall. Engrs., 180, 163 (1949).

56. P: Gordion and R. A. Vandermeer, Trans. AIME, 224, 917 (1962).

57. R. W. Rice, NRL Report 7335, 1971.

58. R. W. Rice, and W. J. McDonough Mechanical Behavior of Metals, 4, Soc. of Mat. Sc1., Japan,422 (1972).

59. R. A. Swalin, "Thermodynamics of Sollds", Wiley and Sons" N. Y., 49 (1962).

60. W. J. Moore, "Physical Chemistry", Prentice Hall; Englewood 
Clififs, New Jersey, 896 (1972).

61. G. Kittel, "Introduction to Solid State Physics", W1ley and Sons, N. Y. $200 \mathrm{ff}$ (1971).

62. W. J. Moore, Ib1d. P. 913.

63. M. McLean and E. D. Hondros, J. Mat. Sc1., 6, 19 (1971).

64. W. D. Kingery, J. Amer. Ceram. Soc:, 37, 42 (1954). 